\title{
CHUVA DE SEMENTES, BANCO DE SEMENTES E REGENERAÇÃO NATURAL SOB TRÊS ESPÉCIES DE INÍCIO DE SUCESSÃO EM UMA ÁREA RESTAURADA EM IRACEMÁPOLIS (SP)
}

\section{Daniela Cristine Mascia Vieira}

\author{
Dissertação apresentada à Escola Superior de \\ Agricultura "Luiz de Queiroz", Universidade de São \\ Paulo, para obtenção do título de Mestre em \\ Recursos Florestais, com opção em Conservação \\ de Ecossistemas Florestais.
}

\author{
PIRACICABA \\ Estado de São Paulo - Brasil \\ Abril - 2004
}




\title{
CHUVA DE SEMENTES, BANCO DE SEMENTES E REGENERAÇÃO NATURAL SOB TRÊS ESPÉCIES DE INÍCIO DE SUCESSÃO EM UMA ÁREA RESTAURADA EM IRACEMÁPOLIS (SP)
}

\section{Daniela Cristine Mascia Vieira \\ Ecóloga}

Orientador: Prof. Dr. SERGIUS GANDOLFI

\footnotetext{
Dissertação apresentada à Escola Superior de Agricultura "Luiz de Queiroz", Universidade de São Paulo, para obtenção do título de Mestre em Recursos Florestais, com opção em Conservação de Ecossistemas Florestais.
}

\author{
PIRACICABA \\ Estado de São Paulo - Brasil
}

Abril - 2004 


\section{Dados Internacionais de Catalogação na Publicação (CIP) DIVISÃO DE BIBLIOTECA E DOCUMENTAÇÃO - ESALQ/USP}

Vieira, Daniela Cristine Mascia

Chuva de sementes, banco de sementes e regeneração natural sob três espécies de início de sucessão em uma área restaurada em Iracemápolis (SP) / Daniela Cristine Mascia Vieira. - - Piracicaba, 2004.

87 p. : il.

Dissertação (mestrado) - - Escola Superior de Agricultura Luiz de Queiroz, 2004.

Bibliografia.

1. Árvores florestais 2. Boraginaceae 3. Comunidades vegetais 4. Fabaceae 5. Proteção ambiental 6. Recursos florestais 7. Reflorestamento 8. Rutales 9. Sementes I. Título

CDD 634.9

\section{"Permitida a cópia total ou parcial deste documento, desde que citada a fonte - $\mathrm{O}$ autor"}


Aos meus pais, Mércia e Benedito, e

ao Fábio

dedico 


\section{AGRADECIMENTOS}

Ao Prof. Dr. Sergius Gandolfi, pela orientação e apoio em todas as etapas deste trabalho;

Ao CNPq, pela concessão da bolsa de estudos;

Ao Prof. Dr. Ricardo Ribeiro Rodrigues pelas sugestões ao trabalho e pela ajuda na identificação das espécies;

Ao Prof. Dr. Massanori Takaki, pelos favores em vários momentos;

À Prof. Dra. Adriana Rozza e à Prof. Dra. Natália M. Ivanauskas pelas sugestões no "boneco";

Ao Prof. Dr. Reinaldo Monteiro pelas sugestões;

Ao André Nave, pela ajuda na identificação das sementes;

Ao Chico, é claro, pela imprescindível ajuda e companhia no campo;

Aos amigos de Rio Claro, que aos poucos se vão;

À Hérika Zaia, pelas risadas e por tornar tudo mais divertido;

À Eliani, Paulo, André, Sandra, Júlio e Vitor, por serem a minha segunda família;

Aos meus cunhados, Bel e Gustavo, por torcerem por mim desde o início;

Aos meus irmãos, Débora e Daniel, por quererem sempre o meu bem e o meu sucesso e serem verdadeiros irmãos;

Aos meus pais, Mércia e Benedito, pelo carinho e por fazerem parte da minha história;

E, ao Fábio, meu grande e querido companheiro... 


\section{SUMÁRIO}

Página

LISTA DE FIGURAS...................................................................... vii

LISTA DE TABELAS...................................................................... ix

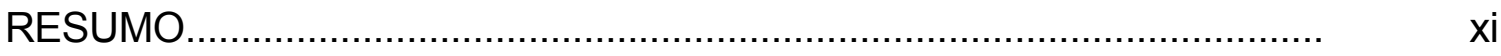

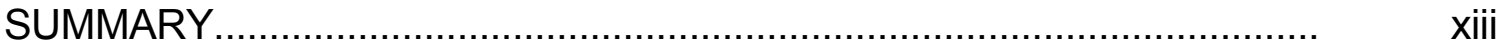

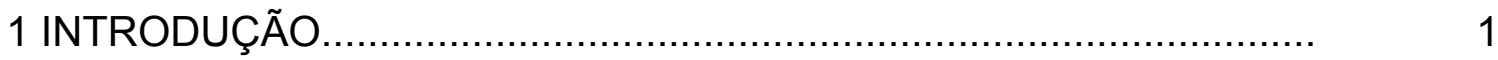

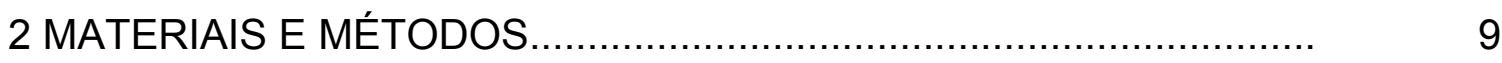

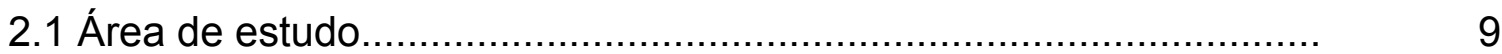

2.1.1 Caracterização física e localização da área................................... 9

2.1.2 Caracterização do projeto de restauração da área......................... 10

2.2 Descrição das espécies selecionadas para a condução do

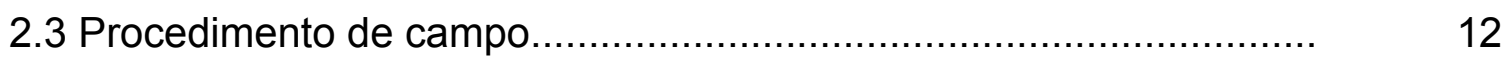

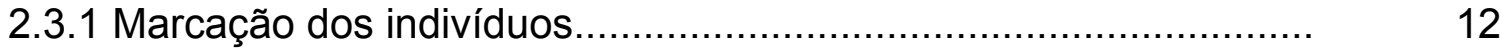

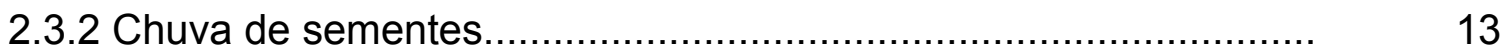

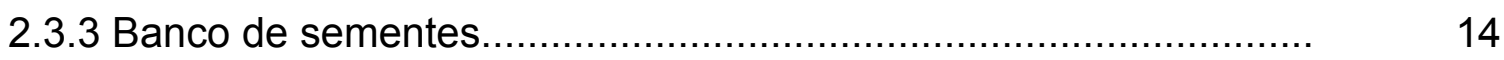

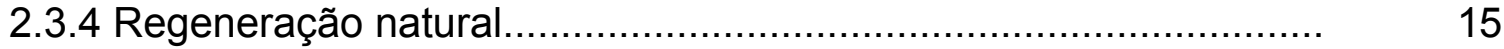

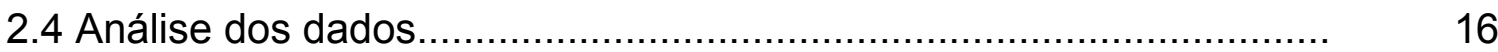

3 RESULTADOS E DISCUSSÃO.......................................................... 20

3.1 Chuva de sementes..................................................................... 20

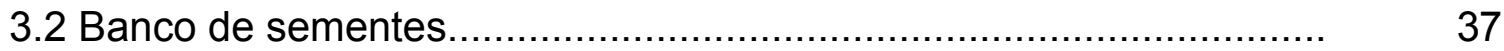

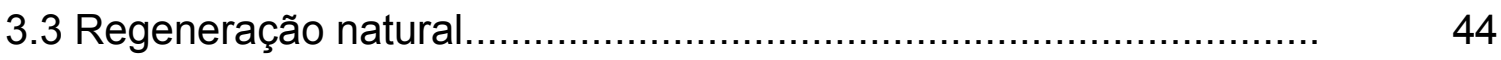

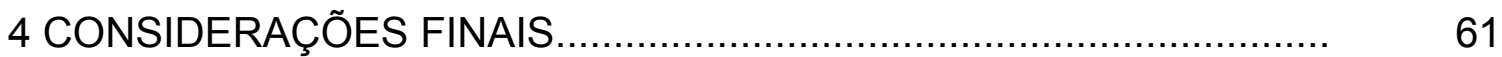


vi

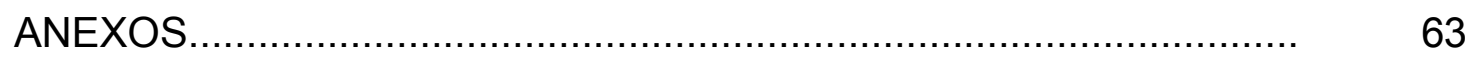

REFERÊNCIAS BIBLIOGRÁFICAS................................................. 77 


\section{LISTA DE FIGURAS}

Página

1 Disposição dos coletores de sementes instalados sob a projeção da copa de um indivíduo de Centrolobium tomentosum, em Iracemápolis.

2 Número total de propágulos coletados sob as três espécies, ao longo do ano. * mês de coleta após vendaval......................

3 Número médio de propágulos coletados na chuva de sementes sob cada uma das três espécies. Letras diferentes indicam diferenças significativas entre os tratamentos $(p<0,05)$ pelo teste Tukey

4 Espécies mais abundantes amostradas na chuva de sementes sob as três espécies, ao longo de um ano................................

5 Abundância das espécies amostradas na chuva de sementes sob os indivíduos de Centrolobium tomentosum, ao longo de um ano.

6 Abundância das espécies amostradas na chuva de sementes sob os indivíduos de Cordia myxa, ao longo de um ano

7 Abundância das espécies amostradas na chuva de sementes sob os indivíduos de Melia azedarach, ao longo de um ano.

8 Número de espécies coletadas na chuva de sementes sob cada uma das três espécies, ao longo do ano 
9 Número de plântulas emergidas observadas no experimento de banco de sementes das três espécies, no período de oito semanas.

10 Número acumulado de espécies observado no experimento de banco de sementes das três espécies, no período de oito semanas.

11 Número médio de plântulas emergidas (log) amostrados no solo sob cada uma das três espécies. Letras diferentes indicam diferenças significativas entre tratamentos $(p<0,05)$ pelo teste Tukey.

12 Número médio de espécies de plântulas amostradas no solo sob cada uma das três espécies. Letras diferentes indicam diferenças significativas entre tratamentos $(p<0,05)$ pelo teste Tukey.

13 Altura média dos indivíduos regenerantes sob cada uma das três espécies. Letras diferentes indicam diferenças significativas entre tratamentos $(p<0,05)$ pelo teste Tukey.

14 Espécies mais abundantes amostradas na regeneração natural sob as três espécies, ao longo do ano...

15 Distribuição dos indivíduos regenerantes sob cada espécie de acordo com a classe de altura, menor e maior que $1 \mathrm{~m}$, e total

16 Distribuição das espécies regenerantes sob cada espécie de acordo com a classe de altura, menor e maior que $1 \mathrm{~m}$, e total 


\section{LISTA DE TABELAS}

Página

1 Densidade anual de propágulos sob cada uma das três espécies estudadas, considerando e excluindo a própria espécie da chuva de sementes...........................................

2 Índices de diversidade de Shannon ( $\left.\mathrm{H}^{\prime}\right)$ e de equabilidade (J) de espécies amostradas na chuva de sementes sob as

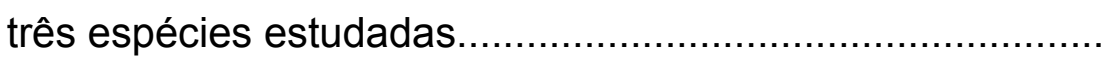

3 Relação das espécies amostradas na chuva de sementes sob C. tomentosum (C.t.), C. myxa (C.m.) e M. azedarach (M.a), seguidas do grupo sucessional (G. s.) e síndrome de dispersão (S. d.) a que pertencem......................................

4 Número médio e densidade média dos indivíduos regenerantes sob as três espécies. Letras iguais indicam que não há diferença significativa entre os tratamentos $(p>0,05)$ pelo teste Tukey

5 Índices de diversidade de Shannon $\left(H^{\prime}\right)$ e de equabilidade (J) de espécies amostradas na regeneração natural sob as três espécies estudadas

6 Distribuição das 10 espécies mais abundantes da regeneração natural nas diferentes condições, em relação ao número de indivíduos menores e maiores que 1 metro, razão dos indivíduos, abundância total e relativa (\%), freqüência relativa $-\operatorname{Fr}(\%)$ - e altura média $(m)$.................. 
7 Relação das espécies amostradas na regeneração natural sob C. tomentosum (C.t.), C. myxa (C.m.) M. azedarach (M.a.), seguidas do grupo sucessional (G. s.) e síndrome de dispersão (S. d.) a que pertencem...................................... 


\title{
CHUVA DE SEMENTES, BANCO DE SEMENTES E REGENERAÇÃO NATURAL SOB TRÊS ESPÉCIES DE INÍCIO DE SUCESSÃO EM UMA ÁREA RESTAURADA EM IRACEMÁPOLIS (SP)
}

\author{
Autora: DANIELA CRISTINE MASCIA VIEIRA \\ Orientador: Prof. Dr. SERGIUS GANDOLFI
}

\section{RESUMO}

O presente estudo teve como objetivos caracterizar a composição da regeneração natural, da chuva e do banco de sementes presentes sob a copa de três espécies de início de sucessão - Centrolobium tomentosum Guill. ex Benth. (Fabaceae), Cordia myxa L. (Boraginaceae) e Melia azedarach L. (Meliaceae) -, bem como avaliar as possíveis diferenças entre as comunidades que se formaram sob estas espécies. Tal estudo foi desenvolvido em uma área de mata restaurada, localizada no entorno da represa de abastecimento público do município de Iracemápolis (SP). Para tanto, foram marcados 15 indivíduos de cada espécie, sob os quais foram instalados dois coletores de sementes (1 $\mathrm{m}^{2}$ cada), de onde se coletou todos os propágulos depositados por um período de um ano, em coletas mensais. Sob cada um destes 45 indivíduos foi retirada uma amostra de solo $(0,5 \mathrm{~m} \times 0,5 \mathrm{~m} \times 0,05 \mathrm{~m})$, que foi posta a pleno sol, por oito semanas, para a avaliação da composição do banco de sementes. A regeneração natural foi avaliada na área de projeção das copas, em uma parcela circular de 2,5 m de raio, na qual se amostraram todos os indivíduos de 
espécies arbustivo-arbóreas de 0,3 m a 2,0 $\mathrm{m}$ de altura. A chuva de sementes sob $M$. azedarach apresentou-se com maior densidade e sob C. myxa com maior riqueza $(p<0,05)$. Igualmente, a maior densidade de emergentes do banco de sementes foi observada nas amostras sob $M$. azedarach e a maior riqueza foi observada sob C. myxa. Quanto à regeneração natural, as comunidades sob as três espécies diferenciaram-se em relação à diversidade de espécies, maior sob os indivíduos de $M$. azedarach, e à estrutura da comunidade, que se apresentou mais alta sob $C$. myxa $(p<0,05)$. A maior parte dos indivíduos e espécies amostradas, tanto na chuva quanto no banco e na regeneração natural, pertencem aos estágios iniciais da sucessão secundária, sendo que muitas, dentre as mais abundantes, são exóticas. As três espécies formam nichos de regeneração, permitindo a germinação e desenvolvimento de plântulas sob elas, influenciando, cada uma, na estrutura e composição das comunidades e contribuindo para a manutenção da diversidade. Por fim, alguns resultados obtidos através deste estudo são importantes para planejamento do monitoramento da área, o qual é fundamental para o emprego de medidas de intervenção, bem como para o entendimento da evolução da floresta que se forma. 


\title{
SEED RAIN, SEED BANK AND NATURAL REGENERATION UNDER THREE SPECIES OF EARLY SUCCESSION IN A RESTORED AREA AT IRACEMÁPOLIS (SP)
}

\author{
Author: DANIELA CRISTINE MASCIA VIEIRA \\ Adviser: Prof. Dr. SERGIUS GANDOLFI
}

\section{SUMMARY}

The present study describes the composition of natural regeneration, seed rain and seed bank under three early species - Centrolobium tomentosum Guill. ex Benth. (Fabaceae), Cordia myxa L. (Boraginaceae) e Melia azedarach L. (Meliaceae) - and evaluatuation of the possible differences among understory regeneration. The study area, a restored area, is located at the margins of city water reservatory at Iracemápolis (SP). For the study, 15 individuals were selected and under their crown the seed rain was monthly sampled through of the material deposited in $901 \mathrm{~m} \times 1 \mathrm{~m}$ traps (two by individual). The seed bank was evaluated by 45 soil samples removed from $0,5 \mathrm{~m} \times 0,5 \mathrm{~m}$ plots and $5 \mathrm{~cm}$ depth, placed under full sun for a period of eight weeks. The natural regeneration was evaluated in circular plots $\left(17 \mathrm{~m}^{2}\right)$, under projection of the crown, where all individuals of timber species, between $0,3 \mathrm{~m}$ and 2,0 $\mathrm{m}$ tall, were counted and identified. The seed rain under $M$. azedarach showed higher mean density and under $C$. myxa higher mean number of species $(p<0,05)$. 
Identically, the higher density of seedlings was found in soil samples under $M$. azedarach and higher number of species under C. myxa. For natural regeneration, the communities showed differences in species diversity, being higher under individuals of $M$. azedarach, and structure, under individuals of $C$. myxa was found higher number of seedlings $(p<0,05)$. The majority of individuals and species sampled is from early secondary succession species, and those species, most of them are exotics. The three species create microsites, allowing the seed germination and growth of seedling under their crowns, acting on community structure and contributing for the maintenance of diversity. Some results obtained in this study are important for projection of monitoring of this restored area, which is fundamental for intervention actions, as well as to the understanding of evolution of the forest under formation. 


\section{INTRODUÇÃO}

Atualmente, com a redução das florestas paulistas, a recuperação de ecossistemas florestais degradados vem sendo uma ação cada vez mais perseguida (Rodrigues \& Gandolfi, 1996). De acordo com Barbosa (2000), o processo de desmatamento, causando a fragmentação das formações florestais, tem levado à extinção de muitas espécies vegetais e animais, apesar dos avanços nas leis que disciplinam a ação antrópica nas florestas de proteção.

A recuperação de áreas degradadas pode ser conceituada como um conjunto de ações que visam proporcionar o restabelecimento de condições e sustentabilidade existentes em ecossistemas naturais, sendo uma atividade que exige uma abordagem sistemática de planejamento e visão a longo prazo (Dias \& Griffith, 1998), e não apenas uma tentativa limitada de remediar um dano que, na maioria das vezes, poderia ter sido evitado (Rodrigues \& Gandolfi, 2000).

A intervenção, nestas áreas degradadas, através de técnicas de manejo pode acelerar o processo de regeneração, permitir o processo de sucessão e evitar a perda de biodiversidade. Estas técnicas, no entanto, são desenvolvidas a partir do conhecimento científico obtido com estudos tanto em áreas naturais como em áreas restauradas, que tentam compreender os mecanismos que levam à formação das comunidades (Rodrigues \& Gandolfi 2000). A abordagem científica deve enfocar não somente uma busca de soluções mais eficazes para a recuperação de uma dada degradação ambiental, mas também deve atuar como ferramenta para trabalhos de ecologia experimental, testando 
hipóteses e teorias normalmente elaboradas a partir de estudos em ecossistemas naturais (Allen et al., 1997).

Contudo, a recuperação de uma área pode ocorrer naturalmente através da sucessão secundária, sem a intervenção de técnicas que acelerem e direcionem a recuperação de um ecossistema.

Em áreas de floresta, o processo sucessional é o que mantém as comunidades. Alguns eventos, como a queda e a quebra de árvores do dossel, levam à formação de clareiras dentro da mata e estas clareiras, com o passar do tempo, são preenchidas, inicialmente, por espécies arbustivo-arbóreas exigentes em luz e, mais tarde, por espécies tolerantes à sombra, havendo uma gradual substituição das espécies (Gandolfi, 2003). A freqüência e área das clareiras determinam um mosaico, composto por manchas de fase de clareira, de fase de construção e de fase madura (Gandolfi, 2003), diferenciando-se pela idade, tamanho e composição de espécies (Brokaw, 1985). Nota-se, portanto, uma relação entre as clareiras e a geração ou manutenção da diversidade de espécies (Barbosa, 2000).

Sempre que possível é recomendável a recuperação de uma área degradada através do processo natural de sucessão secundária, ainda que com intervenções mínimas de isolamento da área e retirada dos fatores de degradação. Porém, muitas vezes esse processo de recuperação demanda uma intervenção mais direta e continuada, onde se torna fundamental o monitoramento das atividades implementadas (Rodrigues \& Gandolfi, 2000).

\subsection{A hipótese do dossel florestal como "filtro de diversidade"}

Muitos estudos já foram realizados no sentido de identificar os processos relacionados a auto-perpetuação das florestas tropicais e dos mecanismos que mantém a sua diversidade (Wright, 2002), produzindo informações fundamentais para uma efetiva proteção das florestas remanescentes e dando suporte à restauração florestal das áreas degradadas. 
Embora reconhecido há muito tempo o papel do indivíduo na determinação das características e dos processos de organização e dinâmica das comunidades vegetais (Callaway, 1995; Watt, 1947, 1968), recentemente tem recebido maior atenção por parte dos pesquisadores.

Cada espécie arbórea que ocupa o dossel de uma floresta, devido ao seu porte e à sua longa permanência num determinado local, pode exercer grande influência sobre o ambiente situado sob a projeção da sua copa, afetando, por exemplo, o padrão de luz no sub-bosque ou sobre o solo (Gandolfi, 2000; Facelli \& Pickett, 1991b; Vázquez-Yanez et al., 1990; VázquezYanez \& Orosco-Segovia, 1990) que, conseqüentemente, afetam a temperatura da superfície do solo (Molofsky \& Augspurger, 1992); afetando também a germinação de sementes, o recrutamento de plântulas, a deposição e decomposição de sua serapilheira (Cintra, 1997; Facelli \& Pickett, 1991a; Guariguata et al., 1995; Hirabuki,1991; Metacalfe \& Turner, 1998; Ponge et al., 1998), ou ainda, determinando a composição e fertilidade superficial do solo (Amiotti et al., 2000; Boettcher \& Kalis, 1990; Zinke, 1962).

Recentemente Gandolfi (2000), considerando o efeito produzido por cada árvore do dossel, propôs uma hipótese segundo a qual as árvores do dossel florestal funcionariam como "filtros da biodiversidade", ou seja, atuariam como "filtros ecológicos" determinando, em maior ou menor extensão, a composição e a estrutura da comunidade de plantas arbustivo-arbóreas que atualmente se desenvolvem sobre a projeção das suas copas, assim como poderiam determinar, parcialmente, a estrutura, a composição e a distribuição espacial das árvores do futuro dossel da floresta.

Um melhor esclarecimento do papel dos indivíduos de uma espécie na estruturação de uma floresta e a avaliação dessa hipótese tem conseqüências importantes tanto para a manutenção da biodiversidade das florestas nativas quanto no estabelecimento de estratégias mais eficazes na restauração florestal de áreas degradadas (Gandolfi, 2003). A possível diferenciação das espécies no desenvolvimento de uma área restaurada faria com que alguns 
modelos de plantio, como os homogêneos ou com baixa diversidade, fossem descartados quando o objetivo da recuperação é a retomada e manutenção da biodiversidade.

\subsection{0 monitoramento de áreas restauradas}

Áreas em processo de restauração são adequadas para estudos teóricos, bem como monitoramento, objetivando a conservação e desenvolvimento adequados. O monitoramento dessas comunidades em formação deve ser efetuado, tanto para permitir a correção de eventuais problemas como para a criação de uma base de dados que permitam avaliar e refinar as estratégias prescritas para a restauração de áreas degradadas.

Para isto, são de fundamental importância a definição e escolha de indicadores para a avaliação e monitoramento que traduzam as informações fundamentais sobre a evolução das comunidades em restauração.

Com sucesso, já foram utilizados indicadores relativos tanto à comunidade animal (invertebrados e vertebrados) quanto à comunidade vegetal (Guevara et al., 1986) para a avaliação e monitoramento de áreas naturais e restauradas.

Os indicadores referentes à comunidade vegetal consideram alguns parâmetros (Mantovani, 1998), como a riqueza, diversidade, equabilidade vegetal, fisionomia e características estruturais dos estratos ou grupos ecológicos (Rodrigues, 1998), os fluxos de nutrientes e de propágulos no solo e na serapilheira (Batista \& Leite, 1997).

Estes indicadores permitem avaliar a dinâmica florestal de uma área, como por exemplo, se há produção de propágulos (autóctones), se estes propágulos são recrutados e se a área está recebendo sementes de áreas próximas (alóctones) e oferecendo condições de recrutamento a essas espécies. 
Aspectos do banco e da chuva de sementes permitem a avaliação do papel das populações arbóreas que podem se estabelecer após perturbações (Putz \& Appanah, 1987).

A avaliação e monitoramento são de grande importância para o aperfeiçoamento metodológico dos projetos de recuperação de áreas degradadas (Nappo, 1999; Rodrigues \& Gandolfi, 1996), uma vez que estão relacionados com o sucesso da recuperação, ao avaliar a sustentabilidade da área recuperada (Rodrigues, 1998).

Segundo Pickett et al. (1987), a disponibilidade de sementes de diferentes espécies na área, provindas da chuva de sementes ou presentes no banco de sementes (previamente), é uma das exigências para que ocorra a sucessão ecológica, além da disponibilidade de um local para que estas se estabeleçam e das diferenças de requerimentos de cada espécie para germinar e se desenvolver, ou seja, devem existir categorias sucessionais distintas para que ocorra a substituição das espécies ao longo do tempo.

Grombone-Guarantini \& Rodrigues (2002) enfatizam a importância do banco e da chuva de sementes como recursos potenciais para o recrutamento de novos indivíduos e espécies, sendo a disponibilidade de propágulos e de agentes dispersores fundamentais para o restabelecimento estrutural da vegetação após um distúrbio. A ausência de sementes dispersas em áreas degradadas é, portanto, um fator limitante para a regeneração florestal (Holl, 1999).

Kageyama et al. (1989) afirmam que em áreas em processo de reabilitação onde não há nem banco de sementes nem mesmo a chegada de sementes das proximidades, o plantio de espécies pioneiras e não pioneiras deve dar início ao processo de sucessão, sendo as espécies do plantio fornecedoras de propágulos para a colonização das áreas.

De acordo com Parrota et al. (1997), as plantações de espécies florestais produzem um efeito catalítico, pois elas promovem mudanças das condições microclimáticas, aumento da complexidade estrutural da vegetação e o 
desenvolvimento das camadas de serapilheira e húmus durante os primeiros anos do reflorestamento, fazendo com que aumente a chegada de sementes na área e a atratividade dos agentes dispersores e, ao mesmo tempo, estas mudanças geram condições propícias à germinação e desenvolvimento das espécies. Plantações mistas, com diversidade de espécies, aceleraram o processo sucessional e, além disso, quando comparadas às plantações homogêneas, apresentam um maior valor de conservação de biodiversidade (Carnevale \& Montagnini, 2002; Montagnini, 2001).

As espécies pioneiras facilitam a sucessão mantendo grande interação com a fauna, a qual visita a copa das árvores como local de alimentação e abrigo, atuando como polinizadores e/ou dispersores. Com o passar do tempo, estas árvores pioneiras tornam-se pequenas ilhas de regeneração (Rodrigues \& Gandolfi, 2000), uma vez que os animais visitantes deixam sementes sob suas copas, ao defecá-las ou regurgitá-las (Guevara et al., 1986). As pioneiras têm a vantagem de apresentar sementes pequenas e abundância de frutos, consumidas por pequenos dispersores (Wunderle, 1997), como aves, por exemplo.

Estas interações, como relações mutualísticas, são necessárias para o restabelecimento de processos ecológicos em áreas degradadas ou em recuperação.

Em estudo realizado em área tropical no México, Guevara et al. (1986) observaram que as árvores remanescentes em pastagens comportavam-se como foco de recrutamento de sementes zoocóricas. Nepstad et al. (1998), analisando a deposição de sementes em pastagem abandonada na Amazônia, observaram que frugívoros depositavam sementes com maior freqüência sob árvores isoladas de Solanum crinitum do que na área coberta por gramíneas e arbustos, que cobriam cerca de $90 \%$ da pastagem. A existência destas árvores em pastagens permite que aves fiquem empoleiradas e, por conseqüência, defequem, sendo a disponibilidade destes poleiros um fator importante que influencia no número de plântulas, provindas de sementes dispersas pela 
avifauna, em lugares abertos (Wunderle., 1997), já que estes indivíduos podem facilitar a germinação e o estabelecimento de algumas espécies, devido às condições microclimáticas favoráveis existentes sob suas copas (Guariguata \&Ostertag, 2001).

A importância das árvores isoladas nos pastos deve aumentar ainda mais com o distanciamento da floresta (Miriti, 1998). Aide \& Cavelier (1994), em estudo na Colômbia, não observaram sementes dispersas na pastagem a uma distância de 20 metros do fragmento.

A chegada de sementes é um fator limitante para a recuperação, mas não o único. Estudos em pastagens mostram que muitas plântulas morrem nos estágios iniciais de desenvolvimento devido à alta taxa de predação por insetos e mamíferos ou mesmo pela competição com gramíneas (Nepstad et al., 1998). As gramíneas interferem no desenvolvimento destas plântulas, competindo por recursos e espaço (dificultando o enraizamento), constituindo, portanto, uma barreira física para as espécies lenhosas (Miriti, 1998). Em áreas de reflorestamentos, as gramíneas também constituem uma barreira física para o estabelecimento das mudas e das sementes dispersas na área, principalmente nos primeiros anos de implantação, quando não há condição de sombreamento, que poderia prejudicar, ou mesmo impedir, o aparecimento de gramíneas. Com o passar dos anos, o estabelecimento de plântulas em áreas já reflorestadas é favorecido pela supressão da vegetação herbácea nas condições de sombreamento e alta produção de serapilheira dentro destas matas, diminuindo, desta maneira, a competição dos regenerantes (Montagnini, 2001).

Estudando áreas restauradas com diferentes idades, Sorreano (2002) constatou que o número de espécies herbáceas germinadas no banco de sementes diminuía enquanto o das arbóreas aumentava com a idade da restauração. Wijdeven \& Kuzee (2000) compararam a densidade do banco de sementes de diferentes ambientes e constataram que a densidade de gramíneas e herbáceas diminuía e que, contrariamente, a densidade de 
arbustos e arbóreas aumentava das áreas agricultáveis para as áreas de floresta madura.

Apesar de limitantes, as sementes disponíveis numa área, vindas da chuva de sementes ou presentes o banco, podem fornecer indicativos sobre a capacidade de regeneração (Siqueira, 2002).

Contudo, baseando-se na hipótese de que as espécies influenciam diferentemente na composição e estrutura da comunidade sob a copa de seus indivíduos e que a maioria das espécies apresentam limite de dispersão, ou seja, a maior parte de suas sementes estão próximas à origem (Willson, 1993), é esperado que sob distintas espécies se encontrem diferentes aportes de sementes e comunidades de plântulas.

\section{Objetivos}

Este estudo tem como objetivos caracterizar a composição da regeneração natural, da chuva e do banco de sementes presentes sob a copa de três espécies de início de sucessão - Centrolobium tomentosum Guill. ex Benth. (Fabaceae), Cordia myxa L. (Boraginaceae) e Melia azedarach L. (Meliaceae) - implantadas em uma área restaurada no entorno da represa de abastecimento público do município de Iracemápolis (SP), bem como avaliar as possíveis diferenças entre as comunidades que se formam sob estas espécies. 


\section{MATERIAIS E MÉTODOS}

\section{1 Área de estudo}

\subsubsection{Caracterização física e localização da área}

A área de estudo localiza-se na bacia hidrográfica do Ribeirão Cachoeirinha, no Município de Iracemápolis, interior do Estado de São Paulo, a $22^{\circ} 35^{`} \mathrm{~S}$ de latitude e $47^{\circ} 31^{`} \mathrm{~W}$ de longitude.

O clima da região é do tipo Cwa e os índices pluviométricos variam de 1.100 a $1.700 \mathrm{~mm}$ anuais. Os solos existentes são Latossolo Vermelho Amarelo Húmico, Latossolo Roxo eutrófico, Latossolo Roxo distrófico, Terra Roxa Estruturada e Podzólico Vermelho-Amarelo abruptico (Siqueira, 2002).

$A$ área estudada faz parte de um projeto de recuperação realizado com a iniciativa do município iniciado em 1987, no qual foi restaurado o entorno da represa de abastecimento público do Município de Iracemápolis, abrangendo uma área de aproximadamente 50 ha. Em 2002, observaram-se diferentes estratos na vegetação e um dossel de aproximadamente $10 \mathrm{~m}$ de altura (Siqueira, 2002).

O entorno desta área restaurada é dominado pelo cultivo de cana-deaçúcar e entre a área e a monocultura existe uma estrada de terra, a qual tem a função de aceiro.

O presente estudo foi conduzido em uma faixa de $1,1 \mathrm{~km}$ ao redor da represa, perfazendo uma área de 5,5 ha. 


\subsubsection{Caracterização do projeto de restauração da área}

A área onde se encontra a represa de abastecimento do Município foi desapropriada pelo governo local, em conseqüência do assoreamento do reservatório público de água original, o qual teve seu entorno recuperado. A área destinada para a recuperação consistiu de uma faixa de $50 \mathrm{~m}$, no entorno do reservatório e onde havia plantio de cana-de-açúcar e de outra, com $30 \mathrm{~m}$ de largura, localizada ao longo dos demais afluentes da microbacia do Ribeirão Cachoeirinha.

$\mathrm{Na}$ implantação deste projeto, a maior parte das espécies selecionadas para era arbórea. A seleção destas foi feita a partir de estudos florísticos e fitossociológicos dos remanescentes florestais da região. Foram introduzidas espécies frutíferas para a atração da fauna regional, com o objetivo de facilitar o fluxo de propágulos na área, e algumas espécies exóticas agressivas, implantadas na borda, com o intuito de amenizar os efeitos do cultivo da canade-açúcar no entorno da área restaurada, protegendo-a de possíveis incêndios e erosões provenientes da monocultura. No projeto de restauração foram utilizadas 140 espécies, as quais foram implantadas em módulos contendo 9 indivíduos, sendo 6 de espécies pioneiras, 2 de secundárias iniciais e 1 de secundária tardia ou clímax, num espaçamento de $4 \mathrm{~m} \times 4 \mathrm{~m}$ e posteriormente de $3 \mathrm{~m} \times 3 \mathrm{~m}$ (Rodrigues et al, 1992).

Para a distribuição das espécies na área foram instituídas duas subáreas, de acordo com o encharcamento do solo causado pela flutuação do nível da água: sub-área I, adjacente ao curso d’água, numa faixa de $3 \mathrm{~m}$, onde foram plantadas espécies tolerantes ao encharcamento do solo, típicas de condições ciliares; sub-área II, paralela à sub-área I, onde foram plantadas espécies típicas de Floresta Estacional Semidecidual (Rodrigues et al, 1992). 


\subsection{Descrição das espécies selecionadas para a condução do estudo}

A condução do estudo se deu sob a copa de três espécies de início de sucessão - Centrolobium tomentosum (Fabaceae), Cordia myxa (Boraginaceae) e Melia azedarach (Meliaceae). Estas espécies foram escolhidas devido à presença destas no dossel da mata, já em estado reprodutivo, e à abundância de indivíduos adultos, permitindo o uso de repetições para a condução do estudo.

Centrolobium tomentosum Guill. ex Benth. - Fabaceae

Espécie nativa, com ocorrência em Minas Gerais, Goiás, Mato Grosso do Sul, São Paulo e norte do Paraná, na floresta semidecídua da bacia do Paraná e afluentes. É decídua, heliófita e seletiva xerófita, apresenta rápido crescimento, mostrando-se com grande vigor nos estágios iniciais da sucessão secundária, sendo considerada ótima para o plantio misto em recomposição de áreas degradadas (Lorenzi, 1998).

Árvore com 10-22 m de altura, que produz anualmente grande quantidade de sementes viáveis (Lorenzi, 1998), contidas em frutos tipo sâmara (até três sementes por fruto), que são dispersos pelo vento a curtas distâncias. Floresce durante os meses de janeiro a março, tendo seus frutos amadurecidos entre os meses de abril e outubro (Carvalho, 2003).

\section{Cordia myxa L. - Boraginaceae}

Espécie nativa da Ásia tropical e introduzida e cultivada há vários séculos em diversas regiões quentes do Globo (Martins, 1993). Apresenta-se como subespontânea em algumas regiões, onde é considerada indesejável (Lorenzi et al., 2003).

Árvore semidecídua, pequena, com até $10 \mathrm{~m}$ de altura, com copa alargada, tendo os galhos novos longos e vigorosos; cicatrizes foliares muito 
proeminentes. Produz frutos ovóides, com até $30 \mathrm{~mm}$ de largura, contendo duas sementes e se torna amarelado na maturação (Martins, 1993).

\section{Melia azedarach L. - Meliaceae}

Espécie originária da Índia (White et al., 1979), introduzida no Novo Mundo e comumente cultivada e naturalizada por toda América tropical, desde o México até a Argentina. Em algumas regiões tem crescimento relativamente rápido, sendo plantada comercialmente para uso na manufatura de tábua de fibra (Pennington, 1981).

Árvore caducifólia, de pequeno a médio porte, com vida curta, atingindo 10-15 m de altura, florescendo, por vezes, desde jovem, com $3 \mathrm{~m}$ de altura (White et al., 1979). Apresenta frutos carnosos em abundância, amarronzados na maturação, contendo cinco sementes.

\subsection{Procedimento de campo}

\subsubsection{Marcação dos indivíduos}

Dentro da floresta implantada foram marcados, aleatoriamente, 15 indivíduos, com perímetro à altura do peito $(P A P) \geq 15 \mathrm{~cm}$, adultos e frutificando, de cada uma das três espécies estudadas. Todos esses 45 indivíduos foram plaqueados, numerados e tidos medidos a sua altura e o PAP. Todas as árvores do dossel com copa adjacente (que se tocavam) às copas das árvores amostradas foram identificadas taxonomicamente para que fosse averiguada uma relação destas espécies com aquelas amostradas na chuva de sementes sob cada uma das três espécies estudadas. 


\subsubsection{Chuva de sementes}

Para a avaliação da chuva de sementes foram instalados, sob a copa destes 45 indivíduos, 90 coletores de sementes, sendo dois coletores por indivíduo, distribuídos aleatoriamente - a área sob a copa foi dividida em quadrantes, numerados de 1 a 4 , sendo sorteados dois quadrantes para cada indivíduo, no primeiro quadrante sorteado foi instalado um coletor a distância de $1 \mathrm{~m}$ e no segundo, instalado um outro coletor a distância de $2 \mathrm{~m}$, medidas do caule ao centro do coletor. Os coletores tinham $1 \mathrm{~m}^{2}(1 \mathrm{~m} \times 1 \mathrm{~m})$ com o fundo de tela de náilon (malha de $1 \mathrm{~mm} \times 1 \mathrm{~mm}$ ) e laterais e pés de madeira, estando a $10 \mathrm{~cm}$ de altura do solo, sendo, portanto, a área total amostrada em cada uma das três espécies de $30 \mathrm{~m}^{2}$ (Figura 1)

As sementes presentes nos coletores foram coletadas mensalmente durante o período de um ano, de novembro de 2002 a outubro de 2003, no início de cada mês. No campo, este material foi armazenado em sacos de papel ou de plástico, marcando-se o número do indivíduo, o número do coletor e a data de coleta.

No Laboratório de Ecologia e Restauração Florestal (LERF) do Departamento de Ciências Biológicas da ESALQ/USP, este material foi triado, separando-se as sementes e frutos dos outros materiais eventualmente encontrados (galhos, folhas, flores, insetos, etc.). Posteriormente, fez-se a identificação e a quantificação das sementes e frutos com o auxílio de lupa, quando necessário. A identificação foi realizada por comparação com material de herbário, com material coletado da própria área ou com a ajuda de especialistas. Todas as sementes coletadas foram separadas por síndrome de dispersão, segundo Pijl (1982), em anemocóricas, zoocóricas e autocóricas e por grupo ecológico, em pioneiras, secundárias iniciais e tardias e não caracterizadas, de acordo com Gandolfi (2000).

A chuva de sementes observada sob cada indivíduo foi obtida com a soma do material coletado nos dois coletores $\left(2 \mathrm{~m}^{2}\right)$. 


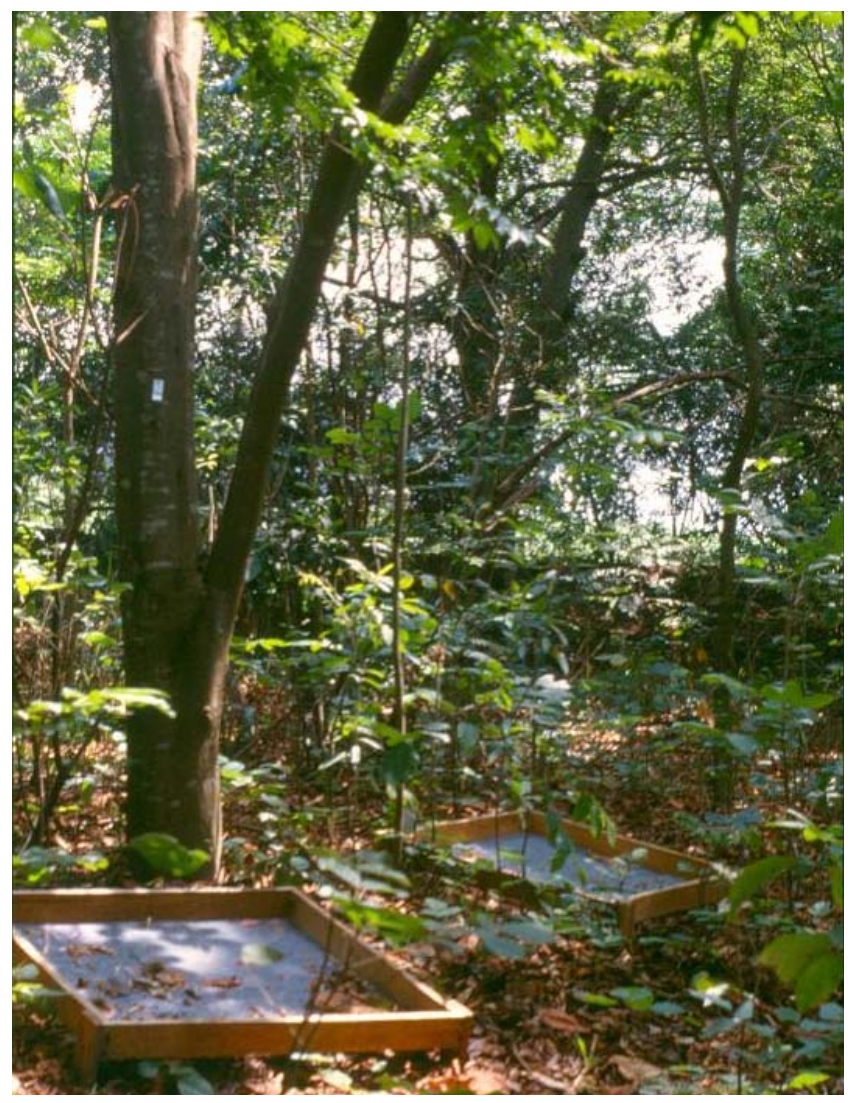

Figura 1 - Disposição dos coletores de sementes instalados sob a projeção da copa de um indivíduo de Centrolobium tomentosum, em Iracemápolis

\subsubsection{Banco de sementes}

Pra a avaliação do banco de sementes encontrado sob a projeção das copas das três espécies foi demarcada uma parcela de 0,25 $\mathrm{m}^{2}(50 \mathrm{~cm} \times 50$ $\mathrm{cm}$ ), por indivíduo, de onde se retirou uma amostra de solo com $5 \mathrm{~cm}$ de profundidade, juntamente com a serapilheira acima existente. O volume de cada amostra foi de cerca de 12,5 litros e o volume total foi de 187,5 litros por espécie. 
Este material foi armazenado em saco plástico preto e levado para o Laboratório de Ecologia e Restauração Florestal (LERF) do Departamento de Ciências Biológicas da ESALQ/USP, onde foi triado, retirando-se a maior parte das folhas e galhos encontrados nas amostras.

Em seguida, cada amostra foi devidamente depositada em duas bandejas brancas de plástico $(27 \mathrm{~cm} \times 19 \mathrm{~cm} \times 7 \mathrm{~cm})$ que, após cobertas por uma tela de náilon, para que se evitasse a chagada de novas sementes, foram postas ao ar livre, em local não sombreado, sujeitas, portanto, a alta intensidade de luz e, em conseqüência, a altas temperaturas.

Durante oito semanas, entre setembro e outubro de 2003, elas foram molhadas diariamente e uma vez por semana foi observada e anotada a evolução da germinação - foram contados e identificados os indivíduos com emissão das folhas cotiledonares.

Após a observação da $6^{a}$ semana, o solo foi revolvido para que a germinação fosse eventualmente estimulada, uma vez que foi notada uma estabilização na quantidade de sementes germinadas.

\subsubsection{Regeneração natural}

A avaliação da regeneração natural foi realizada após encerramento da chuva de sementes e teve como área amostral a projeção da copa dos indivíduos. Para tanto, fez-se uma parcela circular, com raio de $2,5 \mathrm{~m}$ e centrada no caule (área de 19,6 $\mathrm{m}^{2}$ ), sendo esta medida escolhida em razão das copas dos 45 indivíduos marcados terem no mínimo 2,5 $\mathrm{m}$ de raio. $\mathrm{A}$ área total amostrada foi de $17,6 \mathrm{~m}^{2}$, pois foi descontada a área ocupada pelos dois coletores de sementes $\left(2 \mathrm{~m}^{2}\right)$.

Dentro de cada parcela circular foram contados, identificados e tidos a altura medida de todos os indivíduos arbustivo-arbóreos com altura entre $30 \mathrm{~cm}$ e $2 \mathrm{~m}$. 
Todas as plântulas foram separadas por síndrome de dispersão e por grupo ecológico.

\subsection{Análise dos dados}

Foi calculado o índice de similaridade de S申rensen, entre os dados da chuva de sementes, do banco de sementes e da regeneração natural, e os índices de diversidade de Shannon ( $\mathrm{H}^{\prime}$ ) e de equabilidade $(\mathrm{J})$ de acordo com Pielou (1975) e Magurran (1988), entre os dados da chuva de sementes e da regeneração natural. Para o cálculo destes dois últimos índices foi utilizado o programa Fitopac (Shepherd, 1995). Alguns parâmetros fitossociológicos (abundância, freqüência absoluta e relativa, densidade absoluta e relativa), foram calculados para os dados de chuva e banco de sementes e para a regeneração natural.

Freqüência:

$$
\begin{aligned}
& F a_{i}=n_{i} / N \times 100 \\
& F r_{i}=F a_{i} /\left(\sum_{l=1}^{p} F a_{i}\right) \times 100
\end{aligned}
$$

Onde:

$\mathrm{Fa}_{\mathrm{i}}=$ freqüência absoluta da i-ésima espécie, dada em porcentagem;

$\mathrm{Fr}_{\mathrm{i}}$ = freqüência relativa da i-ésima espécie, dada em porcentagem;

$\mathrm{n}_{\mathrm{i}}=$ número de unidades amostrais em que a i-ésima espécie está presente;

$\mathrm{N}=$ número total de unidades amostrais;

$\mathrm{P}=$ número de espécies amostradas. 
Densidade:

$D a_{i}=n_{i} / A$

$\mathrm{Dr}_{\mathrm{i}}=\mathrm{Da} \mathrm{a}_{\mathrm{i}} /\left(\sum_{\mathrm{l}=1}^{\mathrm{p}} \mathrm{Da} \mathrm{a}_{\mathrm{i}}\right) \times 100$

Onde:

$D a_{\mathrm{i}}=$ densidade absoluta da i-ésima espécie;

$D r_{i}=$ densidade relativa da i-ésima espécie, dada em porcentagem;

$\mathrm{n}_{\mathrm{i}}=$ número de indivíduos amostrados da i-ésima espécie;

A = área amostrada;

$\mathrm{P}=$ número de espécies amostradas.

Índice de similaridade de Sфrensen:

Ss $=2 c /(a+b) \times 100$

Onde:

Ss $=$ Coeficiente de S $\phi$ rensen

$a=$ número total de espécies na área $A$;

$b=$ número total de espécies na área $B$;

$c=$ número de espécies comuns às áreas $A$ e $B$.

Índice de diversidade de Shannon $\left(\mathrm{H}^{\prime}\right)$ :

$H^{\prime}=-\sum_{i=1}^{s} p_{i} x \ln p_{i}$

Onde:

$\mathrm{H}^{\prime}=$ índice de diversidade de Shannon

$P_{i}=n_{i} / N$ 
$\mathrm{n}_{\mathrm{i}}$ = número de indivíduos amostrados da i-ésima espécie;

$\mathrm{N}=$ número total de indivíduos amostrados.

Índice de equabilidade (J):

$\mathrm{J}=\mathrm{H}^{\prime} / \mathrm{H}_{\text {máx }}^{\prime}$

Onde:

$\mathrm{J}=$ índice de equabilidade;

$\mathrm{H}_{\text {máx }}^{\prime}$ In S (diversidade máxima)

$S$ = número de espécies;

$\mathrm{O}$ valor de $\mathrm{J}$ varia de 0 a 1 , sendo 1 a máxima uniformidade, onde todas as espécies têm igual abundância.

A chuva de sementes foi analisada a partir de uma análise de variância (ANOVA um fator) entre os dados coletados sob as diferentes espécies, avaliando a variação interespecífica na deposição de propágulos. Ao existir diferenças significativas na análise, aplicou-se o teste Tukey HSD ( $\alpha=5 \%)$, para a comparação múltipla das médias (Zar, 1999).

Para a avaliação do banco de sementes fez-se uma análise de variância (ANOVA um fator), transformando os dados (em logaritmo), em caso de não homogeneidade e/ou normalidade dos dados. Ao existir diferenças significativas na análise, aplicou-se o teste Tukey HSD $(\alpha=5 \%)$, para a comparação múltipla das médias (Zar, 1999).

A regeneração natural foi analisada a partir de uma análise de variância (ANOVA um fator) entre os dados coletados sob as diferentes espécies, avaliando a variação interespecífica na regeneração dos indivíduos. Ao existir diferenças significativas na análise, aplicou-se o teste Tukey HSD ( $\alpha=5 \%)$, para a comparação múltipla das médias (Zar, 1999). 
A realização das análises de variância (ANOVA) e a verificação da homogeneidade das variâncias foram feitas com a utilização do programa Statistica. A normalidade dos dados foi verificada com o teste D'agostinho, com a utilização do programa BioEstat 2.0 (Ayres et al., 2000). 


\section{RESULTADOS E DISCUSSÃO}

\subsection{Chuva de sementes}

Os dados referentes à chuva de sementes foram calculados levando em consideração o número de coletores disponíveis na área de estudo a cada mês, uma vez que pela proximidade à área urbana, alguns coletores foram furtados ou mesmo quebrados ou revirados, impossibilitando a coleta de dados em todos os coletores, apesar da reposição dos mesmos. O Anexo A apresenta a relação das quantidades de coletores a cada mês sob cada uma das três espécies.

Durante o período de coleta, de novembro de 2002 a outubro de 2003, foram coletados 26.911 propágulos (frutos e sementes), destes, 3.982 (15\%) foram coletados sob os indivíduos de C. tomentosum, 6.282 (23\%) sob C. myxa e 16.647 (62\%) sob M. azedarach (Figura 2). E apesar da ausência de alguns coletores ao longo do ano, as proporções de propágulos sob cada espécie, acima apresentadas, praticamente não foram alteradas. Isto pode ser notado pela densidade média anual sob cada espécie, 12,8 propágulos. $\mathrm{m}^{-2}$.ano ${ }^{-1}(15 \%)$ sob C. tomentosum, 20,2 propágulos. $\mathrm{m}^{-2}$.ano-1 (24\%) sob C. myxa e 49,9 propágulos. $\mathrm{m}^{-2}$.ano ${ }^{-1}(61 \%)$ sob $M$. azedarach; para o cálculo desta densidade levou-se em consideração a área amostral, ou seja, o número de coletores que efetivamente permaneceu sob a espécie. 


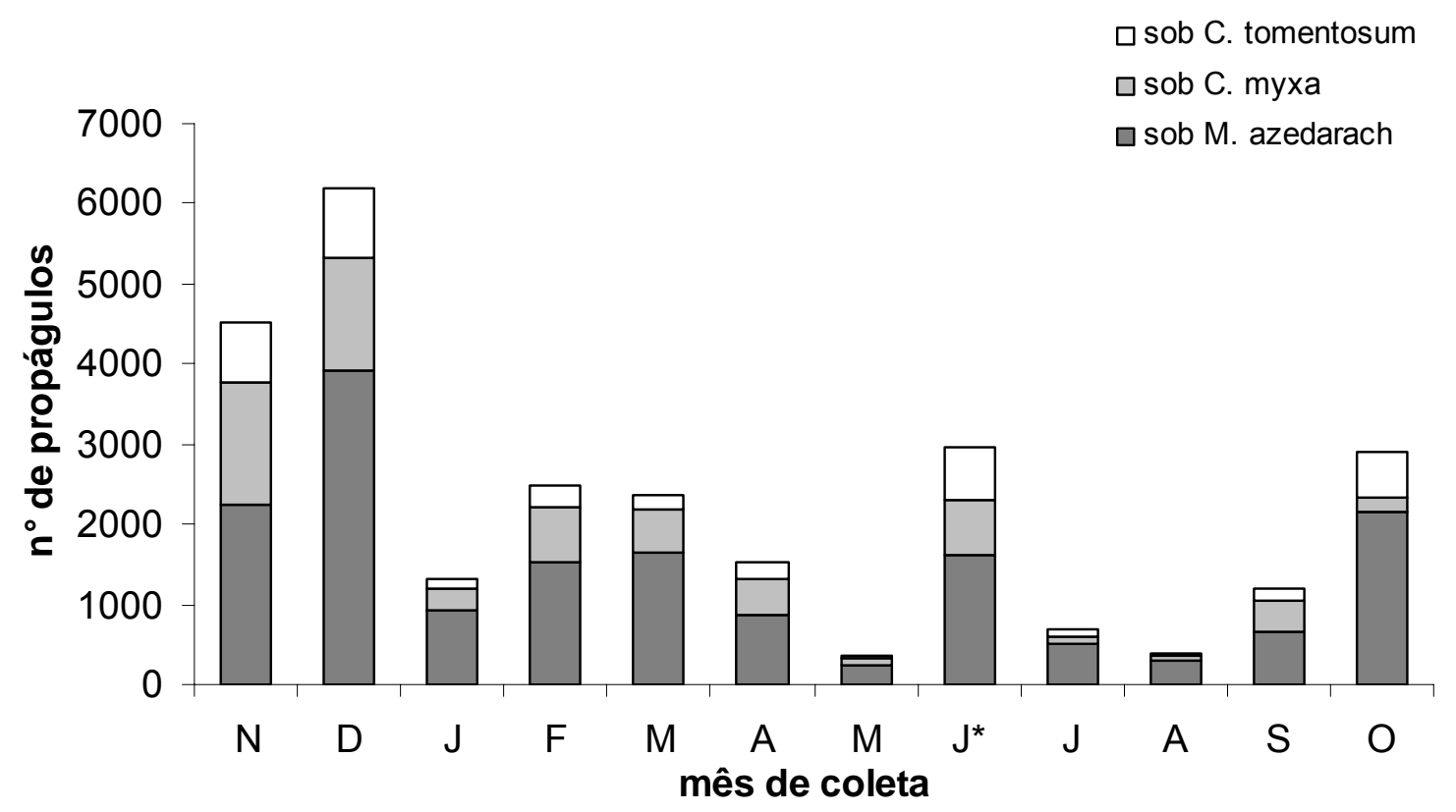

Figura 2 - Número total de propágulos coletados sob as três espécies, ao longo do ano. * Mês de coleta após vendaval

Os meses em que houve maior número de propágulos coletados sob as três espécies foram novembro e dezembro, com totais de $4.523(55,83$ propágulos. $\left.\mathrm{m}^{-2}\right)$ e 6.193 (75,52 propágulos. $\left.\mathrm{m}^{-2}\right)$ propágulos, respectivamente, perfazendo juntos $38,6 \%$ do total de propágulos amostrados.

Notou-se sazonalidade na deposição de propágulos ao longo do ano nas três espécies. Dois picos foram observados, um no mês de dezembro, mais acentuado, com uma grande quantidade de sementes de Tecoma stans (L.) Juss. ex Kunth (32\% do total), sob os indivíduos de M. azedarach e de C. myxa, e de frutos de $M$. azedarach ( $49 \%$ do total), sob os indivíduos de $M$. azedarach e de $C$. tomentosum, havendo também grande quantidade de sementes de Diatenopteryx sorbifolia Radlk. (22\%) sob os indivíduos de C. tomentosum. O outro pico ocorreu no mês de junho, com grande quantidade de frutos de $M$. azedarach (70\% do total), sob as três espécies, de frutos de Ficus benjaminea L. (23\%), sob C. myxa, e de sementes de Anadenanthera peregrina (L.) Speg $(30 \%)$ sob C. tomentosum. 
Este último pico é justificado por um episódio de vento intenso, ocorrido na região da área de estudo, dias antes da coleta. No material coletado foram observados frutos em processo de amadurecimento, que provavelmente não teriam sido depositados nos coletores de sementes se não houvesse o vendaval. Nesta época, C. tomentosum e $M$. azedarach estavam com suas árvores carregadas de frutos, em grande parte, maduros.

Episódios como este, ocasionando aumento da dispersão, queda de árvores e, conseqüentemente, abertura de clareiras, são propícios para a colonização de espécies pioneiras e/ou agressivas, as quais se beneficiam com a maior disponibilidade de luz (Begon et al., 1996).

Penhalber \& Mantovani (1997), estudando a chuva de sementes em uma floresta secundária, localizada na transição de Floresta Ombrófila Densa e Floresta Estacional Semidecidual, observaram o pico de produção de propágulos nesta mesma época, entre outubro e fevereiro, ou seja, entre o fim da estação seca e o início da estação chuvosa. Esta sazonalidade na deposição de sementes também foi observada por Grombone-Guarantini \& Rodrigues (2002) estudando uma área de Floresta Estacional Semidecidual, e por Siqueira (2002), na mesma área do presente estudo.

Segundo Morellato \& Leitão-Filho (1992), estes picos de produção ocorrem em épocas que são mais favoráveis para a dispersão e estabelecimento das espécies.

Sob os indivíduos de $M$. azedarach foi encontrado a maior média de propágulos por indivíduo e também o maior número de propágulos em todos os meses, fazendo com que esta espécie se diferenciasse significativamente das outras duas (Figura 3). Esta diferenciação se deve à grande produção de frutos pela própria espécie, sendo estes coletados todos os meses, e à existência de outros indivíduos desta mesma espécie na vizinhança imediata dos indivíduos estudados.

A contribuição de cada uma das três espécies na chuva de sementes abaixo de suas copas variou muito. Do total de propágulos amostrados sob $M$. 
azedarach, 76,8\% eram frutos de $M$. azedarach, porém, estes valores foram menores sob C myxa $(34,9 \%)$ e mais ainda sob C. tomentosum $(4,9 \%)$. As diferentes contribuições estão relacionadas à síndrome de dispersão e à produção de propágulos de cada espécie. C. tomentosum tem menor produção comparativamente às duas outras (observação pessoal), além de ser uma espécie anemocórica, tendo maior probabilidade de não cair sob sua própria copa, diminuindo assim a chance de ser coletado nas condições experimentais em que o estudo foi conduzido. A produção diferenciada indica diferenças na oferta de recursos para frugívoros pelas diferentes espécies, sendo, entre as zoocóricas, M. azedarach a que proporciona mais recursos. Esta contribuição pode ser notada na densidade de propágulos obtida sob cada espécie (Tabela 1).

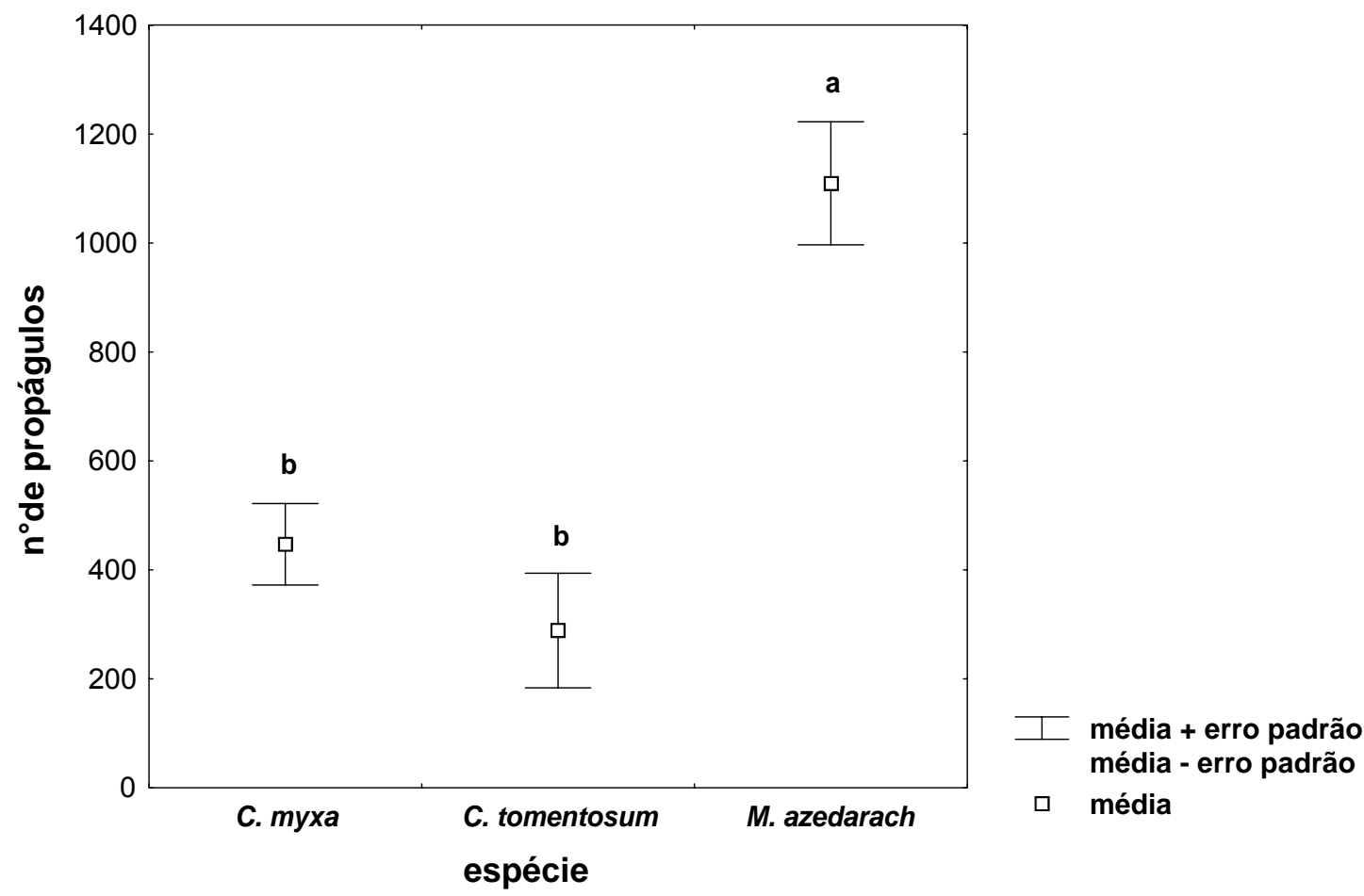

Figura 3 - Número médio de propágulos coletados na chuva de sementes sob cada uma das três espécies. Letras diferentes indicam diferenças significativas entre os tratamentos $(p<0,05)$ pelo teste Tukey 
Tabela 1. Densidade anual de propágulos sob cada uma das três espécies estudadas, considerando e excluindo a própria espécie da chuva de sementes

\begin{tabular}{lcc}
\hline & $\begin{array}{c}\text { Densidade de propágulos } \\
\text { considerando todas as } \\
\text { espécies (propágulos. }{ }^{-2} \text { ) }\end{array}$ & $\begin{array}{c}\text { Densidade de propágulos } \\
\text { excluindo a própria } \\
\text { espécie (propágulos. } \text { ( }^{-2} \text { ) }\end{array}$ \\
\hline Sob C. myxa & 242,0 & 178,9 \\
Sob C. tomentosum & 153,1 & 149,4 \\
Sob M. azedarach & 598,3 & 126,7 \\
\hline
\end{tabular}

Considerando um raio da copa de 2,5 m (17 $\left.\mathrm{m}^{2}\right)$, o número estimado de propágulos depositado em um ano sob cada indivíduo seria de $2.910,8$ para $C$. tomentosum, 4.607,5 para C. myxa e de $11.928,2$ para $M$. azedarach.

Isso demonstra que a quantidade de propágulos depositada é muito diferente, ou seja, sob $M$. azedarach a deposição é cerca de quatro vezes maior do que em $C$. tomentosum e quase três vezes maior do que em C. myxa. Porém, quando considerados apenas os propágulos de outras espécies a diferença entre elas torna-se pequena e é sob $C$. myxa que se observa a chuva de sementes mais densa.

No período de um ano, foram coletadas na chuva de sementes 48 espécies arbustivo-arbóreas, pertencentes a 19 famílias (identificadas). A família com maior riqueza foi Mimosaceae, com cinco espécies (10,4\% do total), seguida de Fabaceae e Bignoniaceae, com quatro espécies cada (8,3\%).

Sob os indivíduos de C. myxa foram amostradas 39 espécies, distribuídas em 19 famílias (identificadas). As famílias com maior riqueza foram Bignoniaceae, com cinco espécies, e Fabaceae, com quatro espécies. As espécies mais abundantes foram Tecoma stans (37,2\% dos propágulos) e C. myxa $(24,6 \%)$, sendo $C$. myxa juntamente com $M$. azedarach as espécies mais freqüentes.

Sob os indivíduos de C. tomentosum foram amostradas 32 espécies, distribuídas em 17 famílias (identificadas). As famílias com maior riqueza foram 
Fabaceae e Bignoniaceae, com três espécies cada. As espécies mais abundantes foram $M$. azedarach $(45,4 \%)$ e $T$. stans $(12 \%)$, sendo $C$. tomentosum e C. myxa as duas espécies mais freqüentes.

$\mathrm{E}$, sob os indivíduos de $M$. azedarach foram amostradas 38 espécies, distribuídas em 16 famílias (identificadas). As famílias com maior riqueza foram Mimosaceae, com quatro espécies, Bignoniaceae, Bombacaceae e Fabaceae, com três espécies cada. As espécies mais abundantes foram $M$. azedarach $(82,5 \%)$ e $T$. stans $(8,6 \%)$, sendo que $M$. azedarach também foi a espécie mais freqüente, seguida de Clausena excavata Burm. f.

A composição das espécies encontradas na chuva de sementes sob as copas das três espécies foi altamente similar. $O$ índice de similaridade de S $\phi$ rensen foi de $78,5 \%$ entre as espécies de $M$. azedarach e C. myxa, $77,8 \%$ entre $M$. azedarach e $C$. tomentosum e de $82,2 \%$ entre $C$. tomentosum e $C$. myxa. Apesar de apresentarem grande similaridade florística, as três espécies diferiram em relação à abundância das espécies encontradas. Os baixos valores de equabilidade $(J)$ e, conseqüentemente, de diversidade $\left(H^{\prime}\right)$ mostraram que há predomínio de espécies, principalmente de $M$. azedarach e T. stans, na chuva de sementes sob as três espécies estudadas (Tabela 2).

Tabela 2. Índices de diversidade de Shannon $\left(\mathrm{H}^{\prime}\right)$ e de equabilidade (J) de espécies amostradas na chuva de sementes sob as três espécies estudadas

\begin{tabular}{lcc}
\hline & H'$^{\prime}$ & J \\
\hline Sob C. myxa & 1,94 & 0,53 \\
Sob C. tomentosum & 1,98 & 0,57 \\
Sob M. azedarach & 0,83 & 0,23 \\
\hline
\end{tabular}

Certas espécies foram exclusivas, sendo que, proporcionalmente, sob $M$. azedarach foram amostradas mais espécies exclusivas (seis espécies ou 16\%) do que sob C. myxa (quatro espécies ou 10\%) e sob C. tomentosum (uma ou 
3\%). Estas espécies, predominantemente anemocóricas e autocóricas, estão, por vezes, localizadas na vizinhança e nenhuma delas apresentou-se com elevada abundância (todas com abundância relativa menor que $0,35 \%$ ), não sugerindo qualquer relação específica com a espécie estudada.

Algumas das espécies mais abundantes também se apresentaram altamente freqüentes - presentes em $66,7 \%$ dos indivíduos, no mínimo - sob as três condições, como é o caso da Clausena excavata, C. myxa, M. azedarach, Tecoma stans e Triplaris americana L., devido ao fato destas espécies estarem presentes na vizinhança e, no caso de $T$. stans e $T$. americana, serem facilmente dispersas por toda área, devido à sua dispersão anemocórica. Outras espécies apresentaram-se abundantes e freqüentes somente sob determinada espécie, como é o caso de Anadenanthera peregrina e Cytharexyllum myrianthum Cham. sob C. myxa e M. azedarach, decorrente da presença destas espécies na vizinhança (Figura 4, Anexos B, C, D e I).

Observa-se, portanto, que a composição da chuva de sementes está muito relacionada ao entorno, ou seja, à vizinhança imediata e à própria matriz em que se insere, e que a espécie do dossel, sob a qual está amostrando, parece não influenciar na riqueza e abundância das demais espécies que compõem a chuva, com exceção dela própria, para $M$. azedarach e C. myxa. Alguns autores (Penhalber \& Mantovani, 1997; Walker \& Neris, 1993) também notaram isto, percebendo que grande parte dos propágulos coletados nas peneiras vinha de indivíduos frutificando a uma curta distância.

A maior parte dos propágulos e espécies depositadas na área pertence aos estágios inicias da sucessão secundária e, dentre as mais abundantes, muitas são exóticas, mostrando que existe um grande potencial regenerativo para espécies de início de sucessão, nativas e exóticas, principalmente com a abertura de clareiras na floresta.

O fato da maior parte dos indivíduos e espécies depositadas na área pertencerem aos estágios inicias da sucessão está relacionado com a idade do plantio, ou seja, o que foi amostrado na chuva de sementes é reflexo das 
espécies que estão em estágio reprodutivo na área, não sendo esperado, portanto, que nesta idade fossem amostrados muitos propágulos e espécies pertencentes aos estágios finais da sucessão.

Em relação à síndrome de dispersão das espécies, a maior parte delas 43,3\% em média sob cada espécie - é anemocórica, seguida das zoocóricas, que correspondem a 31,3\%, em média, e das autocóricas, que correspondem a $25,5 \%$, em média, não havendo diferenças destas proporções entre as três espécies estudadas. Isto mostra que o fato de C. myxa e M. azedarach serem espécies zoocóricas não alterou a porcentagem desta síndrome sob suas copas (Tabela 3).

Tabela 3. Relação das espécies amostradas na chuva de sementes sob $C$. tomentosum (C.t.), C. myxa (C.m.) e M. azedarach (M.a), seguidas do grupo sucessional (G. s.) e síndrome de dispersão (S. d.) a que pertencem

Espécie

sob C. m. $\quad$ sob C.t. $\quad \operatorname{sob} M$. a. $\quad$ G. s. $^{1}$

S. d. $^{2}$

ANACARDIACEAE

Schinus terebinthifolius Raddi

BIGNONIACEAE

Bignoniaceae sp2

Jacaranda mimosaefolia D.Don.

Tabebuia chrysotricha (Mart. ex

DC.) Standl

Tecoma stans (L.) Juss. ex H.B.K.
$\mathrm{X}$

BOMBACACEAE

Bombacaceae sp1

Chorisia speciosa A. St. Hil.

Pseudobombax grandiflorum

(Cav.) A. Robyns

BORAGINACEAE

Cordia myxa L.
$\mathrm{X}$

$\mathrm{X}$

$\mathrm{X}$

$x$

$\mathrm{X}$

$\mathrm{X}$

$\mathrm{X}$

$\mathrm{X}$

$\mathrm{X}$

$\mathrm{X}$

$\mathrm{X}$

$\mathrm{X}$
$\mathrm{X}$

P $\quad$ zoo

ZOO

anemo

anemo

anemo

anemo

$\mathrm{X} \quad \mathrm{P}$ anemo

\section{$\mathrm{x}$}

$x$

$\mathrm{x}$

$\mathrm{x}$

$x$

$x$

X

$\mathrm{X}$ anemo

anemo

Si anemo 
Tabela 3. Relação das espécies amostradas na chuva de sementes sob $C$. tomentosum (C.t.), C. myxa (C.m.) e M. azedarach (M.a), seguidas do grupo sucessional (G. s.) e síndrome de dispersão (S. d.) a que pertencem

\begin{tabular}{|c|c|c|c|c|c|}
\hline Espécie & sob C. $m$. & sob C. $t$. & sob $M$. a. & G. s. $^{1}$ & S. d. ${ }^{2}$ \\
\hline $\begin{array}{l}\text { CAESALPINACEAE } \\
\text { Caesalpinia ferrea var. } \\
\text { leiostachya (Benth.) Duke }\end{array}$ & $x$ & & & St & auto \\
\hline \multicolumn{6}{|l|}{ COMBRETACEAE } \\
\hline Terminalia sp & $x$ & $x$ & & $\mathrm{Si}$ & anemo \\
\hline $\begin{array}{l}\text { FABACEAE } \\
\text { Centrolobium tomentosum Guill. } \\
\text { ex Benth. }\end{array}$ & $x$ & $x$ & $x$ & $\mathrm{Si}$ & anemo \\
\hline Clitoria fairchildiana Howard. & $x$ & $x$ & $x$ & & auto \\
\hline Pterocarpus violaceus Vog. & $x$ & $x$ & $x$ & $\mathrm{Si}$ & anemo \\
\hline Tipuana tipu (Benth.) Kuntze & $x$ & & & & anemo \\
\hline $\begin{array}{l}\text { LAURACEAE } \\
\text { Nectandra megapotamica } \\
\text { (Spreng.) Mez }\end{array}$ & $x$ & $x$ & $x$ & $\mathrm{Si}$ & zoo \\
\hline \multicolumn{6}{|l|}{ LYTHRACEAE } \\
\hline Lafoensia glyptocarpa Koehne & $x$ & $x$ & $x$ & St & auto \\
\hline \multicolumn{6}{|l|}{ MELASTOMATACEAE } \\
\hline Tibouchina sp & $x$ & & $\mathrm{x}$ & $P$ & \\
\hline \multicolumn{6}{|l|}{ MELIACEAE } \\
\hline Melia azedarach L. & $x$ & $x$ & $x$ & $P$ & zoo \\
\hline \multicolumn{6}{|l|}{ MIMOSACEAE } \\
\hline $\begin{array}{l}\text { Albizia hasslerii (Chodat) Burkart } \\
\text { Anadenanthera peregrina (L.) }\end{array}$ & $x$ & & $x$ & $\mathrm{P}$ & auto \\
\hline $\begin{array}{l}\text { Spreg } \\
\text { Leucaena leucocephala (Lam.) de } \\
\text { Wit }\end{array}$ & $x$ & $x$ & $x$ & Si & $\begin{array}{l}\text { auto } \\
\text { auto }\end{array}$ \\
\hline Mimosaceae sp1 & & $x$ & $x$ & & auto \\
\hline
\end{tabular}


Tabela 3. Relação das espécies amostradas na chuva de sementes sob $C$. tomentosum (C.t.), C. myxa (C.m.) e M. azedarach (M.a), seguidas do grupo sucessional (G. s.) e síndrome de dispersão (S. d.) a que pertencem

\begin{tabular}{|c|c|c|c|c|c|}
\hline Espécie & sob C. $m$. & sob C. $t$. & sob $M . a$. & G. s. ${ }^{1}$ & S. d. ${ }^{2}$ \\
\hline \multicolumn{6}{|l|}{ MIMOSACEAE } \\
\hline \multicolumn{6}{|l|}{ Piptadenia gonoacantha (Mart.) } \\
\hline \multicolumn{6}{|l|}{ MORACEAE } \\
\hline Fícus benjaminea L. & $x$ & $x$ & & $\mathrm{Si}$ & zoo \\
\hline \multicolumn{6}{|l|}{ MYRSINACEAE } \\
\hline Rapanea umbellata (Mart.) Mez & $x$ & $x$ & $x$ & $\mathrm{Si}$ & zoo \\
\hline \multicolumn{6}{|l|}{ POLYGONACEAE } \\
\hline Triplaris americana L. & $x$ & $x$ & $x$ & $P$ & anemo \\
\hline \multicolumn{6}{|l|}{ ROSACEAE } \\
\hline Prunus sellowii Koehne & $x$ & $x$ & $x$ & $\mathrm{Si}$ & zoo \\
\hline \multicolumn{6}{|l|}{ RUTACEAE } \\
\hline $\begin{array}{l}\text { Clausena excavata Burm. f. } \\
\text { Balfourodendron riedelianum }\end{array}$ & $x$ & $\mathrm{x}$ & $x$ & & \\
\hline (Engl.) Engl. & $x$ & $x$ & $x$ & St & anemo \\
\hline \multicolumn{6}{|l|}{ SAPINDACEAE } \\
\hline Diatenopteryx sorbifolia Radlk. & $x$ & $x$ & $x$ & $P$ & anemo \\
\hline Koelreuteria bipinnata & $x$ & $x$ & $x$ & & \\
\hline \multicolumn{6}{|l|}{ VERBENACEAE } \\
\hline Aegiphilla sellowiana Cham. & $x$ & $x$ & $x$ & $P$ & zoo \\
\hline Cytharexyllum myrianthum Cham. & $x$ & $x$ & $x$ & $P$ & zoo \\
\hline \multicolumn{6}{|l|}{ INDETERMINADA } \\
\hline morfoespécie 11 & $x$ & & $x$ & & zoo \\
\hline morfoespécie 12 & & & $x$ & & \\
\hline
\end{tabular}


Tabela 3. Relação das espécies amostradas na chuva de sementes sob $C$. tomentosum (C.t.), C. myxa (C.m.) e M. azedarach (M.a), seguidas do grupo sucessional (G. s.) e síndrome de dispersão (S. d.) a que pertencem

\begin{tabular}{|c|c|c|c|c|}
\hline Espécie & sob C. $m$. & sob $C . t$. & sob $M$. a. G. s. $^{1}$ & S. d. ${ }^{2}$ \\
\hline \multicolumn{5}{|l|}{ INDETERMINADA } \\
\hline morfoespécie 17 & & $x$ & & anemo \\
\hline morfoespécie 19 & & $x$ & $x$ & anemo \\
\hline morfoespécie 21 & $x$ & & & \\
\hline morfoespécie 24 & & & $x$ & anemo \\
\hline morfoespécie 25 & & & $x$ & anemo \\
\hline morfoespécie 26 & $x$ & & & \\
\hline morfoespécie 29 & $x$ & $x$ & $x$ & \\
\hline morfoespécie 30 & $x$ & $x$ & $x$ & auto \\
\hline morfoespécie 31 & & & $x$ & auto \\
\hline morfoespécie 35 & $x$ & $x$ & & \\
\hline morfoespécie 38 & $x$ & $x$ & $x$ & auto \\
\hline morfoespécie 43 & & & $x$ & \\
\hline
\end{tabular}

$1 \mathrm{P}=$ pioneira, $\mathrm{Si}=$ secundária inicial e $\mathrm{St}=$ secundária tardia.

2 anemo $=$ anemocórica, auto = autocórica e zoo = zoocórica 


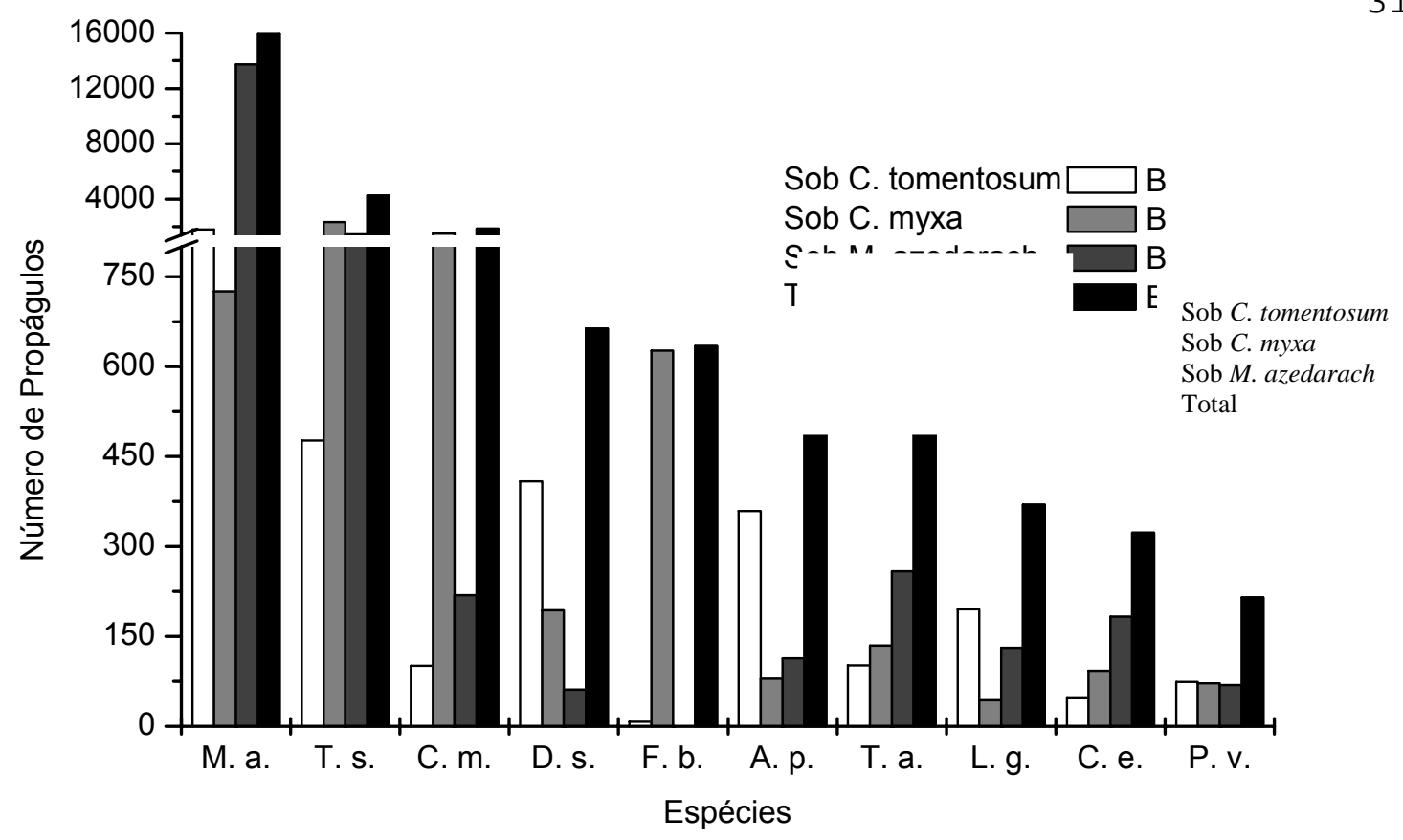

Figura 4 - Espécies mais abundantes amostradas na chuva de sementes sob as três espécies, ao longo de um ano. M.a. = M. azedarach; T.s. = T. stans; C.m. = C. myxa; D.s. = D. sorbifolia; F.b. $=$ F. benjaminea; A.p. $=$ A. peregrina; T.a. $=T$. americana; L.g. $=\mathrm{L}$. glyptocarpa; $\quad$ C.e. $=$ C. excavata; P.v. $=$ P. violaceus

As Figuras 5, 6 e 7 apresentam as espécies coletadas e suas respectivas abundâncias sob cada uma das três espécies. 


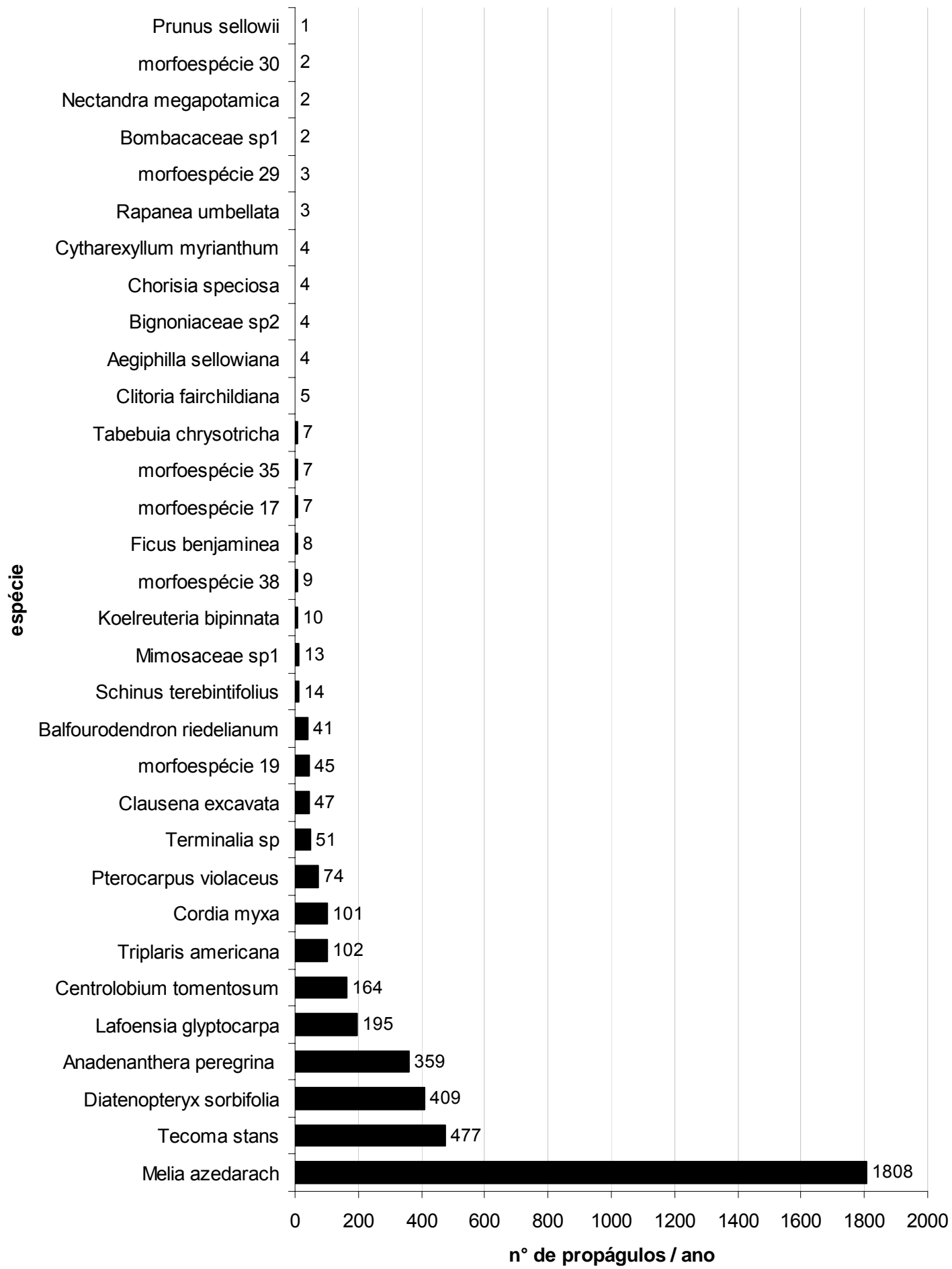

Figura 5 - Abundância das espécies amostradas na chuva de sementes sob os indivíduos de Centrolobium tomentosum, ao longo de um ano 


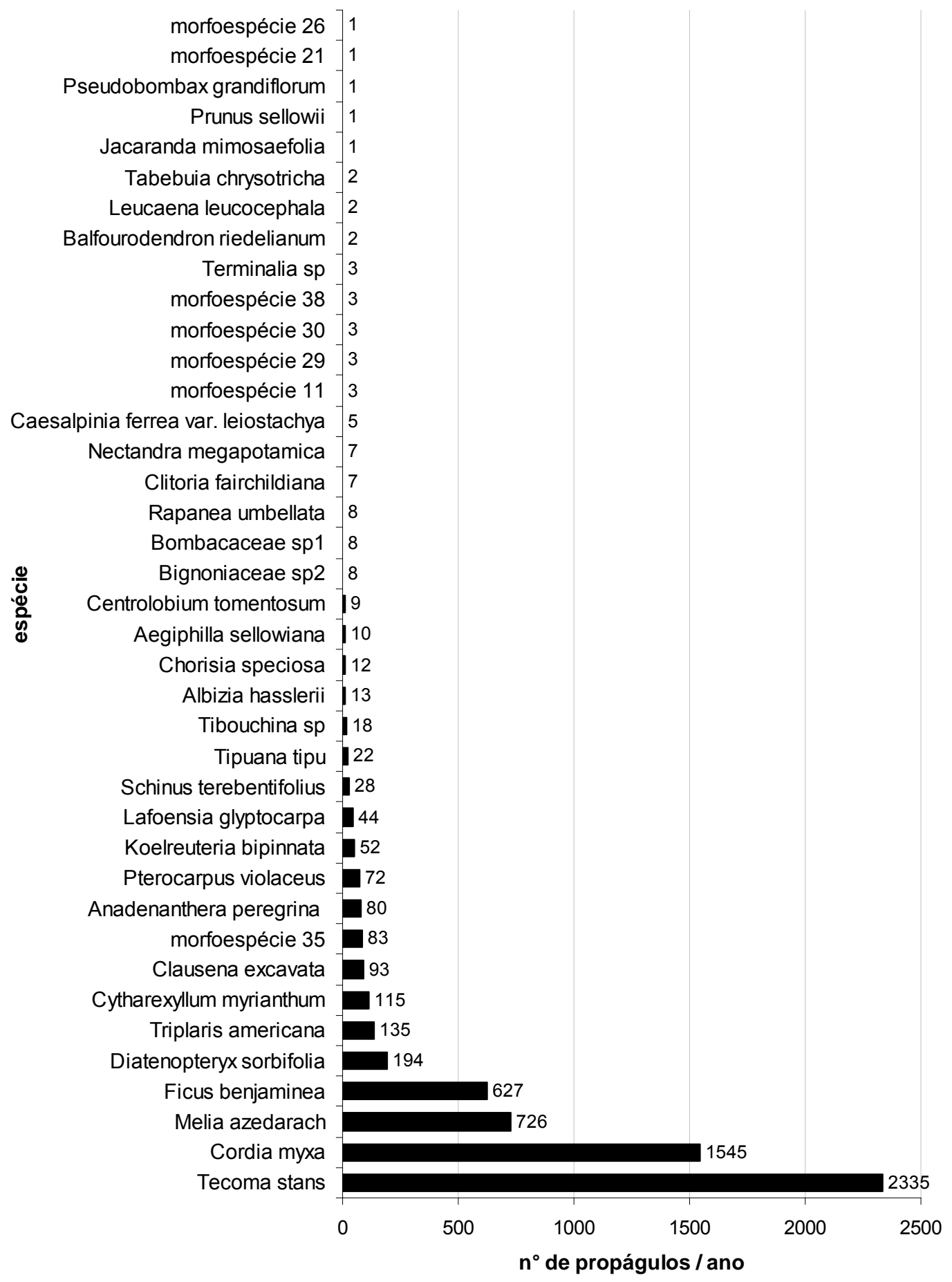

Figura 6 - Abundância das espécies amostradas na chuva de sementes sob os indivíduos de Cordia myxa, ao longo de um ano 


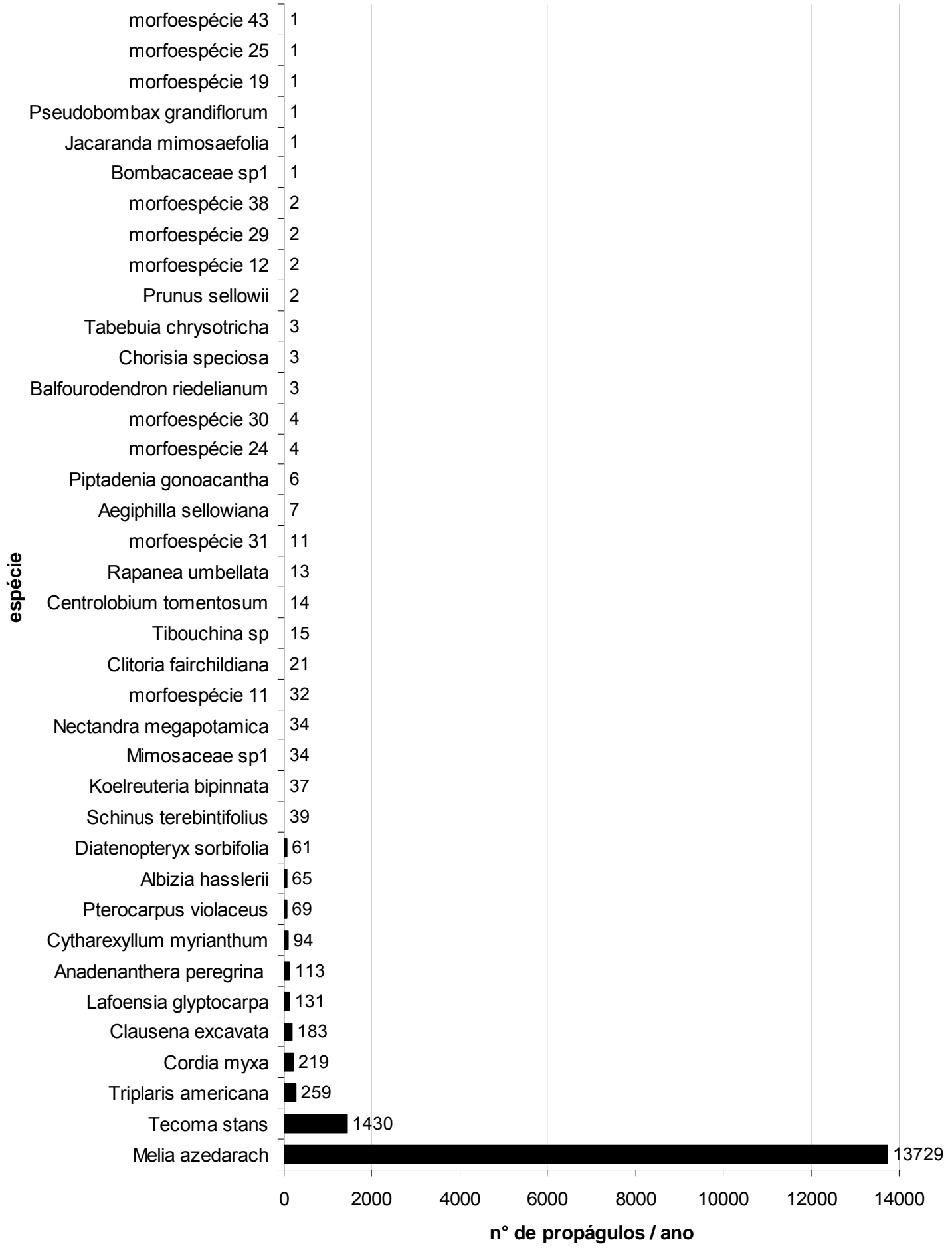

Figura 7 - Abundância das espécies amostradas na chuva de sementes sob os indivíduos de Melia azedarach, ao longo de um ano 
O número de espécies coletadas também variou ao longo do ano (Figura 8, Anexos $B, C$ e $D$ ), porém sendo encontradas espécies em fase reprodutiva em todo o período. O maior número de espécies foi coletado entre os meses de setembro e janeiro, com pico em dezembro (27 espécies). Já no mês de maio, foi coletado o menor número de espécies (8). O aumento e o decréscimo do número de espécies coletadas coincidiu com o maior e menor número de propágulos coletados, respectivamente. As oscilações aqui observadas também foram notadas por Penhalber \& Mantovani (1997), em floresta secundária, e por Carmo \& Morellato (2001), em florestas ciliares.

Foram coletadas, em média, 10,6, 11,6 e 10,4 espécies.mês ${ }^{-1}$ sob $C$. tomentosum, C. myxa e $M$. azedarch, respectivamente, não havendo diferenças significativas entre as três espécies $(p>0,05)$.

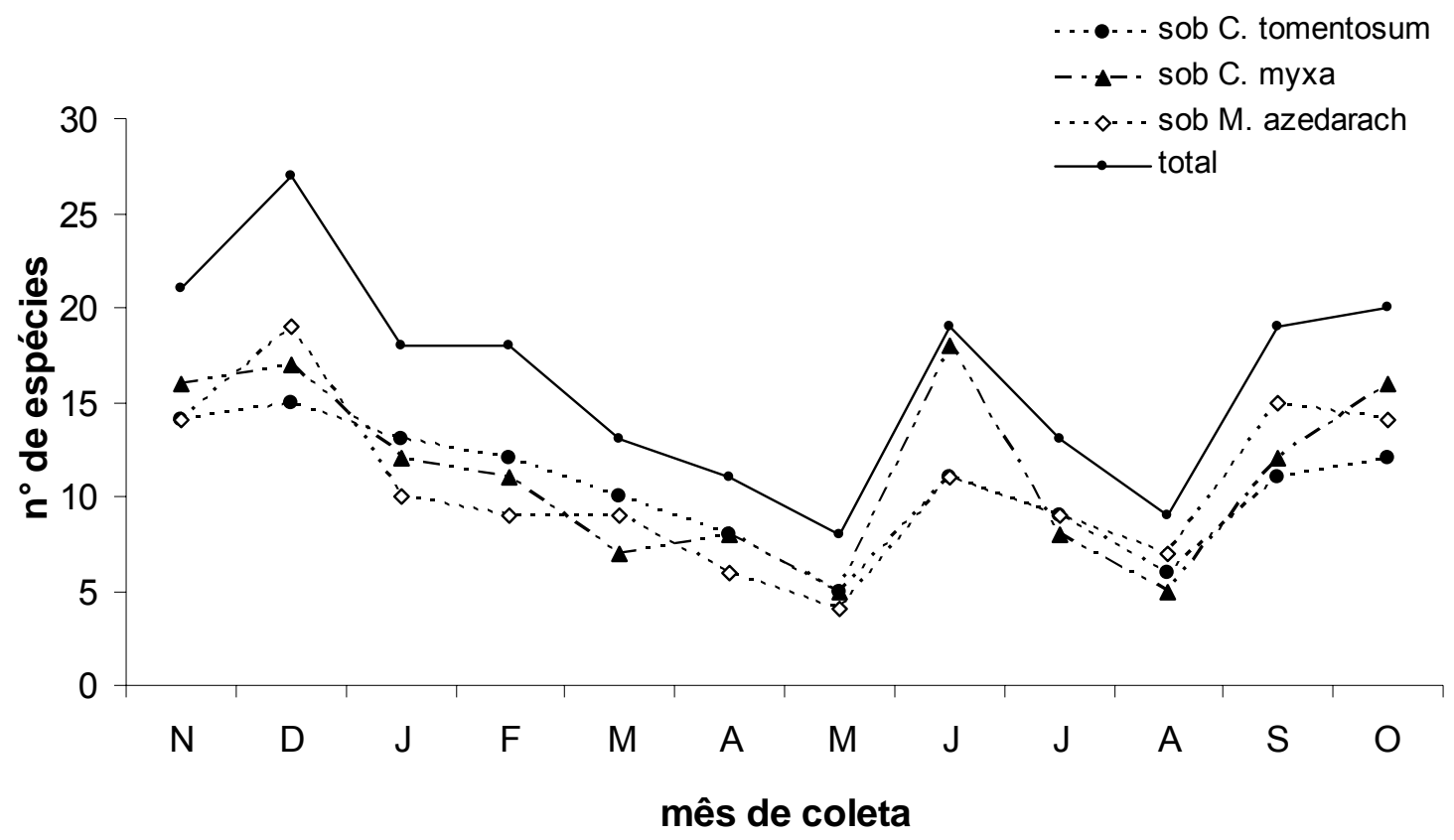

Figura 8 - Número de espécies coletadas na chuva de sementes sob cada uma das três espécies, ao longo do ano 
Algumas espécies foram amostradas todos os meses: Clausena excavata, Anadenanthera peregrina, Cordia myxa e Melia azedarach, podendo esta freqüência ser decorrente do padrão de frutificação e da abundância de indivíduos em estágio reprodutivo destas espécies na área de estudo. As duas últimas espécies, que foram acompanhadas ao longo do estudo, apresentavam frutos em alguns de seus indivíduos, mesmo em pequenas quantidades, juntamente aos seus períodos de floração. Siqueira (2002), estudando a chuva de sementes nesta mesma área, também amostrou propágulos de $C$. myxa e de $M$. azedarach durante todos os meses, juntamente com Leucaena leucocephala (Lam.) de Wit, encontrando-se esta entre as espécies mais abundantes, diferindo deste estudo, em que ocorreu em pequenas quantidades (duas sementes) e em apenas dois meses. Esta diferenciação se deve à localização de alguns dos coletores de sementes, que se encontravam na região de domínio de $L$. leucocephala nesta área.

Alguns dos resultados apresentados, como a similaridade das espécies amostradas na chuva de sementes sob as diferentes espécies, a variação anual na deposição de espécies e propágulos e a variação interespecífica da densidade são importantes para o planejamento do monitoramento da área.

A alta similaridade encontrada mostra que para a avaliação das espécies que chegam na mata, e não de suas respectivas abundâncias, via chuva de sementes, a localização dos coletores abaixo da copa de espécies arbóreas, no caso, abaixo destas três espécies, não interfere.

A variação anual na deposição de espécies cria picos. Nos meses de pico, podem-se fazer levantamentos florísticos da chuva, no caso do monitoramento ser breve, despendendo assim um menor esforço, porém, seria amostrado em torno de $50 \%$ das espécies amostradas ao longo de um ano, já que novas espécies aparecem a cada mês.

Já a variação anual na deposição de propágulos, que também apresenta picos ao longo do ano, ressalta a importância da coleta da chuva por longos 
períodos, sendo a coleta mensal muito pontual, no sentido de não permitir a extrapolação dos dados, em termos de densidade, para o restante do ano.

Por fim, a diferenciação da densidade de propágulos encontrada entre as três espécies indica que a coleta para o monitoramento deve ser feita em pontos aleatórios, não dirigida para a copa de determinada espécie, visto que cada espécie contribui diferentemente na deposição de propágulos, interferindo, conseqüentemente, na densidade. Uma outra alternativa para o monitoramento seria fazer a amostragem sob um grande número de espécies, diminuindo assim a interferência de uma dada espécie.

\subsection{Banco de sementes}

Em condições de pleno sol, foi amostrado um total de 14.469 plântulas (emergentes) nos bancos de sementes das três espécies, destes 12.573 (87\%) germinados no banco sob $M$. azedarach, 1.426 (9,8\%) sob o banco de $C$. myxa e $470(3,2 \%)$ sob o banco de C. tomentosum.

O pico da emergência dos indivíduos ocorreu na terceira semana de experimento (Figura 9), sendo a emergência das plântulas de $M$. azedarach responsável por este pico. Já o máximo de espécies germinadas (19 espécies) ocorreu mais tarde, na quinta semana (Figura 10). Apenas no banco de sementes sob C. tomentosum uma espécie (Leguminosae sp1) germinou após este pico. 


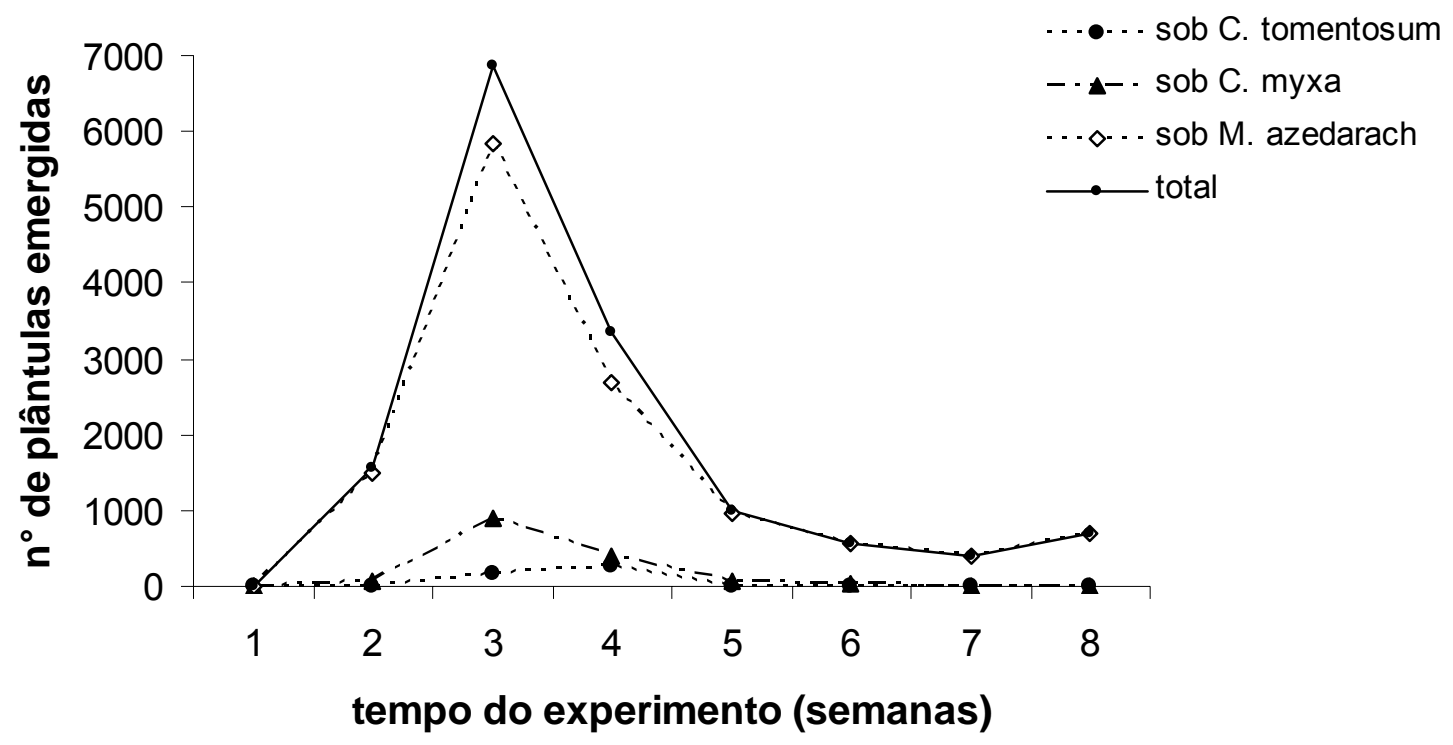

Figura 9 - Número de plântulas emergidas observadas no experimento de banco de sementes das três espécies, no período de oito semanas

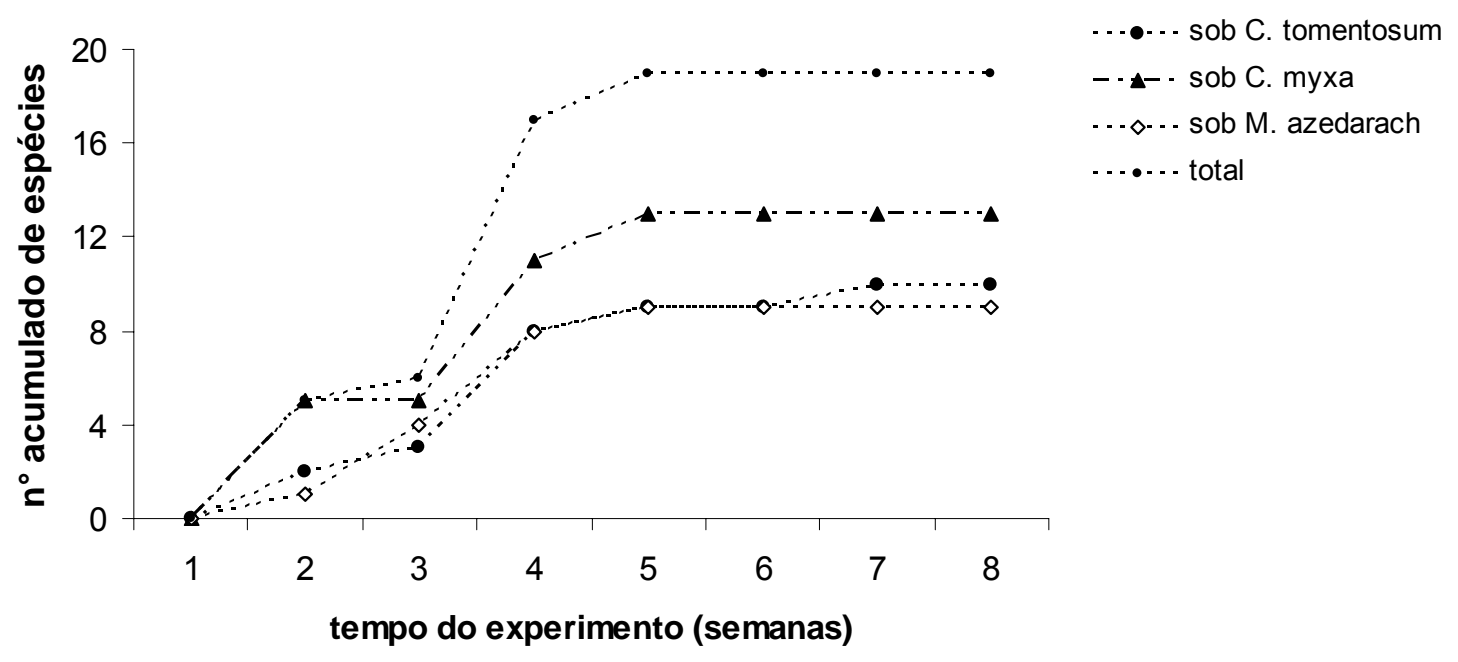

Figura 10 - Número acumulado de espécies observado no experimento de banco de sementes das três espécies, no período de oito semanas 
Houve diferença no número de plântulas emergentes em cada um dos bancos de sementes, existindo um maior número no banco sob $M$. azedarach e um menor sob $C$. tomentosum, o qual teve uma amostra sem qualquer indivíduo germinado (Figura 11).

No banco de sementes sob $M$. azedarach, os indivíduos germinados eram quase que totalmente desta própria espécie $(98,6 \%)$, sendo o restante distribuído entre indivíduos de C. myxa $(0,8 \%)$ e mais sete espécies. Igualmente à chuva de sementes sob esta espécie, há dominância da própria espécie no banco de sementes formado abaixo de suas copas. Isto justifica o maior número de plântulas emergidas sob esta espécie em relação às outras duas.

No banco de sementes sob C. myxa, a grande maioria dos indivíduos germinados era da própria C. myxa $(70,6 \%)$, sendo o restante distribuído entre indivíduos de $M$. azedarach (13,3\%), leguminosae sp1 $(10,2 \%)$ e mais 10 espécies.

Já no banco de sementes de $C$. tomentosum não houve emergentes da própria espécie e $M$. azedarach foi a espécie mais abundante $(64,5 \%)$, seguida de leguminosae sp1 (22,2\%), C. myxa (8,3\%) e mais sete espécies. Frutos de C. tomentosum estavam presentes nas amostras de solo, mas a não emergência desta espécie pode ser decorrente da inviabilidade de suas sementes, mas não das condições experimentais, já que C. tomentosum é capaz de germinar tanto na luz quanto na sombra, com iguais proporções (Penha, 2004).

Comparativamente a outros estudos de banco de sementes em áreas restauradas (Siqueira,2002; Sorreano, 2002), conduzidos a pleno sol, M. azedarach também esteve entre as espécies mais abundantes, assim como na chuva de sementes. 


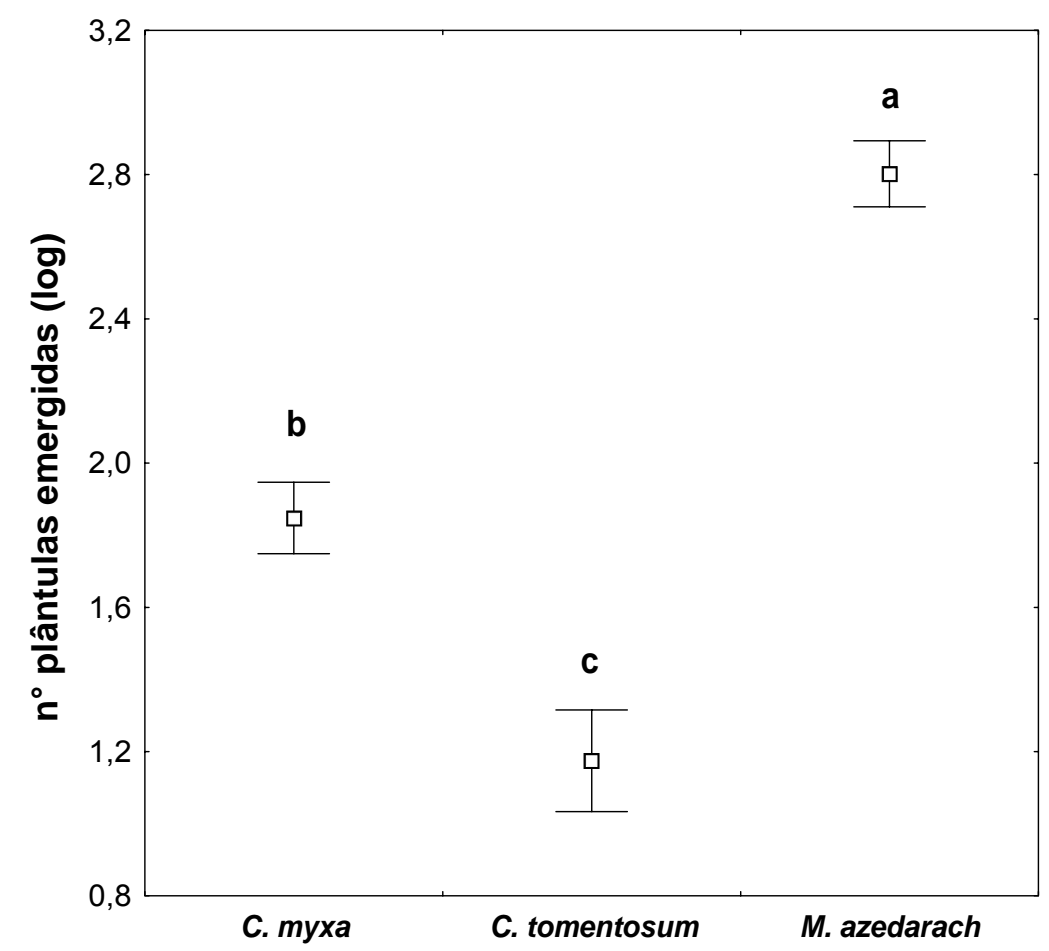

$\mp$ média + erro padrão
média - erro padrão
$\square \quad$ média

Figura 11 - Número médio de plântulas emergidas (log) amostrados no solo sob cada uma das três espécies. Letras diferentes indicam diferenças significativas entre tratamentos $(p<0,05)$ pelo teste Tukey

As densidades dos indivíduos nos três bancos de sementes, por conseqüência, diferiram entre si $(p<0,05)$, sendo de 125,3 ind. $\mathrm{m}^{-2}$ sob o banco de $C$. tomentosum, de 380,2 ind $\mathrm{m}^{-2}$ sob o banco de $C$. myxa e altíssima para o banco sob M. Azedarach, 3.352,8 ind. $\mathrm{m}^{-2}$. No estudo de Siqueira (2002), a densidade de sementes arbustivo-arbóreas encontrada foi de 151,47 ind. $\mathrm{m}^{-2}$, para a coleta na estação seca (agosto). Isso mostra que C. myxa e $M$. azedarach exercem grande influência no banco de sementes encontrado sob seus indivíduos.

O predomínio de indivíduos de C. myxa e M. azedarach no banco pode ser conseqüência do aporte contínuo de sementes destas espécies no solo, via 
chuva de sementes, além de outros fatores que fazem com que estas espécies mantenham-se viáveis no banco.

Hong \& Ellis (1998), estudando o comportamento de estocagem de $M$. azedarach, observaram que as sementes desta espécie sobreviviam à dessecação, com apenas 3,5\% de umidade, mantendo-se viáveis por 26 meses. Estes autores concluíram que $M$. azedarach apresenta sementes ortodoxas.

Além dos fatores apresentados acima, frutos de $M$. azedarach apresentam componentes que têm efeito fungicida em diferentes fungos patogênicos (Carpinella et al., 1999), o que deve contribuir para uma baixa predação de suas sementes e, conseqüentemente, para a alta densidade de frutos desta espécie no banco.

Estas duas espécies exóticas - C. myxa e M. azedarach - apresentam, portanto, grande potencial regenerativo em áreas abertas, como observado nas condições experimentais; em situações de distúrbio, estas podem se constituir em espécies colonizadoras, tendendo a permanecer na área restaurada, o que não seria um benefício para a restauração a longo prazo.

Os dados de abundância e densidade de cada espécie amostrada nos três bancos estão apresentados no Anexo $\mathrm{E}$.

O número médio de espécies amostradas em cada um dos três bancos de sementes também diferiu estatisticamente (Figura 12) e uma variação intraespecífica, ou seja, entre as amostras de solo de uma mesma espécie, também foi observada. Amostras de solo com apenas uma espécie germinada foram observadas nos três bancos, sendo a própria $C$. myxa e $M$. azedarach, em seus respectivos bancos, e leguminosae sp1 no banco sob $C$. tomentosum. 


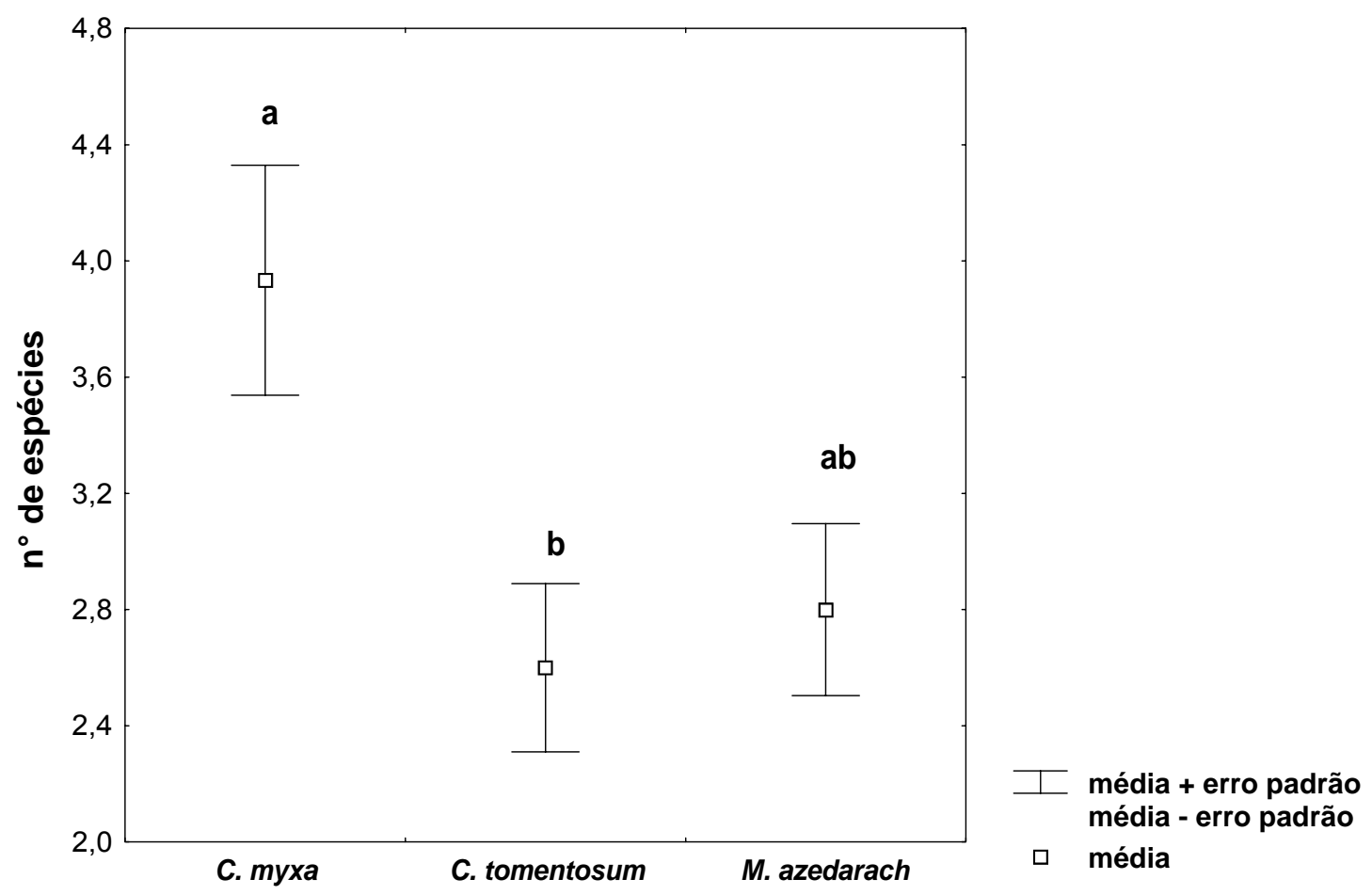

Figura 12 - Número médio de espécies de plântulas amostradas no solo sob cada uma das três espécies. Letras diferentes indicam diferenças significativas entre tratamentos $(p<0,05)$ pelo teste Tukey

Comparativamente com a chuva de sementes (seção 3.1), o número de espécies amostradas no banco de sementes foi cerca de três vezes menor, sugerindo que muitas espécies ao chegar no solo da mata são predadas, carreadas pelo vento ou pela água, ou mesmo encontram ali condições favoráveis para germinar e ficam por um tempo curto no solo. Contudo, deve ser ressaltado que o banco poderia compor mais espécies do que aquelas amostradas, porém, não foram observadas devido às condições experimentais que não favoreceram a germinação de suas sementes. Segundo GromboneGuarantini \& Rodrigues (2002), o método de emergência subestima a composição do banco de sementes.

A similaridade (índice de S $\phi$ rensen) dos bancos foi de 52 e $54,5 \%$ entre as espécies de C. myxa e C. tomentosum e C. myxa e M. azedarach, 
respectivamente, porém, um pouco maior entre as espécies germinadas nos bancos de $C$. tomentosum e $M$. azedarach $(63,2 \%)$.

Apesar da similaridade dos bancos, os resultados demonstram que sob as diferentes espécies formam-se bancos distintos, ou seja, sob C. myxa existe uma maior riqueza de espécies e sob $M$. azedarach, um maior número de indivíduos. Porém, quase a totalidade destes indivíduos é da própria $M$. azedarach.

A diferenciação dos micro sítios abaixo de cada espécie confirma a variação espacial do banco de sementes numa floresta. A heterogeneidade do banco constitui em um mecanismo de grande importância na dinâmica de regeneração de uma floresta (Whitmore, 1983) e na manutenção da diversidade.

A formação destes micro sítios está relacionada, com exceção de $C$. tomentosum, à árvore do dossel, a qual deposita a maior parte de seus propágulos sob sua copa. De acordo com Janzen (1970), a maior parte das espécies tem este comportamento de deposição de propágulos.

Alguns dos resultados apresentados, como a variação no número de espécies e plântulas germinadas e os picos de emergência são importantes para o planejamento do monitoramento da área.

A variação na riqueza de espécies encontradas nos diferentes bancos ressalta a importância de coletas de solo em pontos aleatórios, não localizados predominantemente ou somente sob determinada espécie.

A densidade de plântulas também foi variável entre as espécies estudadas, ressaltando, novamente, a importância de coletas aleatórias no solo da floresta, uma vez que as espécies influenciam na densidade do banco sob seus indivíduos.

Como sugerido para a coleta da chuva de sementes, os pontos de coleta podem se localizar sob um grande número de espécies, diminuindo, desta maneira, a influência de determinadas espécies. 
Como observado neste estudo e por Siqueira (2002), com experimentação a pleno sol, o pico de emergência do banco se deu no primeiro mês do experimento, para as diferentes espécies, indicando que este é o tempo necessário para experimentos similares (a pleno sol), que tenham como objetivo avaliar a densidade do banco.

Por fim, a avaliação da composição florística do banco só foi possível após sete semanas de experimento. Portanto, considerando o monitoramento em uma área já restaurada, o presente estudo sugere que para se avaliar a riqueza o experimento demandaria um tempo maior do que para se avaliar a densidade.

\subsection{Regeneração natural}

Um total de 4.337 indivíduos regenerantes arbustivo-arbóreos, entre $30 \mathrm{~cm}$ e $2 \mathrm{~m}$ de altura, foi amostrado nas 45 áreas amostrais $\left(765 \mathrm{~m}^{2}\right)$ - raios de projeção das copas - sob as três espécies $\left(255 \mathrm{~m}^{2}\right.$.espécie ${ }^{-1}$ e $17 \mathrm{~m}^{2}$.indivíduo$\left.{ }^{1}\right)$. Destes, 1.625 indivíduos foram amostrados sob C. myxa, 1.358 sob $C$. tomentosum e 1.354 sob $M$. azedarach. As espécies amostradas seguidas de seus parâmetros fitossociológicos estão apresentadas nos Anexos $F, G$ e H.

O número médio de indivíduos regenerantes não diferiu entre as espécies $(p>0,05)$, assim como a densidade média (Tabela 4$)$.

Tabela 4. Número médio e densidade média dos indivíduos regenerantes sob as três espécies. Letras iguais indicam que não há diferença significativa entre os tratamentos $(p>0,05)$ pelo teste Tukey

\begin{tabular}{lccc}
\hline & $\begin{array}{c}\text { Número médio de } \\
\text { indivíduos } \\
\text { (mín.-máx.) }\end{array}$ & $\begin{array}{c}\text { Densidade média } \\
\text { (indivíduos.m }\end{array}$ & $\begin{array}{c}\text { Densidade média } \\
\text { (indivíduos.ha) }\end{array}$ \\
\hline Sob C. myxa & $108,33(50-268) \mathbf{a}$ & $6,37 \mathbf{a}$ & $63.700 \mathbf{a}$ \\
Sob C. tomentosum & $90,53(37-184) \mathbf{a}$ & $5,32 \mathbf{a}$ & $53.200 \mathbf{a}$ \\
Sob M. azedarach & $90,26(51-166) \mathbf{a}$ & $5,32 \mathbf{a}$ & $53.200 \mathbf{a}$ \\
\hline
\end{tabular}


Comparando-se os valores de densidade apresentados na Tabela 4 com aqueles obtidos em outros estudos de regeneração, tanto em floresta natural (Passos, 1998) quanto em áreas de reflorestamento misto (Parrota et al., 1997; Souza \& Batista, 2004), observa-se que estes estão bem próximos aos da área natural, sendo superiores aos de outras áreas reflorestadas.

Em um remanescente de floresta ciliar em Mogi-Guaçu (SP), Passos (1998) obteve valores entre 38.500 e 64.500 ind.ha $^{-1}$, já Parrota et al. (1997) obteve um valor de 28.800 ind.ha $^{-1}$, estudando uma área de reflorestamento misto de 10 anos no Pará, e Souza \& Batista (2004) obtiveram valores ainda menores, 3.448 e 6.499 ind.ha $^{-1}$, estudando áreas de reflorestamento misto no Pontal do Paranapanema (SP) de 10 e 11 anos, respectivamente.

Com relação aos indivíduos regenerantes, houve diferença significativa apenas entre as alturas médias. A regeneração observada sob C. myxa foi, em média, mais alta do que à observada sob as outras duas espécies (Figura 13).

Esta diferença deve-se à grande abundância de indivíduos regenerantes de C. myxa encontrada sob suas copas, uma vez que esta espécie apresenta elevada altura média, e de outras espécies, como C. tomentosum e Triplaris americana, que se apresentaram maiores sob ela do que sob a copa das outras duas espécies estudadas. 


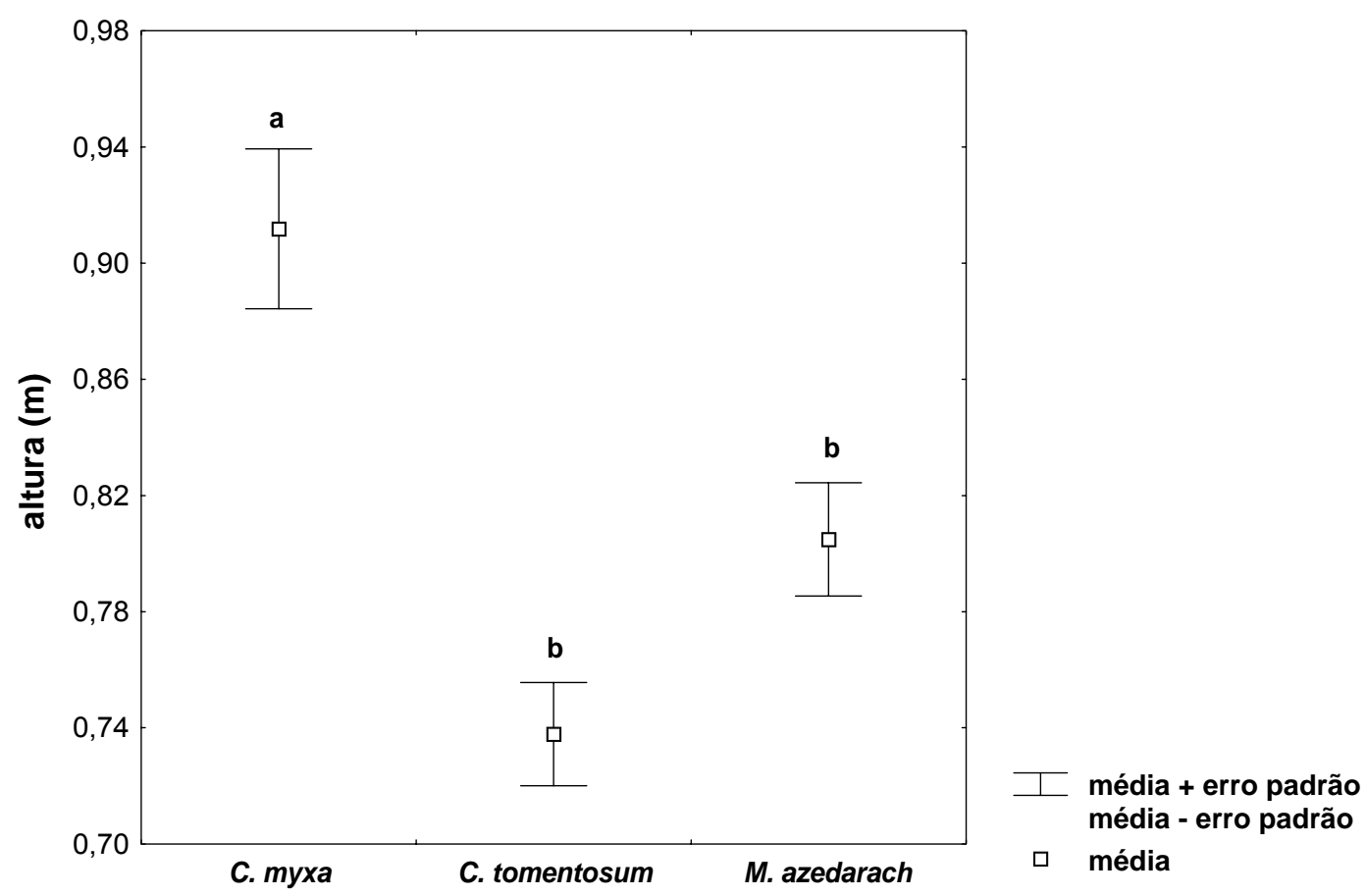

Figura 13 - Altura média dos indivíduos regenerantes sob cada uma das três espécies. Letras diferentes indicam diferenças significativas entre tratamentos $(p<0,05)$ pelo teste Tukey

Quanto às espécies regenerantes, foram amostradas 62, no total, pertencentes a 21 famílias (identificadas). As famílias que apresentaram maior riqueza foram Myrtaceae, com sete espécies $(11,3 \%$ do total), e Caesalpinaceae, com cinco espécies (8\%).

Sob os indivíduos de C. myxa foram amostradas 40 espécies, distribuídas em 20 famílias. As famílias com maior riqueza foram Myrtaceae, com cinco espécies, e Meliaceae, com três espécies. As espécies mais abundantes e freqüentes foram C. myxa $(40,9 \%)$ e Clausena excavata $(38,5 \%)$.

Sob os indivíduos de C. tomentosum foram amostradas 31 espécies, distribuídas em 15 famílias. As famílias com maior riqueza foram Myrtaceae, com quatro espécies, Fabaceae e Rutaceae, com três espécies cada. As espécies mais abundantes e freqüentes foram C. tomentosum $(62,9 \%)$ e Clausena excavata $(19,1 \%)$. 
E, sob os indivíduos de $M$. azedarach foram amostradas 46 espécies, distribuídas em 18 famílias. As famílias com maior riqueza foram Caesalpinaceae e Myrtaceae, com cinco espécies cada, e Rutaceae, com quatro espécies. As espécies mais abundantes foram Clausena excavata $(51,8 \%)$ e $C$. tomentosum $(9,8 \%)$, sendo $C$. excavata e $N$. magapotamica as duas espécies mais freqüentes.

A similaridade (índice de Sprensen) foi de $62 \%$ entre as espécies regenerantes sob $C$. tomentosum e $C$. myxa, de $62,5 \%$ entre as espécies regenerantes sob $C$. tomentosum e $M$. azedarach e de $67,5 \%$ entre as espécies regenerantes sob $M$. azedarach e C. myxa.

Os valores de equabilidade $(J)$ e diversidade $\left(H^{\prime}\right)$ foram maiores sob $M$. azedarach do que sob as duas outras espécies, indicando um menor predomínio das espécies sob ela, tendo somente C. excavata como dominante. Porém, de modo geral, foram obtidos baixos valores, decorrente da grande influência de $C$. tomentosum, $C$. excavata e $C$. myxa na estrutura da comunidade de regenerantes (Tabela 5). A maior diversidade sob $M$. azedarach pode ser notada também pela maior número de espécies regenerantes sob ela em relação às outras duas espécies $(p<0,05)$.

Tabela 5. Índices de diversidade de Shannon ( $\left.H^{\prime}\right)$ e de equabilidade $(J)$ de espécies amostradas na regeneração natural sob as três espécies estudadas

\begin{tabular}{lcc}
\hline & H'$^{\prime}$ & J \\
\hline Sob C. myxa & 1,58 & 0,43 \\
Sob C. tomentosum & 1,36 & 0,40 \\
Sob M. azedarach & 2,02 & 0,53 \\
\hline
\end{tabular}

Comparativamente a outro estudo de regeneração natural em áreas restauradas, Nappo (1999) obteve valores maiores de diversidade, de 2,85 e 
2,65, devido a maior equabilidade das espécies regenerantes nestas áreas ( $\mathrm{J}=0,68$ e $\mathrm{J}=0,75$, respectivamente).

Algumas espécies foram exclusivas da regeneração sob determinada espécie. Proporcionalmente, sob $M$. azedarach foram amostradas mais espécies exclusivas (13 espécies ou 28,3\%) do que sob C. myxa (nove espécies ou 22,5\%) e sob C. tomentosum (cinco espécies ou 16\%). Todas estas espécies exclusivas apresentaram-se com baixa abundância (todas com abundância relativa menor que 0,4\%) e freqüência (no máximo sob três dos 15 indivíduos), não sugerindo uma relação específica com a espécie do dossel estudada.

O aumento da porcentagem de espécies exclusivas da regeneração em relação às exclusivas da chuva de sementes (seção 3.1), faz com que a similaridade dos regenerantes seja menor do que a similaridade da chuva. Ao comparar estas espécies, não se observou coincidência de exclusividade entre as espécies da chuva e da regeneração. Todavia, a chuva de sementes representa, ainda que eficientemente amostrada, uma deposição anual, enquanto que o censo das plântulas realizado sob cada indivíduo resulta, provavelmente, da deposição, germinação e recrutamento ao longo de 14 anos, em média.

A Figura 14 apresenta a distribuição das espécies regenerantes que apresentaram maior abundância, mostrando que algumas espécies foram abundantes somente sob determinada espécie. 


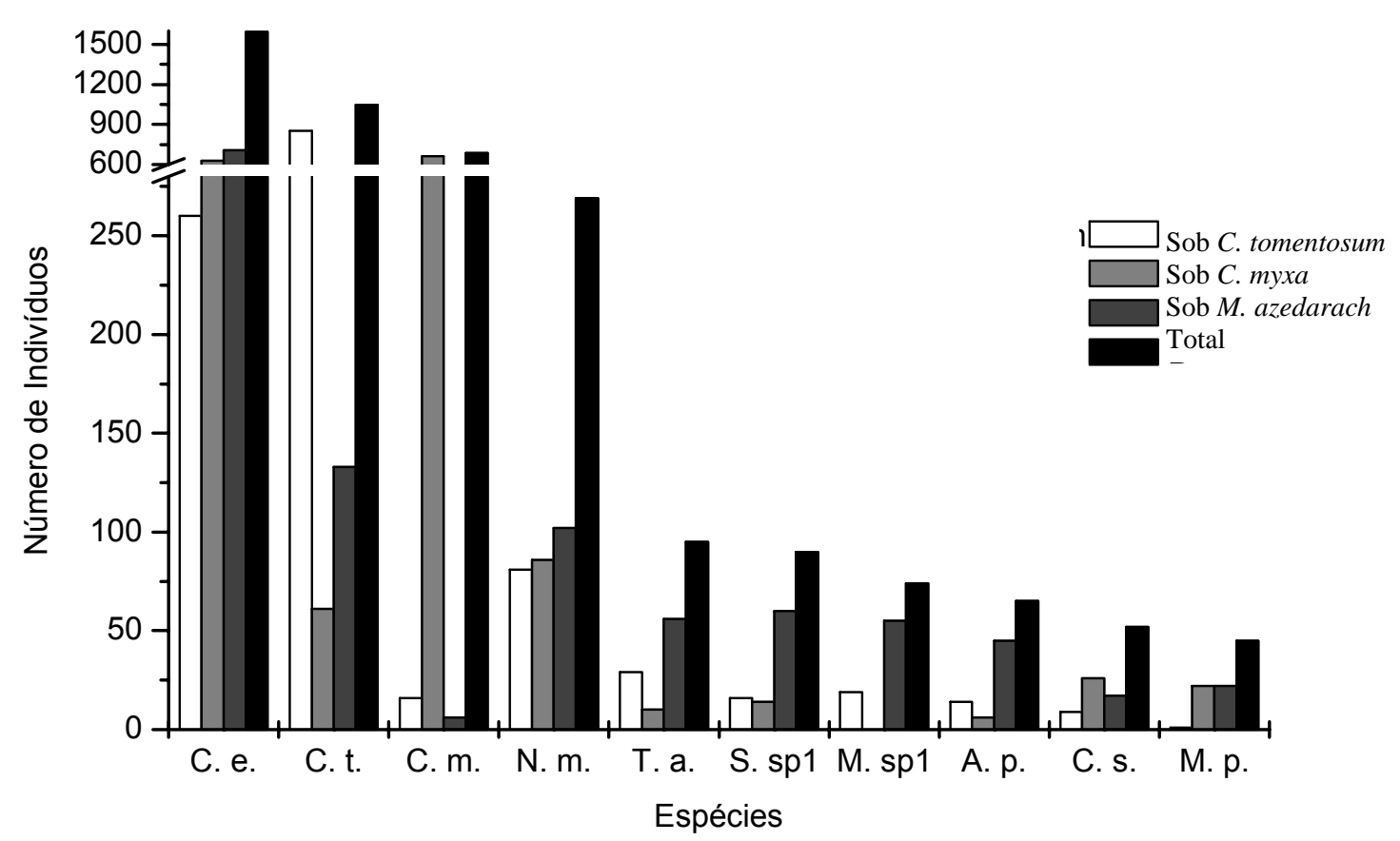

Figura 14 - Espécies mais abundantes amostradas na regeneração natural sob as três espécies, ao longo do ano. As espécies estão com o nome abreviado, veja tabela 6

Dentre as espécies mais abundantes, Clausena excavata, a mais abundante neste estudo e no de Siqueira (2002), foi a única espécie amostrada sob todos os indivíduos das três espécies, mostrando que além de abundante, distribuí-se por toda a área estudada. Depois de $C$. excavata, a espécies que apresentou maior freqüência foi Nectandra megapotamica, sendo a terceira mais abundante sob todas as espécies.

Ainda com relação às espécies mais abundantes, C. myxa e Murraya paniculata (L.) Jack. foram as únicas que apresentaram altura média superior a $1 \mathrm{~m}$ sob as três espécies, apresentando um número igual ou superior de indivíduos maiores que $1 \mathrm{~m}$ em relação aos menores. As demais espécies regenerantes apresentaram-se com altura média superior a $1 \mathrm{~m}$ somente sob 
determinada espécie e, ainda assim, sem predominância dos indivíduos maiores que $1 \mathrm{~m}$ (Tabela 6).

Espécies como C. myxa, C. tomentosum, C. excavata, N. megapotamica e Triplaris americana - sob as copas das três espécies estudadas - e outras, como Eugenia jambosa - sob C. tomentosum, sp12 e A. peregrina - sob C. tomentosum e M. azedarach, Solanaceae sp1 - sob $M$. azedarach, e $M$. paniculata - sob C. myxa e M. azedarach, apresentaram-se abundantes e/ou com elevados valores de altura média, mostrando que sob a copa destas espécies formam-se ambientes propícios para o seu desenvolvimento e sobrevivência, podendo indicar o potencial de ocupação destas espécies no tempo (Nappo, 1999).

De acordo com Hubbell et al. (1999), que estudaram a dinâmica da comunidade vegetal em clareiras, a composição de espécies é estabelecida muito cedo, na fase de regeneração, sendo que a clareira não interfere na manutenção da riqueza, concluindo, portanto, que as espécies que estão em regeneração na floresta tem altíssimo potencial de ocupação. Em vista disso, é ressaltado o potencial das espécies acima citadas ( $A$. peregrina, $C$. tomentosum, C. excavata, C. myxa, E. jambosa, M. paniculata, N. megapotamica, T. americana, Solanaceae sp1 e sp12).

Deste modo, observamos que a maioria das espécies com potencial de regeneração pertencem aos estágios iniciais da sucessão secundária, sendo que três delas são espécies exóticas. Tanto $M$. paniculata quanto $C$. excavata são exóticas e não fazem parte das espécies implantadas na área. Esta última parece ter um potencial de ocupação muito grande em toda a área de estudo, uma vez que foram observados, visualmente, indivíduos regenerantes de várias alturas. Além disso, esta espécie frutifica muito jovem, com 1,5 $\mathrm{m}$, em média (observação pessoal), e tem taxas elevadas de crescimento (Lorenzi et al., 2003).

De modo geral, houve diminuição do número de indivíduos e de espécies regenerantes com o aumento da altura, ou seja, no decorrer do processo 
sucessional. É possível que inicialmente muitas espécies e indivíduos se estabeleçam, mas que com o tempo, há um decréscimo, conseqüente da competição intra e interespecífica, da predação de plântulas ou ainda do mau desenvolvimento de algumas espécies. De acordo com Mogie et al. (1990), o estágio de plântula constitui um dos períodos de maior mortalidade, sendo comum para a maioria das populações.

Com relação à competição entre as plântulas, é provável que, sob $M$. azedarach, C. excavata está mais sujeita à competição intra e interespecífica, com as demais espécies que compõe a regeneração sob esta espécie. Já sob C. tomentosum, os próprios indivíduos regenerantes desta espécie estão sujeitos à competição intra e interespecífica. Mas, sob C. myxa, duas espécies estão mais sujeitas à competição, a própria C. myxa e C. excavata, por comporem quase $80 \%$ dos indivíduos regenerantes.

Contudo, o maior número de indivíduos acima de $1 \mathrm{~m}$ sob C. myxa pode indicar uma maior sobrevivência ou desenvolvimento das plântulas sob esta espécie (Figuras 15 e 16).

Cusack \& Montagnini (2004), estudando a regeneração sob plantios homogêneos de diferentes espécies, também observaram uma diferenciação da altura dos regenerantes sob as espécies, sugerindo uma maior sobrevivência das plântulas sob o dossel de algumas espécies. 


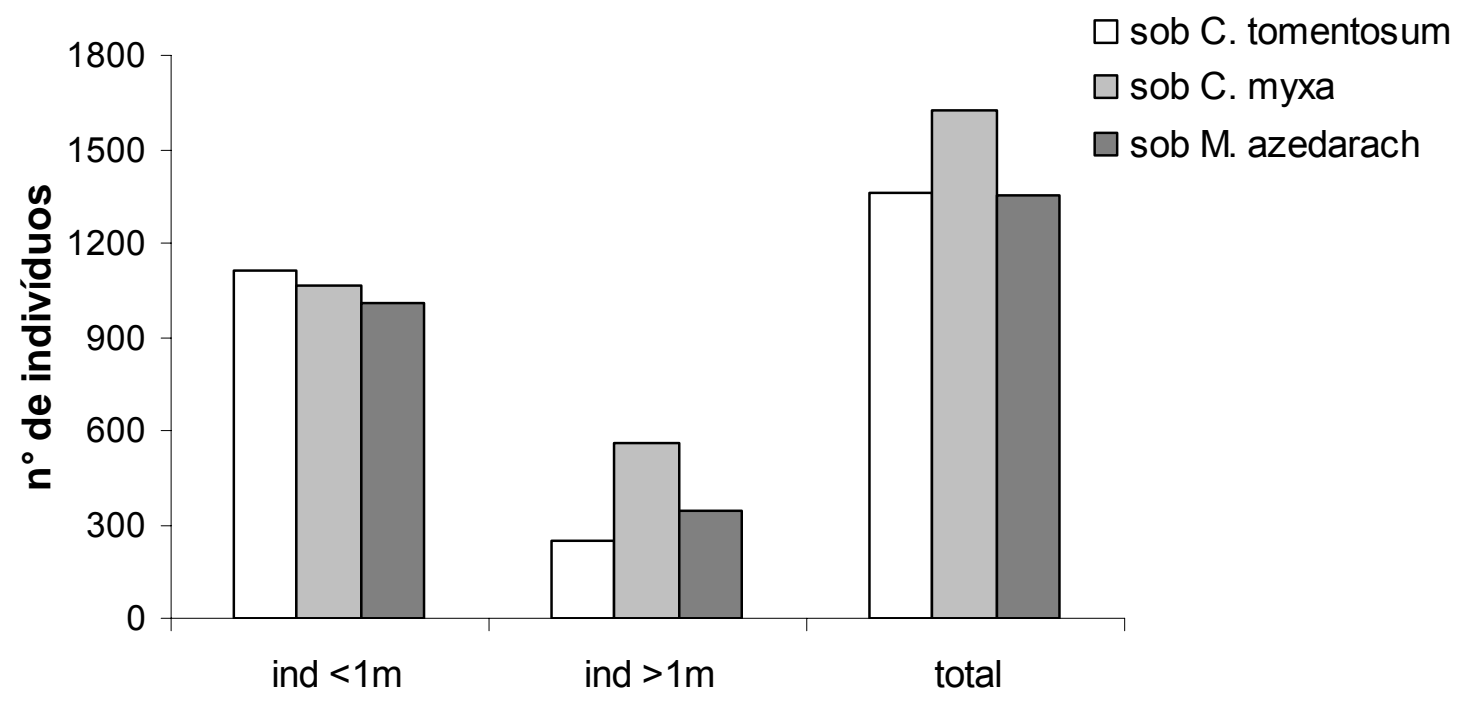

Figura 15 - Distribuição dos indivíduos regenerantes sob cada espécie de acordo com a classe de altura, menor e maior que $1 \mathrm{~m}$, e total

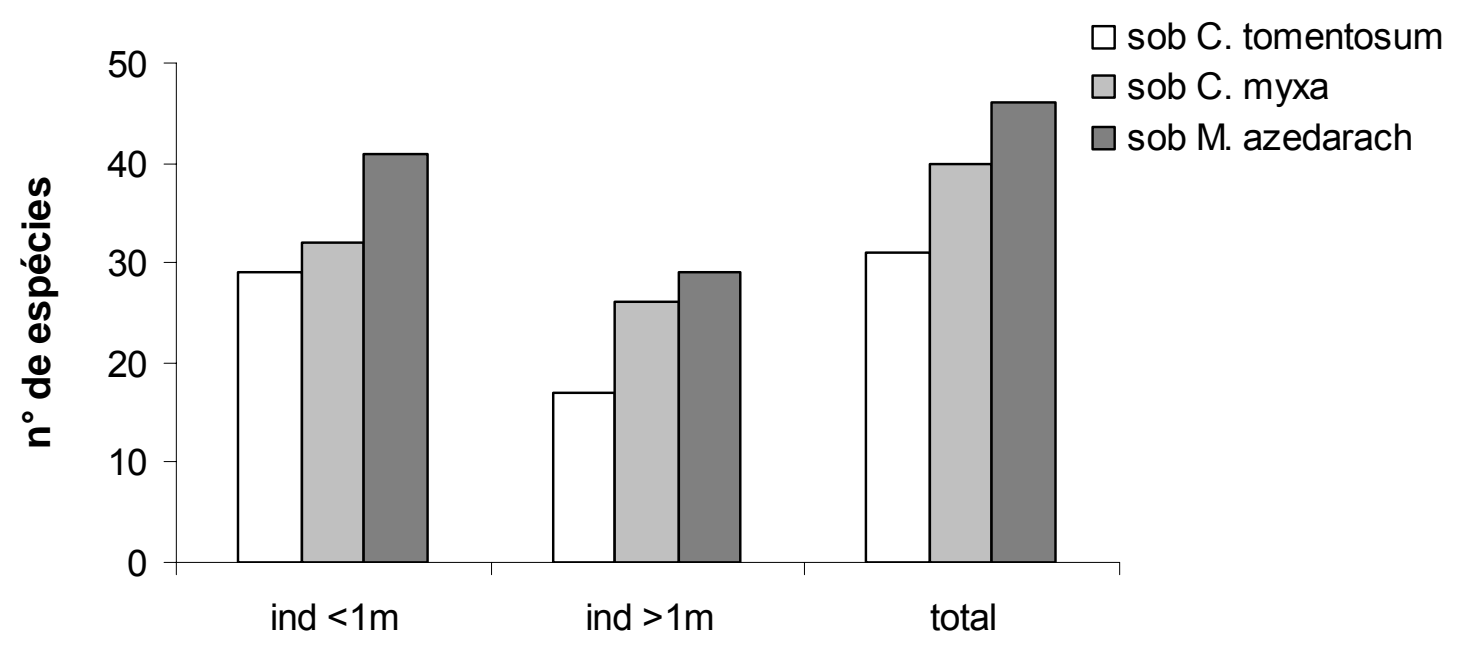

Figura 16 - Distribuição das espécies regenerantes sob cada espécie de acordo com a classe de altura, menor e maior que $1 \mathrm{~m}$, e total 
Tabela 6. Distribuição das 10 espécies mais abundantes da regeneração natural nas diferentes condições, em relação ao número de indivíduos menores e maiores que 1 metro, razão dos indivíduos, abundância total e relativa (\%), freqüência relativa - Fr (\%) - e altura média (m)

\begin{tabular}{|c|c|c|c|c|c|c|c|c|}
\hline Espécie & Condição & $\begin{array}{l}n^{\circ} \text { reg. } \\
<1 \text { m (1) }\end{array}$ & $\begin{array}{l}n^{\circ} \text { reg. } \\
>1 \mathrm{~m}(2)\end{array}$ & (2) / (1) & Abund. & $\begin{array}{c}\text { Abund. } \\
\text { Relativa (\%) }\end{array}$ & $\operatorname{Fr}(\%)$ & $\begin{array}{l}\text { Altura média } \\
(\mathrm{m})\end{array}$ \\
\hline \multirow{4}{*}{ C. excavata } & sob C. tomentosum & 192 & 68 & 0.35 & 260 & 19.2 & 100.0 & 0.83 \\
\hline & sob C. myxa & 514 & 112 & 0.22 & 626 & 38.5 & 100.0 & 0.75 \\
\hline & sob $M$. azedarach & 515 & 191 & 0.37 & 706 & 51.8 & 100.0 & 0.87 \\
\hline & total & 1221 & 371 & & 1592 & & & \\
\hline \multirow{4}{*}{ C. tomentosum } & sob C. tomentosum & 729 & 125 & 0.17 & 854 & 62.9 & 100.0 & 0.68 \\
\hline & sob C. myxa & 40 & 21 & 0.53 & 61 & 3.8 & 46.7 & 1.02 \\
\hline & sob M. azedarach & 101 & 32 & 0.32 & 133 & 9.8 & 46.7 & 0.71 \\
\hline & total & 870 & 178 & & 1048 & & & \\
\hline \multirow{4}{*}{ C. myxa } & sob C. tomentosum & 8 & 8 & 1.00 & 16 & 1.2 & 40.0 & 1.12 \\
\hline & sob C. myxa & 327 & 337 & 1.03 & 664 & 40.9 & 100.0 & 1.10 \\
\hline & sob $M$. azedarach & 3 & 3 & 1.00 & 6 & 0.4 & 20.0 & 1.03 \\
\hline & total & 338 & 348 & & 686 & & & \\
\hline \multirow{4}{*}{ N. megapotamica } & sob C. tomentosum & 62 & 19 & 0.31 & 81 & 6.0 & 93.3 & 0.84 \\
\hline & sob C. myxa & 54 & 32 & 0.59 & 86 & 5.3 & 93.3 & 0.89 \\
\hline & sob $M$. azedarach & 80 & 22 & 0.28 & 102 & 7.5 & 100.0 & 0.80 \\
\hline & total & 196 & 73 & & 269 & & & \\
\hline \multirow{4}{*}{ T. americana } & sob C. tomentosum & 27 & 2 & 0.07 & 29 & 2.1 & 26.7 & 0.57 \\
\hline & sob C. myxa & 8 & 2 & 0.25 & 10 & 0.6 & 20.0 & 0.87 \\
\hline & sob M. azedarach & 54 & 2 & 0.04 & 56 & 4.1 & 20.0 & 0.57 \\
\hline & total & 89 & 6 & & 95 & & & \\
\hline
\end{tabular}


Tabela 6. Distribuição das 10 espécies mais abundantes da regeneração natural nas diferentes condições, em relação ao número de indivíduos menores e maiores que 1 metro, razão dos indivíduos, abundância total e relativa (\%), freqüência relativa - Fr (\%) - e altura média (m)

\begin{tabular}{|c|c|c|c|c|c|c|c|c|}
\hline Espécie & Condição & $\begin{array}{l}n^{\circ} \text { reg. } \\
<1 \text { m (1) }\end{array}$ & $\begin{array}{l}n^{\circ} \text { reg. } \\
>1 \mathrm{~m}(2)\end{array}$ & (2) / (1) & Abund. & $\begin{array}{c}\text { Abund. } \\
\text { Relativa (\%) }\end{array}$ & Fr (\%) & $\begin{array}{c}\text { Altura média } \\
(\mathrm{m})\end{array}$ \\
\hline \multirow{4}{*}{ Solanaceae sp1 } & sob C. tomentosum & 11 & 5 & 0.45 & 16 & 1.2 & 40.0 & 0.87 \\
\hline & sob C. myxa & 10 & 4 & 0.40 & 14 & 0.9 & 53.3 & 0.79 \\
\hline & sob M. azedarach & 42 & 18 & 0.43 & 60 & 4.4 & 86.6 & 1.03 \\
\hline & total & 63 & 27 & & 90 & & & \\
\hline \multirow{4}{*}{ Myrtaceae sp1 } & sob C. tomentosum & 19 & 0 & 0.00 & 19 & 1.4 & 53.3 & 0.55 \\
\hline & sob C. myха & 0 & 0 & - & 0 & 0.0 & 0.0 & - \\
\hline & sob M. azedarach & 49 & 6 & 0.12 & 55 & 4.0 & 53.3 & 0.63 \\
\hline & total & 68 & 6 & & 74 & & & \\
\hline \multirow{4}{*}{ A. peregrina } & sob C. tomentosum & 10 & 4 & 0.40 & 14 & 1.0 & 33.3 & 0.88 \\
\hline & sob C. myxa & 6 & 0 & 0.00 & 6 & 0.4 & 20.0 & 0.68 \\
\hline & sob M. azedarach & 31 & 14 & 0.45 & 45 & 3.3 & 53.3 & 0.95 \\
\hline & total & 47 & 18 & & 65 & & & \\
\hline \multirow{4}{*}{ C. especiosa } & sob C. tomentosum & 8 & 1 & 0.13 & 9 & 0.7 & 20.0 & 0.71 \\
\hline & sob C. myxa & 23 & 3 & 0.13 & 26 & 1.6 & 33.3 & 0.67 \\
\hline & sob M. azedarach & 13 & 4 & 0.31 & 17 & 1.3 & 20.0 & 0.85 \\
\hline & total & 44 & 8 & & 52 & & & \\
\hline \multirow{4}{*}{ M. paniculata } & sob C. tomentosum & 0 & 1 & - & 1 & 0.1 & 6.7 & 1.10 \\
\hline & sob C. myxa & 8 & 14 & 1.75 & 22 & 1.4 & 60.0 & 1.18 \\
\hline & sob M. azedarach & 8 & 14 & 1.75 & 22 & 1.6 & 73.3 & 1.20 \\
\hline & total & 16 & 29 & & 45 & & & \\
\hline
\end{tabular}


Com relação à síndrome de dispersão das espécies, a maior parte das espécies regenerantes - $66 \%$ em média sob cada espécie - é zoocórica, seguida das anemocóricas, que correspondem a 25,3\%, em média, e das autocóricas, que correspondem a $8,7 \%$, em média (Tabela 7). Proporções semelhantes a estas foram observadas em florestas semideciduais paulistas (Morellato, 1991; Morellato \& Leitão-Filho, 1992), sendo a maior representatividade das espécies zoocóricas uma confirmação para florestas tropicais (Howe \& Smallwood, 1982).

Tabela 7. Relação das espécies amostradas na regeneração natural sob $C$. tomentosum (C.t.), C. myxa (C.m.) M. azedarach (M.a.), seguidas do grupo sucessional (G. s.) e síndrome de dispersão (S. d.) a que pertencem

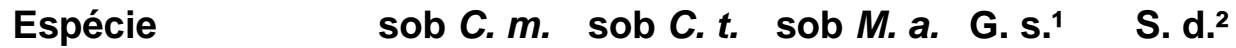

\section{ANACARDIACEAE}

Astronium graveolens Jacq.

Schinus terebinthifolius Raddi

Tapirira guianensis Aubl.

BIGNONIACEAE

Tabebuia chrysotricha (Mart. ex

D.C.) Sandl.

Tabebuia sp

Tecoma stans (L.) Juss. ex H.B.K.

BOMBACACEAE

Bombacaceae sp2

Chorisia speciosa A. St. Hil.

BORAGINACEAE

Cordia ecalyculata Vell.

Cordia myxa L.

BURSERACEAE

Protium sp $\mathrm{x}$

$\mathrm{X}$

$\mathrm{x}$

$x$

$\mathrm{x}$

$\mathrm{X}$

\section{$x$}

$\mathrm{X}$

$\begin{array}{lll}x & P & z 00 \\ x & P & z 00 \\ x & & z 00\end{array}$

zoo

zoo 
Tabela 7. Relação das espécies amostradas na regeneração natural sob $C$. tomentosum (C.t.), C. myxa (C.m.) M. azedarach (M.a.), seguidas do grupo sucessional (G. s.) e síndrome de dispersão (S. d.) a que pertencem

\begin{tabular}{|c|c|c|c|c|c|}
\hline Espécie & sob C. $m$. & sob C. $t$. & sob M. a. & G. s. $^{1}$ & S. d. ${ }^{2}$ \\
\hline \multicolumn{6}{|l|}{ CAESALPINACEAE } \\
\hline Cassia ferruginea Schrad. ex D.C. & $x$ & $x$ & $x$ & $\mathrm{Si}$ & \\
\hline Copaifera langsdorffii Desf. & & & $x$ & St & zoo \\
\hline $\begin{array}{l}\text { Hymenaea courbaril L. } \\
\text { Peltophorum dubium (Spreng.) }\end{array}$ & & & $x$ & $\mathrm{C}$ & zoo \\
\hline $\begin{array}{l}\text { Taub. } \\
\text { Senna macranthera (Collad) Irwin }\end{array}$ & & & $\mathrm{x}$ & Si & \\
\hline $\begin{array}{l}\text { Senna macranthera (Collad.) Irwin } \\
\text { et Barn. }\end{array}$ & $\mathrm{x}$ & & $\mathrm{x}$ & & anemo \\
\hline $\begin{array}{l}\text { FABACEAE } \\
\text { Centrolobium tomentosum Guill. } \\
\text { ex Benth }\end{array}$ & $\mathrm{x}$ & $x$ & $\mathrm{x}$ & $\mathrm{Si}$ & anemo \\
\hline Erythrina sp & & & $x$ & & \\
\hline Fabaceae sp1 & & $x$ & & & \\
\hline Pterocarpus violaceus Vog. & $x$ & $x$ & $x$ & $\mathrm{Si}$ & anemo \\
\hline $\begin{array}{l}\text { LAURACEAE } \\
\text { Nectandra megapotamica } \\
\text { (Spreng.) Mez }\end{array}$ & $\mathrm{x}$ & $\mathrm{x}$ & $\mathrm{x}$ & $\mathrm{Si}$ & zoo \\
\hline \multicolumn{6}{|l|}{ LYTHRACEAE } \\
\hline Lafoensia glyptocarpa Koehne & $x$ & & $x$ & St & auto \\
\hline \multicolumn{6}{|l|}{ MALVACEAE } \\
\hline Malvaceae sp1 & $x$ & & & & \\
\hline \multicolumn{6}{|l|}{ MELIACEAE } \\
\hline Guarea sp & $x$ & & & & \\
\hline Melia azedarach L. & $x$ & & $x$ & $\mathrm{P}$ & zoo \\
\hline Trichilia pallida Sw. & $\mathrm{x}$ & & $x$ & & zoo \\
\hline \multicolumn{6}{|l|}{ MIMOSACEAE } \\
\hline Spreng. & $x$ & $x$ & $x$ & $\mathrm{P}$ & auto \\
\hline Inga sp & & & $x$ & & zoo \\
\hline
\end{tabular}


Tabela 7. Relação das espécies amostradas na regeneração natural sob $C$. tomentosum (C.t.), C. myxa (C.m.) M. azedarach (M.a.), seguidas do grupo sucessional (G. s.) e síndrome de dispersão (S. d.) a que pertencem

\begin{tabular}{|c|c|c|c|c|c|}
\hline Espécie & sob C. $m$. & sob C. $t$. & sob M. a. & G. S. $^{1}$ & S. d. ${ }^{2}$ \\
\hline $\begin{array}{l}\text { MIMOSACEAE } \\
\text { Piptadenia gonoacantha (Mart.) } \\
\text { J.F.Macbr. }\end{array}$ & & $x$ & $x$ & $P$ & auto \\
\hline \multicolumn{6}{|l|}{ MORACEAE } \\
\hline $\begin{array}{l}\text { MYRTACEAE } \\
\text { Campomanesia guazumifolia } \\
\text { (Cambess.) O.Berg. }\end{array}$ & $x$ & & $x$ & & zoo \\
\hline Eugenia jambosa L. & $x$ & $x$ & $x$ & & zoo \\
\hline Myrtaceae sp1 & & $x$ & $x$ & & zoo \\
\hline Myrtaceae sp2 & $x$ & $x$ & & & zoo \\
\hline Myrtaceae sp3 & $x$ & $x$ & $x$ & & zoo \\
\hline Psidium guajava L. & & & $x$ & & zoo \\
\hline Syzygium cuminii Steud. & $x$ & & & & zoo \\
\hline \multicolumn{6}{|l|}{ POLYGONACEAE } \\
\hline Triplaris americana L. & $x$ & $x$ & $x$ & $P$ & anemo \\
\hline \multicolumn{6}{|l|}{ ROSACEAE } \\
\hline Prunus sellowii Koehne & $x$ & & & $\mathrm{Si}$ & zoo \\
\hline \multicolumn{6}{|l|}{ RUBIACEAE } \\
\hline Rubiaceae sp1 & & & $x$ & & \\
\hline \multicolumn{6}{|l|}{ RUTACEAE } \\
\hline Clausena excavata Burm. f. & $x$ & $x$ & $x$ & & zoo \\
\hline Esenbeckia leiocarpa Engl. & & & $x$ & $\mathrm{C}$ & zoo \\
\hline Murraya paniculata (L.) Jack. & $x$ & $x$ & $x$ & & zoo \\
\hline Zanthaxylum rhoifolium Lam. & & $x$ & $x$ & & zoo \\
\hline \multicolumn{6}{|l|}{ SOLANACEAE } \\
\hline Solanaceae sp1 & $x$ & $x$ & $x$ & & \\
\hline Solanaceae sp2 & $x$ & & $x$ & & \\
\hline
\end{tabular}


Tabela 7. Relação das espécies amostradas na regeneração natural sob $C$. tomentosum (C.t.), C. myxa (C.m.) M. azedarach (M.a.), seguidas do grupo sucessional (G. s.) e síndrome de dispersão (S. d.) a que pertencem

\begin{tabular}{|c|c|c|c|c|c|}
\hline Espécie & sob C. $m$. & sob C. $t$. & sob $M$. a. & G. s. $^{1}$ & S. d. ${ }^{2}$ \\
\hline \multicolumn{6}{|l|}{ SOLANACEAE } \\
\hline Solanum sp & & $x$ & & & \\
\hline \multicolumn{6}{|l|}{ STYRACACEAE } \\
\hline Styrax sp & $x$ & $x$ & $x$ & & \\
\hline \multicolumn{6}{|l|}{ VERBENACEAE } \\
\hline Aegiphilla sellowiana Cham. & $x$ & $x$ & $x$ & $\mathrm{P}$ & zoo \\
\hline Lantana brasiliensis & $x$ & $x$ & $x$ & & \\
\hline \multicolumn{6}{|l|}{ INDETERMINADA } \\
\hline morfoespécie 10 & & & $x$ & & \\
\hline morfoespécie 15 & $x$ & $x$ & $x$ & & \\
\hline morfoespécie 13 & & & $x$ & & \\
\hline morfoespécie 14 & $x$ & & $x$ & & \\
\hline morfoespécie 18 & & $x$ & & & \\
\hline morfoespécie 20 & & $x$ & & & \\
\hline morfoespécie 3 & $x$ & & & & \\
\hline morfoespécie 5 & $x$ & & & & \\
\hline morfoespécie 6 & $x$ & & & & \\
\hline morfoespécie 7 & $x$ & & & & \\
\hline morfoespécie 8 & $x$ & $x$ & & & \\
\hline morfoespécie 9 & & & $x$ & & \\
\hline
\end{tabular}

Algumas espécies, Anadenathera peregrina, Clausena excavata, C. myxa e Triplaris americana, foram bastante abundantes tanto na chuva quanto na regeneração natural. 
Porém, Melia azedarach e Tecoma stans apresentaram-se como as mais abundantes na chuva de sementes sob as três espécies, mas na regeneração natural, estas se apresentaram com poucos indivíduos regenerantes.

M. azedarach foi a única, dentre as espécies estudadas, que não apresentou grande abundância e freqüência de regenerantes de sua própria espécie sob suas copas. Tanto $C$. tomentosum quanto $C$. myxa estiveram entre os mais abundantes e freqüentes sob seus indivíduos. Além da grande abundância na chuva, $M$. azedarach também foi a mais abundante no banco de sementes (seção 3.2), indicando um potencial no solo. Isso mostra que apesar do potencial reprodutivo, a espécie não deve estar encontrando sob a copa destas espécies ambientes favoráveis para o seu desenvolvimento e sobrevivência, já que para a germinação parecem favorecê-la, uma vez que foram observados emergentes no solo da mata (observação pessoal).

Em estudo populacional com M. azedarach no Paraná, Silva et al. (1994) amostraram indivíduos regenerantes por toda a área de capoeira, já na área de floresta a regeneração foi ausente. Segundo estes mesmos autores, a espécie deve ocorrer em áreas florestais mais abertas e de clareiras, pois esta parece não suportar o sombreamento existente nas condições de floresta fechada.

A pequena abundância e freqüência de indivíduos regenerantes de $M$. azedarach sob copas de $M$. azedarach, diferentemente do ocorrido com os regenerantes das duas outras espécies, sugere que a idéia de que as espécies do dossel podem atuar como filtros semi permeáveis, para as espécies que regeneram sob si, pode ser correta.

Tecoma stans também foi bastante abundante na chuva, porém não amostrada no banco de sementes. A regeneração desta espécie ocorreu somente sob um indivíduo de C. tomentosum (três indivíduos regenerantes). Esta baixa abundância e freqüência podem estar relacionadas à não adaptação da espécie ao ambiente de sombra, encontrado sob a copa das espécies. Isto pode ser evidenciado devido à existência de um grande número de indivíduos, regenerantes e adultos, desta espécie na borda da área estudada (observação 
pessoal). Em áreas de pastagem, onde há grande incidência de luz, a espécie chega a ser considerada uma planta daninha (Lorenzi et al., 2003).

Por fim, como sugerido para a coleta da chuva e do banco de sementes para diminuir a influência da espécie do dossel, é recomendável para o monitoramento do estrato regenerativo que as unidades amostrais não estejam localizadas sob determinada espécie, procurando amostrar em pontos aleatórios ou sob um número grande de espécies. 


\section{CONSIDERAÇÕES FINAIS}

A maior parte das espécies e indivíduos amostrados, tanto na chuva quanto no banco e na regeneração natural, pertence aos estágios inicias da sucessão secundária, sendo que muitas, dentre as mais abundantes, são exóticas;

A chuva de sementes observada sob as três espécies foi bastante similar, mostrando que a composição da chuva de sementes está muito relacionada ao entorno e que a espécie sob a qual a chuva é amostrada parece não influenciar na riqueza e abundância das demais espécies que compõem a chuva, com exceção dela própria, para Cordia myxa e Melia azedarach;

As três espécies estudadas contribuíram diferentemente com o aporte de propágulos da própria espécie, $M$. azedarach foi a espécie que mais contribuiu e Centrolobium tomentosum a que menos contribuiu, sendo isto reflexo da produção da espécie e também da síndrome de dispersão, no caso da segunda espécie;

Sob as diferentes espécies estudadas observaram-se distintos bancos de sementes (a pleno sol), confirmando a variação espacial do banco; sob Melia azedarach houve a maior densidade de emergentes enquanto que a maior riqueza de espécie foi observada sob Cordia myxa;

Apesar da diferenças observadas, as três possibilitam a germinação e desenvolvimento de plântulas sob elas, influenciando, cada uma, na composição e estrutura das comunidades aí existentes;

A importância da diversidade de espécies utilizadas em projetos de restauração florestal é ressaltada. Além da diversidade de propágulos que se 
obtém, as espécies disponibilizam diferentes nichos de regeneração, contribuindo para manutenção da diversidade;

Estudos futuros, envolvendo variáveis ambientais, como incidência luz e profundidade do folhedo sob a copa das espécies, são importantes para determinar os fatores condicionantes destas diferenças, como observado na estrutura dos regenerantes;

Os processos ecológicos parecem estar se recuperando, visto que alguns fatos observados neste estudo, como a sazonalidade de frutificação, o predomínio de espécies zoocóricas no estrato regenerativo e a densidade dos regenerantes, também são observados em florestas naturais;

Por fim, alguns resultados obtidos através deste estudo, como picos de deposição de propágulos e espécies, picos de emergência, variação no número de espécies e plântulas germinadas do banco e similaridade e diversidade de espécies da chuva e da regeneração, são importantes para planejamento do monitoramento da área, o qual é fundamental para o emprego de medidas de intervenção, bem como para o entendimento da evolução da floresta que se forma. 
ANEXOS 
ANEXO A - Número de coletores de sementes presentes na área sob cada espécie, no período de estudo (novembro de 2002 a outubro de 2003). Inicialmente foram colocados 30 coletores $\left(1 \mathrm{~m}^{2}\right)$ sob cada espécie, sendo dois coletores por indivíduo

\begin{tabular}{lcccc}
\hline \multicolumn{5}{c}{ Número de coletores } \\
\hline Nob C. tomentosum & sob C. myxa & sob M. azedarach & Total \\
\hline D & 25 & 27 & 29 & 81 \\
J & 26 & 27 & 29 & 82 \\
F & 28 & 28 & 27 & 83 \\
M & 26 & 28 & 26 & 80 \\
A & 24 & 22 & 26 & 72 \\
M & 21 & 22 & 27 & 70 \\
J & 23 & 22 & 27 & 72 \\
J & 27 & 26 & 28 & 81 \\
A & 28 & 26 & 28 & 82 \\
S & 28 & 27 & 28 & 83 \\
O & 28 & 26 & 28 & 82 \\
Total & 28 & 27 & 28 & 83 \\
\hline
\end{tabular}


ANEXO B - Abundância mensal, anual e freqüência absoluta $(\mathrm{Fa})$ das espécies amostradas na chuva de sementes sob os indivíduos de Cordia myxa, no período de novembro de 2002 a outubro de 2003, em Iracemápolis, SP

\begin{tabular}{|c|c|c|c|c|c|c|c|c|c|c|c|c|c|c|}
\hline Espécie & nov & dez & jan & fev & mar & $a b r$ & mai & jun & jul a & ago & set & out & Abund. & $\mathrm{Fa}(\%)$ \\
\hline Tecoma stans* & 1224 & 997 & 13 & 35 & 0 & 0 & 0 & 53 & 0 & 0 & 1 & 12 & 2335 & 80.0 \\
\hline Cordia myxa* & 30 & 141 & 157 & 353 & 379 & 308 & 59 & 48 & 40 & 12 & 12 & 6 & 1545 & 100.0 \\
\hline Melia azedarach* & 57 & 88 & 51 & 95 & 33 & 34 & 1 & 272 & 8 & 7 & 8 & 72 & 726 & 100.0 \\
\hline Ficus benjaminea* & 11 & 16 & 0 & 57 & 55 & 0 & 0 & 153 & 6 & 39 & 279 & 11 & 627 & 13.3 \\
\hline Diatenopteryx sorbifolia & 58 & 78 & 2 & 41 & 0 & 0 & 0 & 0 & 0 & 0 & 13 & 2 & 194 & 33.3 \\
\hline Triplaris americana & 41 & 35 & 2 & 0 & 0 & 0 & 0 & 0 & 0 & 0 & 36 & 21 & 135 & 66.7 \\
\hline Cytharexyllum myrianthum & 0 & 0 & 0 & 65 & 48 & 2 & 0 & 0 & 0 & 0 & 0 & 0 & 115 & 73.3 \\
\hline Clauseni excavata* & 2 & 13 & 28 & 21 & 1 & 6 & 0 & 5 & 8 & 3 & 6 & 0 & 93 & 86.7 \\
\hline morfoespécie 35 & 0 & 0 & 0 & 0 & 18 & 62 & 3 & 0 & 0 & 0 & 0 & 0 & 83 & 20.0 \\
\hline Anadenanthera peregrina & 15 & 12 & 2 & 0 & 0 & 0 & 0 & 31 & 8 & 0 & 2 & 10 & 80 & 60.0 \\
\hline Pterocarpus violaceus & 0 & 0 & 0 & 7 & 0 & 0 & 0 & 51 & 7 & 0 & 0 & 7 & 72 & 26.7 \\
\hline Koelreuteria bipinnata* & 0 & 0 & 0 & 0 & 0 & 36 & 12 & 4 & 0 & 0 & 0 & 0 & 52 & 13.3 \\
\hline Lafoensia glyptocarpa & 38 & 0 & 0 & 0 & 0 & 0 & 0 & 0 & 0 & 0 & 0 & 6 & 44 & 33.3 \\
\hline Schinus terebintifolius & 0 & 0 & 0 & 0 & 0 & 0 & 0 & 21 & 7 & 0 & 0 & 0 & 28 & 40.0 \\
\hline Tipuana tipu & 0 & 3 & 0 & 0 & 0 & 0 & 0 & 19 & 0 & 0 & 0 & 0 & 22 & 26.7 \\
\hline Tibouchina sp & 0 & 2 & 0 & 0 & 0 & 0 & 0 & 7 & 0 & 0 & 9 & 0 & 18 & 6.7 \\
\hline Albizia hasslerii & 12 & 0 & 0 & 0 & 0 & 0 & 0 & 0 & 0 & 0 & 0 & 1 & 13 & 20.0 \\
\hline Chorisia speciosa & 0 & 0 & 0 & 0 & 0 & 0 & 0 & 0 & 0 & 0 & 12 & 0 & 12 & 20.0 \\
\hline Aegiphila sellowiana & 1 & 1 & 3 & 3 & 0 & 1 & 0 & 1 & 0 & 0 & 0 & 0 & 10 & 46.7 \\
\hline Centrolobium tomentosum & 1 & 0 & 0 & 0 & 0 & 0 & 1 & 1 & 0 & 0 & 1 & 5 & 9 & 26.7 \\
\hline Bignoniaceae sp2 & 7 & 1 & 0 & 0 & 0 & 0 & 0 & 0 & 0 & 0 & 0 & 0 & 8 & 13.3 \\
\hline Bombacaceae sp1 & 0 & 0 & 0 & 0 & 0 & 0 & 0 & 6 & 0 & 2 & 0 & 0 & 8 & 13.3 \\
\hline Rapanea umbellata & 0 & 5 & 0 & 1 & 0 & 0 & 0 & 0 & 2 & 0 & 0 & 0 & 8 & 20.0 \\
\hline Clitoria fairrchildiana & 0 & 0 & 0 & 0 & 0 & 0 & 0 & 7 & 0 & 0 & 0 & 0 & 7 & 6.7 \\
\hline Nectandra megapotamica & 0 & 5 & 2 & 0 & 0 & 0 & 0 & 0 & 0 & 0 & 0 & 0 & 7 & 26.7 \\
\hline Caesalpinia ferrea var. leiostachya & 0 & 0 & 0 & 2 & 0 & 0 & 0 & 0 & 0 & 0 & 3 & 0 & 5 & 6.7 \\
\hline morfoespécie 11 & 1 & 2 & 0 & 0 & 0 & 0 & 0 & 0 & 0 & 0 & 0 & 0 & 3 & 13.3 \\
\hline morfoespécie 29 & 0 & 0 & 1 & 0 & 1 & 1 & 0 & 0 & 0 & 0 & 0 & 0 & 3 & 20.0 \\
\hline morfoespécie 30 & 0 & 0 & 3 & 0 & 0 & 0 & 0 & 0 & 0 & 0 & 0 & 0 & 3 & 13.3 \\
\hline morfoespécie 38 & 0 & 0 & 0 & 0 & 0 & 0 & 0 & 3 & 0 & 0 & 0 & 0 & 3 & 6.7 \\
\hline Terminalia sp & 1 & 2 & 0 & 0 & 0 & 0 & 0 & 0 & 0 & 0 & 0 & 0 & 3 & 13.3 \\
\hline Leucaena leucocephala* & 0 & 0 & 0 & 0 & 0 & 0 & 0 & 1 & 0 & 0 & 0 & 1 & 2 & 13.3 \\
\hline Balfourodendron riedelianum & 0 & 0 & 0 & 0 & 0 & 0 & 0 & 0 & 0 & 0 & 0 & 2 & 2 & 6.7 \\
\hline Tabebuia chrysotricha & 0 & 0 & 0 & 0 & 0 & 0 & 0 & 0 & 0 & 0 & 0 & 2 & 2 & 6.7 \\
\hline Prunus sellowii & 0 & 0 & 1 & 0 & 0 & 0 & 0 & 0 & 0 & 0 & 0 & 0 & 1 & 6.7 \\
\hline Pseudobombax grandiflorum & 0 & 0 & 0 & 0 & 0 & 0 & 0 & 0 & 0 & 0 & 0 & 1 & 1 & 6.7 \\
\hline morfoespécie 21 & 1 & 0 & 0 & 0 & 0 & 0 & 0 & 0 & 0 & 0 & 0 & 0 & 1 & 6.7 \\
\hline morfoespécie 26 & 0 & 1 & 0 & 0 & 0 & 0 & 0 & 0 & 0 & 0 & 0 & 0 & 1 & 6.7 \\
\hline Jacaranda mimosaefolia* & 0 & 0 & 0 & 0 & 0 & 0 & 0 & 0 & 0 & 0 & 0 & 1 & 1 & 6.7 \\
\hline Total & 1500 & 1402 & 265 & 680 & 535 & 450 & 76 & 683 & 86 & 63 & 382 & 160 & 6282 & \\
\hline
\end{tabular}

* espécies exóticas 
ANEXO C - Abundância mensal, anual e freqüência absoluta $(\mathrm{Fa})$ das espécies amostradas na chuva de sementes sob os indivíduos de Centrolobium tomentosum, no período de novembro de 2002 a outubro de 2003, em Iracemápolis, SP

\begin{tabular}{|c|c|c|c|c|c|c|c|c|c|c|c|c|c|c|}
\hline Espécie & nov & dez & jan & fev & mar & $a b r$ & mai & jun & jul & ago & set & out & Abund. & $\mathrm{Fa}(\%)$ \\
\hline$\overline{\text { Melia azedarach* }}$ & 112 & 423 & 49 & 204 & 104 & 71 & 8 & 375 & 27 & 21 & 59 & 355 & 1808 & 86.7 \\
\hline Tecoma stans* & 323 & 143 & 0 & 0 & 0 & 0 & 0 & 0 & 0 & 0 & 1 & 10 & 477 & 73.3 \\
\hline Diatenopteryx sorbifolia & 108 & 192 & 31 & 27 & 0 & 0 & 0 & 10 & 0 & 0 & 30 & 11 & 409 & 20.0 \\
\hline Anadenanthera peregrina & 24 & 6 & 5 & 5 & 27 & 18 & 3 & 197 & 16 & 5 & 5 & 48 & 359 & 53.3 \\
\hline Lafoensia glyptocarpa & 91 & 0 & 0 & 0 & 0 & 0 & 0 & 0 & 0 & 0 & 1 & 103 & 195 & 46.7 \\
\hline Centrolobium tomentosum & 11 & 16 & 7 & 4 & 2 & 56 & 5 & 14 & 1 & 16 & 9 & 23 & 164 & 93.3 \\
\hline Triplaris americana & 23 & 37 & 1 & 0 & 0 & 0 & 0 & 0 & 0 & 1 & 29 & 11 & 102 & 73.3 \\
\hline Cordia myxa* & 1 & 1 & 3 & 10 & 23 & 33 & 13 & 9 & 4 & 3 & 1 & 0 & 101 & 93.3 \\
\hline Pterocarpus violaceus & 0 & 0 & 0 & 0 & 1 & 0 & 0 & 42 & 20 & 3 & 4 & 4 & 74 & 26.7 \\
\hline Terminalia sp & 45 & 6 & 0 & 0 & 0 & 0 & 0 & 0 & 0 & 0 & 0 & 0 & 51 & 6.7 \\
\hline Clausena excavata* & 3 & 13 & 18 & 5 & 2 & 1 & 0 & 2 & 1 & 0 & 0 & 2 & 47 & 73.3 \\
\hline morfoespécie 19 & 21 & 12 & 10 & 2 & 0 & 0 & 0 & 0 & 0 & 0 & 0 & 0 & 45 & 6.7 \\
\hline Balfourodendron riedelianum & 0 & 1 & 15 & 10 & 8 & 2 & 0 & 0 & 0 & 0 & 0 & 5 & 41 & 13.3 \\
\hline Schinus terebintifolius & 0 & 0 & 0 & 0 & 0 & 0 & 0 & 5 & 9 & 0 & 0 & 0 & 14 & 40.0 \\
\hline Mimosaceae sp1 & 0 & 0 & 0 & 0 & 0 & 0 & 0 & 0 & 12 & 0 & 1 & 0 & 13 & 6.7 \\
\hline Koelreuteria bipinnata* & 0 & 0 & 0 & 0 & 0 & 5 & 0 & 5 & 0 & 0 & 0 & 0 & 10 & 20.0 \\
\hline morfoespécie 38 & 0 & 0 & 0 & 0 & 0 & 0 & 9 & 0 & 0 & 0 & 0 & 0 & 9 & 20.0 \\
\hline Ficus benjaminea* & 0 & 0 & 0 & 0 & 8 & 0 & 0 & 0 & 0 & 0 & 0 & 0 & 8 & 6.7 \\
\hline morfoespécie 17 & 0 & 7 & 0 & 0 & 0 & 0 & 0 & 0 & 0 & 0 & 0 & 0 & 7 & 6.7 \\
\hline morfoespécie 35 & 0 & 0 & 0 & 0 & 0 & 7 & 0 & 0 & 0 & 0 & 0 & 0 & 7 & 6.7 \\
\hline Tabebuia chrysotricha & 0 & 0 & 0 & 0 & 0 & 0 & 0 & 0 & 0 & 0 & 0 & 7 & 7 & 33.3 \\
\hline Clitoria fairchiliana & 0 & 0 & 0 & 0 & 0 & 0 & 0 & 0 & 5 & 0 & 0 & 0 & 5 & 6.7 \\
\hline Aegiphilla sellowiana & 0 & 2 & 1 & 1 & 0 & 0 & 0 & 0 & 0 & 0 & 0 & 0 & 4 & 13.3 \\
\hline Bignoniaceae sp2 & 4 & 0 & 0 & 0 & 0 & 0 & 0 & 0 & 0 & 0 & 0 & 0 & 4 & 13.3 \\
\hline Chorisia speciosa & 0 & 0 & 0 & 0 & 0 & 0 & 0 & 0 & 0 & 0 & 4 & 0 & 4 & 20.0 \\
\hline Cytharexyllum myrianthum & 0 & 0 & 0 & 1 & 3 & 0 & 0 & 0 & 0 & 0 & 0 & 0 & 4 & 13.3 \\
\hline Rapanea umbellata & 1 & 0 & 1 & 0 & 0 & 0 & 0 & 1 & 0 & 0 & 0 & 0 & 3 & 13.3 \\
\hline morfoespécie 29 & 0 & 0 & 1 & 1 & 1 & 0 & 0 & 0 & 0 & 0 & 0 & 0 & 3 & 20.0 \\
\hline Bombacaceae sp1 & 0 & 0 & 0 & 0 & 0 & 0 & 0 & 0 & 0 & 0 & 0 & 2 & 2 & 6.7 \\
\hline Nectandra megapotamica & 1 & 1 & 0 & 0 & 0 & 0 & 0 & 0 & 0 & 0 & 0 & 0 & 2 & 13.3 \\
\hline morfoespécie 30 & 0 & 0 & 1 & 1 & 0 & 0 & 0 & 0 & 0 & 0 & 0 & 0 & 2 & 13.3 \\
\hline Prunus sellowii & 0 & 1 & 0 & 0 & 0 & 0 & 0 & 0 & 0 & 0 & 0 & 0 & 1 & 6.7 \\
\hline Total & 768 & 861 & 143 & 271 & 179 & 193 & 38 & 660 & 95 & 49 & 144 & 581 & 3982 & \\
\hline
\end{tabular}




\begin{abstract}
ANEXO D - Abundância mensal, anual e freqüência absoluta $(\mathrm{Fa})$ das espécies amostradas na chuva de sementes sob os indivíduos de Melia azedarach, no período de novembro de 2002 a outubro de 2003, em Iracemápolis, SP
\end{abstract}

\begin{tabular}{|c|c|c|c|c|c|c|c|c|c|c|c|c|c|c|}
\hline Espécie & nov & dez & jan & fev & mar & $a b r$ & mai & jun & jul & ago & set & out & Abund. & $\mathrm{Fa} \mathrm{( \% )}$ \\
\hline Melia azedarach* & 1563 & 2818 & 814 & 1360 & 1497 & 817 & 248 & 1431 & 484 & 271 & 525 & 1901 & 13729 & 100.0 \\
\hline Tecoma stans* & 505 & 865 & 9 & 0 & 0 & 0 & 0 & 0 & 2 & 0 & 8 & 41 & 1430 & 73.3 \\
\hline Triplaris americana & 33 & 109 & 5 & 1 & 0 & 0 & 0 & 0 & 0 & 2 & 48 & 61 & 259 & 66.7 \\
\hline Cordia myxa* & 2 & 10 & 20 & 72 & 69 & 32 & 3 & 5 & 6 & 0 & 0 & 0 & 219 & 80.0 \\
\hline Clausena excavata* & 8 & 50 & 51 & 31 & 11 & 20 & 1 & 1 & 1 & 1 & 5 & 3 & 183 & 93.3 \\
\hline Lafoensia glyptocarpa & 41 & 1 & 1 & 0 & 0 & 0 & 0 & 0 & 0 & 0 & 1 & 87 & 131 & 26.7 \\
\hline Anadenanthera peregrina & 2 & 13 & 0 & 10 & 9 & 0 & 0 & 45 & 1 & 12 & 9 & 12 & 113 & 66.7 \\
\hline Cytharexyllum myrianthum & 0 & 0 & 0 & 55 & 38 & 1 & 0 & 0 & 0 & 0 & 0 & 0 & 94 & 73.3 \\
\hline Pterocarpus violaceus & 0 & 1 & 0 & 0 & 2 & 0 & 0 & 50 & 4 & 2 & 3 & 7 & 69 & 26.7 \\
\hline Albizia hasslerii & 51 & 3 & 0 & 0 & 0 & 0 & 0 & 0 & 0 & 0 & 0 & 11 & 65 & 20.0 \\
\hline Diatenopteryx sorbifolia & 16 & 3 & 0 & 2 & 0 & 0 & 0 & 0 & 0 & 0 & 17 & 23 & 61 & 46.7 \\
\hline Schinus terebintifolius & 0 & 0 & 0 & 0 & 0 & 0 & 0 & 31 & 8 & 0 & 0 & 0 & 39 & 13.3 \\
\hline Koelreuteria bipinnata* & 0 & 0 & 0 & 0 & 0 & 0 & 0 & 37 & 0 & 0 & 0 & 0 & 37 & 6.7 \\
\hline Nectandra megapotamica & 7 & 26 & 0 & 0 & 1 & 0 & 0 & 0 & 0 & 0 & 0 & 0 & 34 & 26.7 \\
\hline Mimosaceae sp1 & 0 & 0 & 0 & 0 & 0 & 0 & 0 & 0 & 0 & 0 & 34 & 0 & 34 & 20.0 \\
\hline morfoespécie 11 & 23 & 9 & 0 & 0 & 0 & 0 & 0 & 0 & 0 & 0 & 0 & 0 & 32 & 26.7 \\
\hline Clitoria fairchildiana & 0 & 0 & 0 & 0 & 0 & 0 & 0 & 21 & 0 & 0 & 0 & 0 & 21 & 6.7 \\
\hline Tibouchina $\mathrm{sp}$ & 0 & 0 & 0 & 0 & 7 & 0 & 0 & 0 & 0 & 0 & 1 & 7 & 15 & 13.3 \\
\hline Centrolobium tomentosum & 0 & 1 & 0 & 0 & 0 & 0 & 0 & 4 & 0 & 2 & 0 & 7 & 14 & 26.7 \\
\hline Rapanea umbellata & 1 & 12 & 0 & 0 & 0 & 0 & 0 & 0 & 0 & 0 & 0 & 0 & 13 & 20.0 \\
\hline morfoespécie 31 & 0 & 0 & 11 & 0 & 0 & 0 & 0 & 0 & 0 & 0 & 0 & 0 & 11 & 6.7 \\
\hline Aegiphilla sellowiana & 0 & 2 & 3 & 1 & 1 & 0 & 0 & 0 & 0 & 0 & 0 & 0 & 7 & 46.7 \\
\hline Piptadenia gonoacantha & 0 & 0 & 0 & 0 & 0 & 0 & 0 & 0 & 0 & 0 & 6 & 0 & 6 & 6.7 \\
\hline morfoespécie 24 & 1 & 3 & 0 & 0 & 0 & 0 & 0 & 0 & 0 & 0 & 0 & 0 & 4 & 6.7 \\
\hline morfoespécie 30 & 0 & 0 & 2 & 2 & 0 & 0 & 0 & 0 & 0 & 0 & 0 & 0 & 4 & 13.3 \\
\hline Chorisia speciosa & 0 & 0 & 0 & 0 & 0 & 0 & 0 & 0 & 0 & 0 & 3 & 0 & 3 & 13.3 \\
\hline Balfourodendron riedelianum & 0 & 1 & 0 & 0 & 0 & 0 & 0 & 0 & 0 & 0 & 0 & 2 & 3 & 20.0 \\
\hline Tabebuia chrysotricha & 0 & 0 & 0 & 0 & 0 & 0 & 0 & 0 & 0 & 0 & 0 & 3 & 3 & 13.3 \\
\hline Prunus sellowii & 0 & 2 & 0 & 0 & 0 & 0 & 0 & 0 & 0 & 0 & 0 & 0 & 2 & 6.7 \\
\hline morfoespécie 12 & 2 & 0 & 0 & 0 & 0 & 0 & 0 & 0 & 0 & 0 & 0 & 0 & 2 & 6.7 \\
\hline morfoespécie 29 & 0 & 0 & 1 & 0 & 0 & 1 & 0 & 0 & 0 & 0 & 0 & 0 & 2 & 13.3 \\
\hline morfoespécie 38 & 0 & 0 & 0 & 0 & 0 & 0 & 0 & 2 & 0 & 0 & 0 & 0 & 2 & 6.7 \\
\hline Bombacaceae sp1 & 0 & 0 & 0 & 0 & 0 & 0 & 0 & 0 & 1 & 0 & 0 & 0 & 1 & 6.7 \\
\hline Pseudobombax grandiflorum & 0 & 0 & 0 & 0 & 0 & 0 & 0 & 0 & 0 & 0 & 1 & 0 & 1 & 6.7 \\
\hline morfoespécie 19 & 0 & 0 & 0 & 0 & 0 & 0 & 0 & 0 & 0 & 0 & 0 & 1 & 1 & 6.7 \\
\hline morfoespécie 25 & 0 & 1 & 0 & 0 & 0 & 0 & 0 & 0 & 0 & 0 & 0 & 0 & 1 & 6.7 \\
\hline Jacaranda mimosaefolia* & 0 & 0 & 0 & 0 & 0 & 0 & 0 & 0 & 0 & 0 & 1 & 0 & 1 & 6.7 \\
\hline morfoespécie 43 & 0 & 0 & 0 & 0 & 0 & 0 & 0 & 0 & 0 & 0 & 1 & 0 & 1 & 6.7 \\
\hline Total & 2255 & 3930 & 917 & 1534 & 1635 & 871 & 252 & 1627 & 507 & 290 & 663 & 2166 & 16647 & \\
\hline
\end{tabular}

* espécies exóticas 
ANEXO E - Parâmetros fitossociológicos (abundância - Abund., densidade absoluta - Da, densidade relativa - Dr) das espécies germinadas nas amostras de solo sob C. myxa, C. tomentosum e M. azedarach, no período de agosto a outubro de 2003

\begin{tabular}{|c|c|c|c|c|c|c|c|c|c|}
\hline \multirow{2}{*}{ Espécie } & \multicolumn{3}{|c|}{ C. myxa } & \multicolumn{3}{|c|}{ C. tomentosum } & \multicolumn{3}{|c|}{ M. azedarach } \\
\hline & Abund. & $\mathrm{Da}$ (ind. $\mathrm{m}^{-2}$ ) & $\operatorname{Dr}(\%)$ & Abund. & $\mathrm{Da}$ (ind. $\mathrm{m}^{-2}$ ) & $\operatorname{Dr}(\%)$ & Abund. & $\mathrm{Da}$ (ind. $\mathrm{m}^{-2}$ ) & $\operatorname{Dr}(\%)$ \\
\hline Cecropia sp & 1 & 0,27 & 0,07 & 0 & 0 & 0 & 0 & 0 & 0 \\
\hline Cordia myxa L. & 1006 & 268,27 & 70,56 & 39 & 10,40 & 8,30 & 101 & 26,93 & 0,80 \\
\hline Melia azedarach L. & 189 & 50,40 & 13,26 & 303 & 80,80 & 64,49 & 12403 & 3307,47 & 98,65 \\
\hline Leguminosae sp1 & 146 & 38,93 & 10,24 & 104 & 27,73 & 22,13 & 53 & 14,13 & 0,42 \\
\hline morfoespécie 10 & 0 & 0 & 0 & 1 & 0,27 & 0,21 & 0 & 0 & 0 \\
\hline morfoespécie 11 & 0 & 0 & 0 & 1 & 0,27 & 0,21 & 2 & 0,53 & 0,02 \\
\hline morfoespécie 12 & 3 & 0,80 & 0,21 & 16 & 4,27 & 3,41 & 3 & 0,80 & 0,02 \\
\hline morfoespécie 13 & 0 & 0 & 0 & 1 & 0,27 & 0,21 & 0 & 0 & 0 \\
\hline morfoespécie 14 & 27 & 7,20 & 1,89 & 0 & 0 & 0 & 0 & 0 & 0 \\
\hline morfoespécie 15 & 1 & 0,27 & 0,07 & 0 & 0 & 0 & 0 & 0 & 0 \\
\hline morfoespécie 16 & 0 & 0 & 0 & 0 & 0 & 0 & 3 & 0,80 & 0,02 \\
\hline morfoespécie 2 & 2 & 0,53 & 0,14 & 1 & 0,27 & 0,21 & 0 & 0 & 0 \\
\hline morfoespécie 3 & 2 & 0,53 & 0,14 & 0 & 0 & 0 & 1 & 0,27 & 0,01 \\
\hline morfoespécie 4 & 5 & 1,33 & 0,35 & 0 & 0 & 0 & 0 & 0 & 0 \\
\hline morfoespécie 5 & 25 & 6,67 & 1,75 & 3 & 0,80 & 0,64 & 6 & 1,60 & 0,05 \\
\hline morfoespécie 6 & 1 & 0,27 & 0,07 & 0 & 0 & 0 & 0 & 0 & 0 \\
\hline morfoespécie 7 & 18 & 4,80 & 1,26 & 0 & 0 & 0 & 0 & 0 & 0 \\
\hline morfoespécie 8 & 0 & 0 & 0 & 1 & 0,27 & 0,21 & 0 & 0 & 0 \\
\hline morfoespécie 9 & 0 & 0 & 0 & 0 & 0 & 0 & 1 & 0,27 & 0,01 \\
\hline
\end{tabular}


ANEXO F - Parâmetros fitossociológicos - abundância total e relativa (\%), freqüência absoluta (Fa), freqüência relativa $(\mathrm{Fr})$ - , altura média e número de indivíduos com altura menor e maior que 1 metro das espécies regenerantes sob Cordia myxa

\begin{tabular}{|c|c|c|c|c|c|c|c|}
\hline Espécie & abundância & abund. (\%) & $\mathrm{Fa} \mathrm{( \% )}$ & $\operatorname{Fr}(\%)$ & altura média & $\mathrm{n}^{\circ}$ ind $<1 \mathrm{~m}$ & $\mathrm{n}^{\circ}$ ind $>1 \mathrm{~m}$ \\
\hline Cordia myxa* & 664 & 40.9 & 100.0 & 11.3 & 1.097 & 327 & 337 \\
\hline Clausena excavata* & 626 & 38.5 & 100.0 & 11.3 & 0.754 & 514 & 112 \\
\hline Nectandra megapotamica & 86 & 5.3 & 93.3 & 10.5 & 0.894 & 54 & 32 \\
\hline Centrolobium tomentosum & 61 & 3.8 & 46.7 & 5.3 & 1.023 & 40 & 21 \\
\hline Myrtaceae sp2 & 44 & 2.7 & 53.3 & 6.0 & 0.588 & 39 & 5 \\
\hline Chorisia speciosa & 26 & 1.6 & 33.3 & 3.8 & 0.674 & 23 & 3 \\
\hline Murraya paniculata* & 22 & 1.4 & 60.0 & 6.8 & 1.180 & 8 & 14 \\
\hline Solaceae sp1 & 14 & 0.9 & 53.3 & 6.0 & 0.791 & 10 & 4 \\
\hline Triplaris americana & 10 & 0.6 & 20.0 & 2.3 & 0.873 & 8 & 2 \\
\hline Styrax sp & 8 & 0.5 & 26.7 & 3.0 & 1.090 & 2 & 6 \\
\hline Anadenthera peregrina & 6 & 0.4 & 20.0 & 2.3 & 0.680 & 6 & 0 \\
\hline Ficus sp & 6 & 0.4 & 13.3 & 1.5 & 0.427 & 6 & 0 \\
\hline Eugenia jambosa* & 5 & 0.3 & 13.3 & 1.5 & 0.866 & 3 & 2 \\
\hline Cassia ferruginea & 4 & 0.2 & 20.0 & 2.3 & 1.248 & 1 & 3 \\
\hline Myrtaceae sp3 & 4 & 0.2 & 20.0 & 2.3 & 0.980 & 3 & 1 \\
\hline Tabebuia chrysotricha & 4 & 0.2 & 26.7 & 3.0 & 0.790 & 2 & 2 \\
\hline Lantana brasiliensis & 3 & 0.2 & 20.0 & 2.3 & 0.950 & 2 & 1 \\
\hline Melia azedarach* & 3 & 0.2 & 6.7 & 0.8 & 1.260 & 1 & 2 \\
\hline Pterocarpus violaceus & 3 & 0.2 & 6.7 & 0.8 & 1.000 & 2 & 1 \\
\hline morfoespécie 8 & 3 & 0.2 & 13.3 & 1.5 & 0.573 & 3 & 0 \\
\hline Syzygium cuminii* & 2 & 0.1 & 13.3 & 1.5 & 1.035 & 1 & 1 \\
\hline Protium sp & 2 & 0.1 & 6.7 & 0.8 & 0.510 & 2 & 0 \\
\hline
\end{tabular}


ANEXO F - Parâmetros fitossociológicos - abundância total e relativa (\%), freqüência absoluta (Fa), freqüência relativa $(\mathrm{Fr})$ - , altura média e número de indivíduos com altura menor e maior que 1 metro das espécies regenerantes sob Cordia myxa

\begin{tabular}{|c|c|c|c|c|c|c|c|}
\hline Espécie & abundância & abund. (\%) & $\mathrm{Fa} \mathrm{( \% )}$ & Fr (\%) & altura média & $\mathrm{n}^{\circ}$ ind $<1 \mathrm{~m}$ & $n^{\circ}$ ind $>1 m$ \\
\hline morfoespécie 15 & 2 & 0.1 & 6.7 & 0.8 & 0.540 & 2 & 0 \\
\hline Aegiphilla sellowiana & 1 & 0.1 & 6.7 & 0.8 & 0.340 & 1 & 0 \\
\hline Solanaceae sp2 & 1 & 0.1 & 6.7 & 0.8 & 0.970 & 1 & 0 \\
\hline Cordia ecalyculata & 1 & 0.1 & 6.7 & 0.8 & 0.750 & 1 & 0 \\
\hline Campomanesia guazumifolia & 1 & 0.1 & 6.7 & 0.8 & 1.100 & 0 & 1 \\
\hline Malvaceae sp1 & 1 & 0.1 & 6.7 & 0.8 & 1.050 & 0 & 1 \\
\hline Guarea sp & 1 & 0.1 & 6.7 & 0.8 & 1.480 & 0 & 1 \\
\hline Astronium graveolens & 1 & 0.1 & 6.7 & 0.8 & 0.680 & 1 & 0 \\
\hline Lafoensia glyptocarpa & 1 & 0.1 & 6.7 & 0.8 & 2.000 & 0 & 1 \\
\hline Prunus sellowii & 1 & 0.1 & 6.7 & 0.8 & 0.780 & 1 & 0 \\
\hline morfoespécie 14 & 1 & 0.1 & 6.7 & 0.8 & 0.640 & 1 & 0 \\
\hline Senna macranthera & 1 & 0.1 & 6.7 & 0.8 & 1.100 & 0 & 1 \\
\hline Morfoespécie 3 & 1 & 0.1 & 6.7 & 0.8 & 1.940 & 0 & 1 \\
\hline Morfoespécie 5 & 1 & 0.1 & 6.7 & 0.8 & 0.390 & 1 & 0 \\
\hline Morfoespécie 6 & 1 & 0.1 & 6.7 & 0.8 & 1.490 & 0 & 1 \\
\hline Morfoespécie 7 & 1 & 0.1 & 6.7 & 0.8 & 1.180 & 0 & 1 \\
\hline Tapirira guianensis & 1 & 0.1 & 6.7 & 0.8 & 0.380 & 1 & 0 \\
\hline Trichilia pallida & 1 & 0.1 & 6.7 & 0.8 & 0.420 & 1 & 0 \\
\hline
\end{tabular}

* espécies exóticas 
ANEXO G - Parâmetros fitossociológicos - abundância total e relativa (\%), freqüência absoluta (Fa), freqüência relativa $(\mathrm{Fr})$ - , altura média e número de indivíduos com altura menor e maior que 1 metro das espécies regenerantes sob Centrolobium tomentosum

\begin{tabular}{|c|c|c|c|c|c|c|c|}
\hline Espécie & abundância & abund. (\%) & $\mathrm{Fa}(\%)$ & Fr (\%) & altura média & $\mathrm{n}^{\circ}$ ind $<1 \mathrm{~m}$ & $n^{\circ}$ ind $>1 \mathrm{~m}$ \\
\hline Centrolobium tomentosum & 854 & 62.9 & 100.0 & 12.9 & 0.682 & 729 & 125 \\
\hline Clausena excavata* & 260 & 19.1 & 100.0 & 12.9 & 0.832 & 192 & 68 \\
\hline Nectandra megapotamica & 81 & 6.0 & 93.3 & 12.1 & 0.837 & 62 & 19 \\
\hline Triplaris americana & 29 & 2.1 & 26.7 & 3.4 & 0.568 & 27 & 2 \\
\hline Myrtaceae sp1 & 19 & 1.4 & 53.3 & 6.9 & 0.545 & 19 & 0 \\
\hline Cordia myxa* & 16 & 1.2 & 40.0 & 5.2 & 1.118 & 8 & 8 \\
\hline Solanaceae sp1 & 16 & 1.2 & 40.0 & 5.2 & 0.868 & 11 & 5 \\
\hline Anadenanthera peregrina & 14 & 1.0 & 33.3 & 4.3 & 0.875 & 10 & 4 \\
\hline Eugenia jambosa* & 13 & 1.0 & 46.7 & 6.0 & 1.445 & 7 & 6 \\
\hline Chorisia speciosa & 9 & 0.7 & 20.0 & 2.6 & 0.711 & 8 & 1 \\
\hline Lantana brasiliensis & 6 & 0.4 & 26.7 & 3.4 & 0.925 & 5 & 1 \\
\hline Piptadenia gonoacantha & 6 & 0.4 & 13.3 & 1.7 & 0.856 & 5 & 1 \\
\hline morfoespécie 15 & 6 & 0.4 & 33.3 & 4.3 & 1.191 & 3 & 3 \\
\hline Schinus terebenthifolius & 4 & 0.3 & 6.7 & 0.9 & 0.427 & 4 & 0 \\
\hline Aegiphilla sellowiana & 3 & 0.2 & 20.0 & 2.6 & 0.937 & 2 & 1 \\
\hline Ficus $\mathrm{sp}$ & 3 & 0.2 & 20.0 & 2.6 & 0.420 & 3 & 0 \\
\hline Tecoma stans* & 3 & 0.2 & 6.7 & 0.9 & 0.993 & 2 & 1 \\
\hline Cassia ferruginea & 2 & 0.1 & 6.7 & 0.9 & 0.715 & 2 & 0 \\
\hline Zanthoxylum rhoifolium & 2 & 0.1 & 6.7 & 0.9 & 1.035 & 1 & 1 \\
\hline Fabaceae sp1 & 1 & 0.1 & 6.7 & 0.9 & 0.430 & 1 & 0 \\
\hline Solanum sp & 1 & 0.1 & 6.7 & 0.9 & 0.940 & 1 & 0 \\
\hline Murraya paniculata* & 1 & 0.1 & 6.7 & 0.9 & 1.100 & 0 & 1 \\
\hline Myrtaceae sp3 & 1 & 0.1 & 6.7 & 0.9 & 0.580 & 1 & 0 \\
\hline
\end{tabular}


ANEXO G - Parâmetros fitossociológicos - abundância total e relativa (\%), freqüência absoluta (Fa), freqüência relativa $(\mathrm{Fr})$ - , altura média e número de indivíduos com altura menor e maior que 1 metro das espécies regenerantes sob Centrolobium tomentosum

\begin{tabular}{|c|c|c|c|c|c|c|c|}
\hline Espécie & abundância & abund. (\%) & $\mathrm{Fa}(\%)$ & Fr (\%) & altura média & $\mathrm{n}^{\circ}$ ind $<1 \mathrm{~m}$ & $n^{\circ}$ ind $>1 m$ \\
\hline Myrtaceae sp2 & 1 & 0.1 & 6.7 & 0.9 & 1.250 & 0 & 1 \\
\hline Pterocarpus violaceus & 1 & 0.1 & 6.7 & 0.9 & 0.530 & 1 & 0 \\
\hline morfoespécie 18 & 1 & 0.1 & 6.7 & 0.9 & 0.730 & 1 & 0 \\
\hline morfoespécie 20 & 1 & 0.1 & 6.7 & 0.9 & 0.470 & 1 & 0 \\
\hline morfoespécie 8 & 1 & 0.1 & 6.7 & 0.9 & 0.730 & 1 & 0 \\
\hline Styrax sp & 1 & 0.1 & 6.7 & 0.9 & 0.420 & 1 & 0 \\
\hline Tabebuia chrysotricha & 1 & 0.1 & 6.7 & 0.9 & 0.820 & 1 & 0 \\
\hline Tapirira guianensis & 1 & 0.1 & 6.7 & 0.9 & 0.310 & 1 & 0 \\
\hline
\end{tabular}

* espécies exóticas 
ANEXO H - Parâmetros fitossociológicos - abundância total e relativa (\%), freqüência absoluta (Fa), freqüência relativa $(\mathrm{Fr})$ - , altura média e número de indivíduos com altura menor e maior que 1 metro das espécies regenerantes sob Melia azedarach

\begin{tabular}{|c|c|c|c|c|c|c|c|}
\hline Espécie & abundância & abund. (\%) & $\mathrm{Fa} \mathrm{( \% )}$ & $\operatorname{Fr}(\%)$ & altura média & $\mathrm{n}^{\circ}$ ind $<1 \mathrm{~m}$ & $n^{\circ}$ ind $>1 \mathrm{~m}$ \\
\hline Clausena excavata* & 706 & 51.8 & 100.0 & 8.7 & 0.871 & 515 & 191 \\
\hline Centrolobium tomentosum & 133 & 9.8 & 46.7 & 4.1 & 0.709 & 101 & 32 \\
\hline Nectandra megapotamica & 102 & 7.5 & 100.0 & 8.7 & 0.796 & 80 & 22 \\
\hline Solanaceae sp1 & 60 & 4.4 & 86.7 & 7.6 & 1.026 & 42 & 18 \\
\hline Triplaris americana & 56 & 4.1 & 20.0 & 1.7 & 0.572 & 54 & 2 \\
\hline Myrtaceae sp1 & 55 & 4.0 & 53.3 & 4.7 & 0.626 & 49 & 6 \\
\hline Anadenanthera peregrina & 45 & 3.3 & 53.3 & 4.7 & 0.945 & 31 & 14 \\
\hline Murraya paniculata* & 22 & 1.6 & 73.3 & 6.4 & 1.195 & 8 & 14 \\
\hline Melia azedarach* & 19 & 1.4 & 20.0 & 1.7 & 1.306 & 12 & 7 \\
\hline Chorisia speciosa & 17 & 1.2 & 20.0 & 1.7 & 0.853 & 13 & 4 \\
\hline morfoespécie 15 & 13 & 1.0 & 40.0 & 3.5 & 1.226 & 4 & 9 \\
\hline Tabebuia chrysotricha & 12 & 0.9 & 33.3 & 2.9 & 0.669 & 11 & 1 \\
\hline Lantana brasiliensis & 11 & 0.8 & 40.0 & 3.5 & 1.032 & 10 & 1 \\
\hline Eugenia jambosa* & 9 & 0.7 & 33.3 & 2.9 & 0.784 & 7 & 2 \\
\hline Cassia ferruginea & 8 & 0.6 & 33.3 & 2.9 & 0.758 & 5 & 3 \\
\hline Myrtaceae sp3 & 8 & 0.6 & 46.7 & 4.1 & 0.623 & 8 & 0 \\
\hline Aegiphilla sellowiana & 6 & 0.4 & 26.7 & 2.3 & 0.769 & 6 & 0 \\
\hline Cordia myxa* & 6 & 0.4 & 20.0 & 1.7 & 1.026 & 3 & 3 \\
\hline Bombacaceae sp2 & 6 & 0.4 & 20.0 & 1.7 & 0.636 & 5 & 1 \\
\hline Tapirira guianensis & 6 & 0.4 & 26.7 & 2.3 & 0.497 & 6 & 0 \\
\hline Pterocarpus violaceus & 5 & 0.4 & 13.3 & 1.2 & 0.532 & 5 & 0 \\
\hline Schinus terebinthifolius & 5 & 0.4 & 13.3 & 1.2 & 1.077 & 3 & 2 \\
\hline Styrax sp & 5 & 0.4 & 13.3 & 1.2 & 0.866 & 4 & 1 \\
\hline
\end{tabular}


ANEXO H - Parâmetros fitossociológicos - abundância total e relativa (\%), freqüência absoluta (Fa), freqüência relativa $(\mathrm{Fr})$ - , altura média e número de indivíduos com altura menor e maior que 1 metro das espécies regenerantes sob Melia azedarach

\begin{tabular}{|c|c|c|c|c|c|c|c|}
\hline Espécie & abundância & abund. (\%) & $\mathrm{Fa}(\%)$ & $\operatorname{Fr}(\%)$ & altura média & $\mathrm{n}^{\circ}$ ind $<1 \mathrm{~m}$ & $n^{\circ}$ ind $>1 \mathrm{~m}$ \\
\hline Psidium guajava & 3 & 0.2 & 13.3 & 1.2 & 1.245 & 1 & 2 \\
\hline Astronium graveolens & 3 & 0.2 & 20.0 & 1.7 & 1.083 & 1 & 2 \\
\hline Lafoensia glyptocarpa & 3 & 0.2 & 13.3 & 1.2 & 0.873 & 1 & 2 \\
\hline Piptadenia gonoacantha & 3 & 0.2 & 6.7 & 0.6 & 0.817 & 3 & 0 \\
\hline morfoespécie 14 & 3 & 0.2 & 13.3 & 1.2 & 0.787 & 2 & 1 \\
\hline Campomanesia guazumifolia & 2 & 0.1 & 13.3 & 1.2 & 0.640 & 2 & 0 \\
\hline Ficus sp & 2 & 0.1 & 13.3 & 1.2 & 0.340 & 2 & 0 \\
\hline Esenbeckia leiocarpa & 2 & 0.1 & 6.7 & 0.6 & 0.975 & 1 & 1 \\
\hline Peltophorum dubium & 2 & 0.1 & 6.7 & 0.6 & 0.670 & 2 & 0 \\
\hline Senna macranthera & 2 & 0.1 & 13.3 & 1.2 & 1.100 & 0 & 2 \\
\hline Zanthaxylum rhoifolium & 2 & 0.1 & 13.3 & 1.2 & 0.595 & 2 & 0 \\
\hline Solanaceae sp2 & 1 & 0.1 & 6.7 & 0.6 & 0.540 & 1 & 0 \\
\hline Cordia ecalyculata & 1 & 0.1 & 6.7 & 0.6 & 1.200 & 0 & 1 \\
\hline Copaifera langsdorffii & 1 & 0.1 & 6.7 & 0.6 & 0.310 & 1 & 0 \\
\hline Erythrina sp & 1 & 0.1 & 6.7 & 0.6 & 1.640 & 0 & 1 \\
\hline Hymenaea courbaril & 1 & 0.1 & 6.7 & 0.6 & 0.480 & 1 & 0 \\
\hline Inga sp & 1 & 0.1 & 6.7 & 0.6 & 0.530 & 1 & 0 \\
\hline Rubiaceae sp1 & 1 & 0.1 & 6.7 & 0.6 & 0.920 & 1 & 0 \\
\hline morfoespécie 10 & 1 & 0.1 & 6.7 & 0.6 & 1.740 & 0 & 1 \\
\hline morfoespécie 13 & 1 & 0.1 & 6.7 & 0.6 & 0.530 & 1 & 0 \\
\hline Tabebuia sp & 1 & 0.1 & 6.7 & 0.6 & 0.590 & 1 & 0 \\
\hline Trichilia pallida & 1 & 0.1 & 6.7 & 0.6 & 0.570 & 1 & 0 \\
\hline
\end{tabular}


ANEXO H - Parâmetros fitossociológicos - abundância total e relativa (\%), freqüência absoluta (Fa), freqüência relativa $(\mathrm{Fr})$ - , altura média e número de indivíduos com altura menor e maior que 1 metro das espécies regenerantes sob Melia azedarach

\begin{tabular}{|c|c|c|c|c|c|c|c|}
\hline Espécie & abundância & abund. (\%) & Fa (\%) & $\operatorname{Fr}(\%)$ & altura média & $\mathrm{n}^{\circ}$ ind $<1 \mathrm{~m}$ & $\mathrm{n}^{\circ}$ ind $>1 \mathrm{~m}$ \\
\hline morfoespécie 9 & 1 & 0.1 & 6.7 & 0.6 & 1.130 & 0 & 1 \\
\hline
\end{tabular}


ANEXO I - Freqüência absoluta $(\mathrm{Fa}-\%)$ das espécies amostradas na vizinhança imediata dos indivíduos de Cordia myxa, de Centrolobium tomentosum e de Melia azedarach

\begin{tabular}{|c|c|c|c|}
\hline Espécie & $\begin{array}{c}\text { C. } \\
\text { myxa }\end{array}$ & $\begin{array}{c}C . \\
\text { tomentosum }\end{array}$ & $\begin{array}{c}\text { M. } \\
\text { azedarach }\end{array}$ \\
\hline Albizia hasslerii (Chodat) Burr. & 0 & 6.7 & 0 \\
\hline Anadenanthera peregrina (L.) Spreng. & 40.0 & 26.7 & 26.7 \\
\hline Caesalpinia ferrea var. leiostachya (Benth.) Duke & 20.0 & 6.7 & 6.7 \\
\hline Caesalpinia peltophoroides Spreng. & 6.7 & 0 & 0 \\
\hline Cariniana estrellensis (Raddi) Kuntze & 6.7 & 13.3 & 13.3 \\
\hline Cariniana legalis (Mart.) Kuntze & 6.7 & 6.7 & 6.7 \\
\hline Centrolobium tomentosum Guill. ex Benth. & 13.3 & 20.0 & 40.0 \\
\hline Chorisia speciosa A.St.Hill & 13.3 & 6.7 & 6.7 \\
\hline Clitoria fairchildiana Howard & 20.0 & 13.3 & 13.3 \\
\hline Copaifera langsdorfii Desf. & 0 & 0 & 6.7 \\
\hline Cordia myxa L. & 0 & 33.3 & 20.0 \\
\hline Cordia trichotona (Vell.) Arrab.ex Steud. & 0 & 0 & 13.3 \\
\hline Didimopanax sp & 6.7 & 0 & 0 \\
\hline Erytrina sp & 0 & 0 & 6.7 \\
\hline Eugenia jambosa L. & 0 & 13.3 & 13.3 \\
\hline Ficus benjaminea L. & 13.3 & 0 & 0 \\
\hline Guarea sp & 6.7 & 0 & 0 \\
\hline Inga sp & 6.7 & 0 & 6.7 \\
\hline Jacaranda mimosaefolia D.Don. & 33.3 & 20.0 & 6.7 \\
\hline Lafoensia glyptocarpa Koehne & 20.0 & 33.3 & 26.7 \\
\hline Ligustrum sp & 0 & 0 & 6.7 \\
\hline Melia azedarach L. & 66.7 & 80.0 & 53.3 \\
\hline Myroxylon peruiferum L.f & 0 & 6.7 & 0 \\
\hline Nectandra megapotamica (Spreng.) Mez & 6.7 & 13.3 & 26.7 \\
\hline Piptadenia gonoacantha (Mart.) Macbr. & 13.3 & 6.7 & 26.7 \\
\hline Prunus sellowii Koehne & 6.7 & 6.7 & 6.7 \\
\hline Pterocarpus violaceus Vog. & 13.3 & 13.3 & 6.7 \\
\hline Pterogyne nitens Tul. & 6.7 & 0 & 0 \\
\hline Senna macranthera (Collad.) Irwin et Barn. & 0 & 6.7 & 0 \\
\hline Triplaris americana & 6.7 & 6.7 & 20.0 \\
\hline morfoespécie 1 & 0 & 0 & 6.7 \\
\hline morfoespécie 2 & 0 & 6.7 & 0 \\
\hline
\end{tabular}




\section{REFERÊNCIAS BIBLIOGRÁFICAS}

AIDE, T.M.; CAVELIER, J. Barriers to lowland tropical forest restoration in the Sierra Nevada de Santa Marta, Colombia. Restoration Ecology, v. 2, p. 219-229, 1994.

ALLEN, E.B.; COVINGTON, W.W.; FALK, D.A. Developing the concept basis to restoration ecology. Restoration Ecology, v. 5, p. 275-276, 1997.

AMIOTTI, N.M.; ZALBA, P.; SÁNCHES, L.F.; PEINEMANN, N. The impact of single trees on proprieties pf loess-derived grassland soils in Argentina. Ecology, v. 81, n. 12, p. 3283-3290, 2000.

AYRES, M.; AYRES JUNIOR., M.; AYRES, D.L.; SANTOS, A.S. BioEstat. Versão 2.0. Belém: Sociedade Civil Mamirauá: MCT - CNPq, 2000. 272 p.

BATISTA, G.M. de M.; LEITE, L.L. Adoção de técnicas de espectrorradiometria de reflexão como indicativo de recuperação de áreas degradadas: Contribuição ao conhecimento ecológico do cerrado. In: CONGRESSO DE ECOLOGIA DO BRASIL, 3., Brasília, DF, 1997. Anais. Brasília: Universidade de Brasília, 1997. p. 197-310. 
BARBOSA, L.M. Considerações gerais e modelos de recuperação de formações ciliares. In: RODRIGUES, R.R; LEITÃO-FILHO, H.F. (Ed.). Matas Ciliares: Conservação e recuperação. São Paulo: Universidade de São Paulo: Fapesp, 2000. cap. 15.4, p. 289-312.

BEGON, M.; HARPER, J.L.; TWONSEND, C.D. Ecology: Individuals, populations and communities. 2. ed. Oxford: Blackwell, 1990. cap. 17, p. 613-647.

BOETTCHER, S.E.; KALIS, J.P. Single-tree influence on soil properties in the Mountains of Eastern Kentucky. Ecology, v. 71, n. 4, p. 1365-1372, 1990.

BROKAW, N.V.L. Gap-phase regeneration in tropical forest. Ecology, v. 66, n. 3, p. 682-687, 1985.

CALLAWAY, R.M. Positive interactions among plants. The Botanical Review, v. 61, n. 4, p.306-349, 1995.

CARMO, M.R.B.do; MORELLATO, L.P.C. Fenologia de árvores e arbustos das matas ciliares da bacia do Rio Tibagi, Estado do Paraná, Brasil. In: RODRIGUES, R.R; LEITÃO-FILHO, H.F. (Ed.). Matas Ciliares: Conservação e recuperação. São Paulo: Universidade de São Paulo: Fapesp, 2000. cap. 8, p. 125-141.

CARNEVALE, N.J.; MONTAGNINI, F. Facilitating regeneration of secondary forests with the use of mixed and pure plantations of indigenous tree species. Forest Ecology and Management, v. 163, p. 217-227, 2002. 
CARPINELLA, M.C.; HERRERO, G.G.; ALONSO, R.A.; PALACIOS, S.M. Antifungal activity of Melia azedarach fruit extract. Fitoterapia, v. 70, p. 296-298, 1999.

CARVALHO, P.E.R. Espécies arbóreas brasileiras. Brasília: Embrapa Informação Tecnológica, 2003. 1039 p.

CINTRA, R. Leal litter effects on seed and seedling predation of the palm Astrocaryum murumuru and the legume tree Dipteryx micrantha in Amazonian forest. Journal of Tropical Ecology, v. 13, n. 5, p. 709-725, 1997.

CUSACK, D.; MONTAGNINI, F. The role of native species plantations in recovery of understory wood diversity in degraded pasturelands of Costa Rica. Forest Ecology and Management, v. 188, p. 1-15, 2004.

DIAS, L.E.; GRIFFITH, J.J. Conceituação e caracterização de áreas degradadas. In: SIMPÓSIO NACIONAL SOBRE RECUPERAÇÃO DE ÁREAS DEGRADADAS, 3., Viçosa, MG, 1998. Anais. Viçosa: Universidade Federal de Viçosa,1998. p. 1-7.

FACELLI, J.M.; PICKETT, S.T.A. Plant litter: Its dynamics and effects on plant community structure. The Botanical Review, v. 57, n. 1, p. 1-32, 1991 a.

FACELLI, J.M.; PICKETT, S.T.A. Plant litter: Light interception and effects on an old-field plant community. Ecology, v. 72, n. 3, p. 1024-1031, 1991 b.

GANDOLFI, S. História natural de uma Floresta Semidecidual no município de Campinas (São Paulo, Brasil). Campinas, 2000. 520p. Tese (Doutorado)Universidade Estadual de Campinas. 
GANDOLFI, S. Regimes de luz em florestas estacionais semideciduais e suas possíveis conseqüências. In: SALES, V.C. (Org.). Ecossistemas brasileiros: manejo e conservação. Fortaleza: Expressão Gráfica e Editora, 2003. cap. 7 , p. 305-311.

GROMBONE-GUARANTINI, M.T.; RODRIGUES, R.R. Seed bank and seed rain in a seasonal semi-deciduous forest in south-eastern Brazil. Journal of Tropical Ecology, v. 18, p. 759-774, 2002.

GUARIGUATA, M.R.; OSTERTAG, R. Neotropical secondary Forest succession: changes in structural and functional characteristics. Forest Ecology and Management, v. 148, p. 185-206, 2001.

GUEVARA, S.; PURATA, S.E. \& VAN DER MAAREL, E. The role remnant forest trees in tropical secundary succession. Vegetatio, v. 66, p. 77-84, 1986.

HIRABUKI, Y. Heterogeneous dispersal of tree litterfall corresponding with patchy canopy structure in a temperate mixed forest. Vegetatio, v. 94, p. 69-79, 1991.

HOLL, K.D. Factors limiting rain forest regeneration in abandoned pasture: seed rain, seed germination, microclimate, and soil. Biotropica, v. 31, p. 229-242, 1999.

HONG, T.D.; ELLIS, R.H. Contrasting seed storage behaviour among different species of Meliaceae. Seed Science and Technology, v. 26, n. 1, p. 77-95, 1998. 
HUBBELL, S.P.; FOSTRE, R.B.; O'BRIEN, S.T.; HARMS, K.E.; CONDIT, R.; WECHSTER, B.; WRIGTH, S.J.; LOO de LAO, S. Light-gap disturbances, recruitment limitation and tree diversity in a neotropical forest. Science, v. 283, n. 5401, p. 554-557, 1999.

JANZEN, D.H. Herbivores and the number of tree species in tropical forest. The American Naturalist, v. 23, p. 1-27, 1970.

KAGEYAMA, P.Y.; CASTRO, C.E.A.; CARPANEZZI, A.A. Implantação de matas ciliares: estratégia para auxiliar a sucessão secundária. In: SIMPÓSIO SOBRE MATAS CILIARES, 1., Campinas, SP, 1989. Anais. Campinas: Fundação Cargil, 1989. p. 130-143.

LORENZI, H. Árvores brasileiras: manual de identificação e cultivo de plantas arbóreas do Brasil. 2 ed. Nova Odessa: Plantarum, 1998. 352 p. 2 v.

LORENZI, H.; SOUZA, H.M.; TORRES, M.A.V.; BACHER, L.B. Árvores exóticas no Brasil: madeireiras, ornamentais e aromáticas. Nova Odessa: Plantarum, 2003. $368 \mathrm{p}$.

MAGURRAN, A.E. Ecological diversity and its measurement. Cambridge: University Press, 1988. $185 \mathrm{p}$.

MANTOVANI, W. Recuperação e monitoramento de Ecossistemas: Escalas de Abordagem. In: SIMPÓSIO DE ECOSSISTEMAS BRASILEIROS, 4., Águas de Lindóia, SP, 1998. Anais. Águas de Lindóia: ACIESP, 1998. v. 5. p. 288-294.

MARTINS, E. Boraginaceae. Flora de Moçambique, n. 112, p. 15-16, 1993. 
McCLANAHAN, T.R.; WOLFE, R.W. Accelerating forest succession in a fragmented landscape: the role pf birds and perches. Conservation Biology, v. 7, p. 279-288, 1993.

METACALFE, D. J.; TURNER, I. M. Soil seed bank from lowland rain forest in Singapore: canopy-gap and litter-gap demanders. Journal of Tropical Ecology, v. 14, n. 1, p. 103-108, 1998.

MIRITI, M.N. Regeneração florestal em pastagens abandonadas na Amazônia central: competição, predação e dispersão de sementes. In: GASCON, C.; MOUTINHO, P. (Ed.). Floresta Amazônica: Dinâmica, regeneração e manejo. Manaus: INPA, 1998. cap. 12, p. 179-190.

MOGIE, M.; LATHAM, J.R.; WARMAM, E.A. Genotype-independent aspects of seed ecology in Taraxacum. Oikos, v. 59, p. 175-182, 1990.

MOLOFSKY, J.; AUGSPURGER, C.K. The effect of leaf litter on early seedling establishment in a tropical forest. Ecology, v. 73, n. 1, p. 68-77, 1992.

MONTAGNINI, F. Strategies for the recovery of degraded ecosystems: experiences from Latin America. Interciencia, v. 26, n. 10, p. 498-503, 2001.

MORELLATO, L.C.P. Estudos da fenologia de árvores, arbustos e lianas de uma floresta semidecídua no sudeste de Brasil. Campinas, 1991. 176 p. Tese (Doutorado)-Universidade Estadual de Campinas. 
MORELLATO, L.C.P.; LEITÃO-FILHO, H.F. Padrões de frutificação e dispersão na Serra do Japi. In: MORELLATO, L.C.P. (Org.). História natural da Serra do Japi: ecologia e preservação de uma área florestal no sudeste do Brasil. Campinas: Unicamp, Fapesp, 1992. cap. 7, p. 112-141.

NAPPO, M.E. Inventário florístico e estrutural da regeneração natural no subbosque de povoamentos homogêneos de Mimosa scabrella Bentham, implantados em áreas mineradas, em Poços de Caldas, Minas Gerais. Lavras, 1999. 87 p. Dissertação (Mestrado)-Universidade Federal de Lavras.

NEPSTAD, D.C.; UHL, C.; PEREIRA, C.A.; SILVA, J.M.C.da. Estudo comparativo do estabelecimento de árvores em pastos abandonados e florestas adultas da Amazônia oriental. In: GASCON, C.; MOUTINHO, P. (Ed.). Floresta Amazônica: Dinâmica, regeneração e manejo. Manaus: INPA, 1998. cap. 13, p. 191-218.

PARROTA, J.A.; TURNBULL, J.W.; JONES, N. Catalyzing native forest regeneration on degraded tropical lands. Forest Ecology and Management, v. 99, p. 1-7, 1997.

PASSOS, M.J. Estrutura da vegetação arbórea e regeneração natural em remanescentes de mata ciliar do Rio Mogi Guaçu, SP. Piracicaba, 1998. 68 p. Dissertação (Mestrado)-Escola Superior de Agricultura "Luiz de Queiroz", Universidade de São Paulo.

PENHA, A.S. Influência da propagação vegetativa a partir de raízes gemíferas na características populacionais de espécies arbóreas em fragmentos de florestas estacionais semideciduais. Campinas, 2004. 142 p. Tese (Doutorado)-Universidade Estadual de Campinas. 
PENHALBER, E.F.; MANTOVANI, W. Floração e chuva de sementes em uma mata secundária em São Paulo, SP. Revista Brasileira de Botânica, v. 20, n. 2, p. 205-220, 1997.

PENNINGTON, T.D. Meliaceae. Flora Neotropica, n. 28, p. 24-25, 1981.

PICKETT, S.T.A.; COLLINS, S.L.; ARMESTO, J.J. A hierarchical consideration of causes and mechanisms of succession. Vegetatio, v. 69, p. 109-114, 1987.

PIELOU, E.C. Ecological diversity. New York: John Wiley, 1975. 165 p.

PIJL, L. van der. Principles of dispersal in higher plants. New York: Springer-Verlag, 1982. 215 p.

PONGE, J.F.; ANDRÉ, J.; ZACKRISSOM, O.; BERNIER, N.; NILSSON, M.C.; GALLET, C. The forest regeneration puzzle. BioScience, v. 48, n. 7, p. 523-530, 1998.

PUTZ, F.E. \& APPANAH, S. Buried seeds, newly dispersed seeds and the dynamics of a lowland forest in Malaysia. Biotropica, v. 19, p. 326-333, 1987.

RODRIGUES, R.R., LEITÃO-FILHO, H.F. \& CRESTANA, M.S.M. Revegetação do entorno da represa de abastecimento de água do município de Iracemápolis/SP. In: SIMPÓSIO NACONAL DE RECUPERAÇÃO DE ÁREAS DEGRADADAS. Curitiba, 1992. Anais. Curitiba: FUPEF, 1992. p. 406-414. 
RODRIGUES, R.R. Restauração de florestas tropicais: indicadores de avaliação e monitoramento vegetal. In: SIMPÓSIO DE ECOSSISTEMAS BRASILEIROS, 4., Águas de Lindóia, SP, 1998. Anais. Águas de Lindóia: ACIESP, 1998. v. 3. p. 179-183.

RODRIGUES, R.R.; GANDOLFI, S. Recomposição de florestas nativas: Princípios gerais e subsídios para uma definição metodológica. Revista Brasileira de Horticultura Ornamental, v. 2, n. 1, p. 4-15, 1996.

RODRIGUES, R.R.; GANDOLFI, S. Conceitos, tendências e ações para a recuperação de florestas ciliares. In: RODRIGUES, R.R; LEITÃO-FILHO, H.F. (Ed.). Matas Ciliares: Conservação e recuperação. São Paulo: Universidade de São Paulo: Fapesp, 2000. cap. 15.1, p. 233-247.

SIQUEIRA, L.P. Monitoramento de áreas restauradas no interior do Estado de São Paulo, Brasil. Piracicaba, 2002. 116 p. Dissertação (Mestrado)-Escola Superior de Agricultura "Luiz de Queiroz", Universidade de São Paulo.

SORREANO, M.C.M. Avaliação de aspectos da dinâmica de florestas restauradas, com diferentes idades. Piracicaba, 2002. 145 p. Dissertação (Mestrado)-Escola Superior de Agricultura "Luiz de Queiroz", Universidade de São Paulo.

SOUZA, F.M.; BATISTA, J.L.F. Restoration of seasonal semideciduous forests in Brazil: influence of age and restoration design on forest structure. Forest Ecology and Management, v. 191, p. 185-200, 2004.

SHEPHERD, G.J. FITOPAC 1: Manual do usuário. Campinas: UNICAMP, 1995. $80 \mathrm{p}$. 
VÁZQUEZ-YANEZ, C.; OROSCO-SEGOVIA, A. Ecological significance of light controlled seed germination in two contrasting tropical habitats. Oecologia, v. 83, n. 2, p. 171-175, 1990.

VÁZQUEZ-YANEZ, C.; OROSCO-SEGOVIA, A.; RINCÓN, E.; SÁNCHESCORONADO, M.E.; HUANTE, P.; TOLEDO, J.R.; BARRADAS, V.L. Light Beneath the litter in a tropical forest: Effect on seed germination. Ecology, v. 75 , n. 1 , p. $1952-1958,1990$.

WALKER, L.A.; NERIS, L.E. Post hurricane seed rain dynamics in Puerto Rico. Biotropica, v. 25, p. 408-418, 1993.

WATT, A.S. Pattern and process in plant community. Journal of Ecology, v. 35, p. 1-22, 1947.

WATT, A.S. The Community and the Individual. Journal of Animal Ecology, v. 33, p. 203-211, 1968.

WIJDEVEN, S.M.J.; KUZEE, M.E. Seed availability as a limiting factor in forest recovery processes in Costa Rica. Restoration Ecology, v. 8, n. 4, p. 414424, 2000.

WHITE, F.; STYLES, B.T.; GONÇALVES, A.E. Meliaceae. Flora de Moçambique, v. 42, p. 17-18, 1979.

WHITEMORE, T.C. Secondary succession from seed in tropical rain forests. Forestry Abstracts, v. 44, p. 767-779, 1983.

WRIGHT, S.J. Plant diversity in topical forests: a review of mechanisms of species coexistence. Oecologia, v. 130, p. 1-14, 2002. 
WUNDERLE JÚNIOR, J.M. The role of animal seed dispersal in accelerating native forest regeneration on degraded tropical lands. Forest Ecology and Management, v. 99, p. 223-235, 1997.

ZAR, J.H. Biostatiscal analysis. 4. ed. New Jersey: Prentice Hall, 1999. cap. 10, 11 e 13. p. $177-281$.

ZINKE, P. J. The pattern on influence of individual forest trees on soil properties. Ecology, v. 43, n. 1, p. 130-133, 1962. 